San Jose State University

SJSU ScholarWorks

Master's Theses

Master's Theses and Graduate Research

Summer 2017

\title{
A Complete Study Of N,N' bis(1 phenylpropyl) 2,6 pyridinedicarboxamide
}

Victoria Y. Chang

San Jose State University

Follow this and additional works at: https://scholarworks.sjsu.edu/etd_theses

\section{Recommended Citation}

Chang, Victoria Y., "A Complete Study Of N,N' bis(1 phenylpropyl) 2,6 pyridinedicarboxamide" (2017). Master's Theses. 4839.

DOI: https://doi.org/10.31979/etd.z83n-k2ca

https://scholarworks.sjsu.edu/etd_theses/4839

This Thesis is brought to you for free and open access by the Master's Theses and Graduate Research at SJSU ScholarWorks. It has been accepted for inclusion in Master's Theses by an authorized administrator of SJSU ScholarWorks. For more information, please contact scholarworks@sjsu.edu. 


\title{
A COMPLETE STUDY OF $N, N$ '-BIS(1-PHENYLPROPYL)-2,6-PYRIDINEDICARBOXAMIDE
}

\author{
A Thesis \\ Presented to \\ The Faculty of the Department of Chemistry \\ San José State University \\ In Partial Fulfillment \\ of the Requirements for the Degree \\ Master of Science
}

by

Victoria Y. Chang

August 2017 
(C) 2017

Victoria Chang

ALL RIGHTS RESERVED 
The Designated Thesis Committee Approves the Thesis Titled

A COMPLETE STUDY OF

$N, N$ '-BIS(1-PHENYLPROPYL)-2,6-PYRIDINEDICARBOXAMIDE

by

Victoria Chang

APPROVED FOR THE DEPARTMENT OF CHEMISTRY

SAN JOSÉ STATE UNIVERSITY

August 2017

Prof. Gilles Muller Department of Chemistry

Prof. Lionel Cheruzel Department of Chemistry

Prof. Daniel Straus Department of Chemistry 


\section{ABSTRACT \\ A COMPLETE STUDY OF $N, N$ '-BIS(1-PHENYLPROPYL)-2,6-PYRIDINEDICARBOXAMIDE}

\section{by Victoria Y. Chang}

Biological systems are often chiral or involve chiral compounds, e.g. L-amino acids, the neurotransmitter L-epinephrine. In some cases, two enantiomers of a chiral drug will have different activities, and in extreme cases, one form is therapeutic while the other form is toxic. Therefore, the development of reliable molecular probes for biological applications and chiral sensing is an important area of study. The unique spectroscopic and coordination properties of some lanthanide ions $\left(\mathrm{Ln}^{3+}\right)$ and their complexes make them suitable for use as molecular probes. Chiral ligand systems have been developed that can coordinate with lanthanide ions to form complexes where the ligand excitation leads to $\mathrm{Ln}^{3+}$ luminescence through the antenna effect. The ligand discussed in this thesis, $(R, R)-N, N^{\prime}$-bis(1-phenylpropyl)-2,6-pyridinedicarboxamide $\mathrm{L}(\mathrm{Et})$, is in a family of ligands with a common 2,6-pyridinedicarboxamide moiety. These ligands form chiral complexes, $\left[\mathrm{LnL}_{3}\right]^{3+}$, where the circularly polarized luminescence (CPL) fingerprint of these complexes reflects the chiral environment at the metal center. Comparison of the photophysical, structural and chiroptical properties of $\mathrm{L}(\mathrm{Et})$, and the $\left[\operatorname{Ln}(\mathrm{L}(\mathrm{Et}))_{3}\right]^{3+}$ complexes it forms, with the results from studies of other related ligands allows us to gain an overall idea of the behavior of this family of ligands. 


\section{ACKNOWLEDGEMENTS}

I would like to thank my research advisor, Dr. Gilles Muller, for his mentorship during my time in his laboratory. He has been a font of knowledge about circularly polarized luminescence, and it has been a pleasure to learn about the subject from him. I would also like to thank my thesis committee, Dr. Lionel Cheruzel and Dr. Daniel Straus, for their time and support. I've enjoyed learning more about Inorganic Chemistry from Dr. Cheruzel, and I always appreciate his sense of humor. I am thankful for Dr. Straus's always insightful questions. Dr. Straus's laboratory synthesized the ligand I studied, for which I am eternally grateful. I would like to thank Victoria Anne Johnson for her work on the ligand.

I am thankful for everyone I've worked with and learned from during my time at San José State. I would like to thank Francoise Muller for her kindness and knowledge about laser spectroscopy, Mike Stephens for his technical insight and brilliant troubleshooting, and Dr. Ed Chichester for teaching me how to teach. I appreciate all of the great work of my past and present group members, who were there with me during overnight experiment setups and long hours in the laboratory. I'm thankful for friendship and coffee with my fellow graduate students.

Finally, this work is dedicated to my family. I am grateful for their support and encouragement, always. 


\section{TABLE OF CONTENTS}

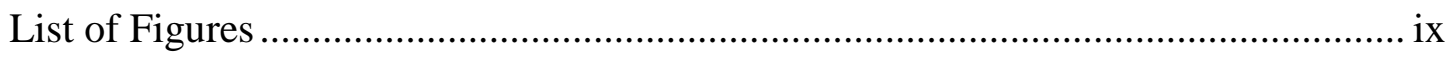

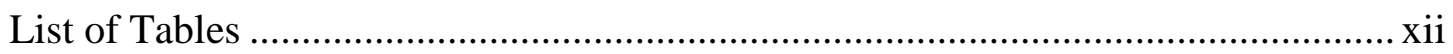

List of Abbreviations ........................................................................................

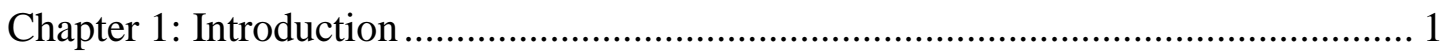

1.1 Chirality in Biological Molecules .......................................................... 1

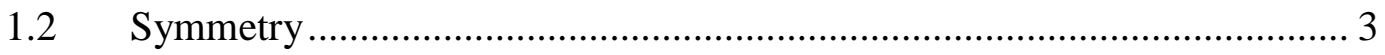

1.3 Chiroptical Spectroscopy Techniques................................................. 5

1.3.1 Circularly polarized light and circular dichroism............................. 6

1.3.2 Circularly polarized luminescence …………………..................... 7

$1.4 \quad$ Lanthanide Complexes........................................................................ 10

1.4.1 General traits of 4f-block metals and the antenna effect................ 10

1.4.2 $\mathrm{Ln}^{3+}$ :ligand coordination complexes ........................................ 12

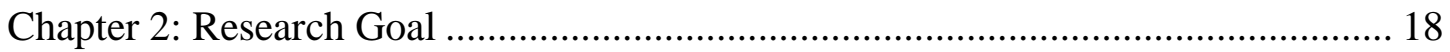

$2.1 \quad$ Objectives of Project...................................................................... 18

2.2 A Promising Family of Ligands........................................................... 19

2.3 Comparison of Chiral 2,6-pyridine dicarboxamide Ligands ................... 20

Chapter 3: Results and Discussion...................................................................... 25

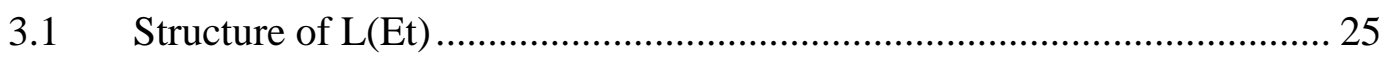

3.1.1 Calculated molecular structure of $\mathrm{L}(\mathrm{Et})$....................................... 25

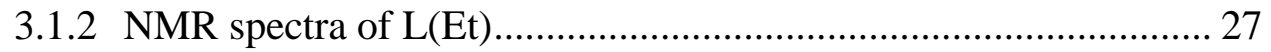

3.2 Ligand Centered Absorbance and Emission .......................................... 28 


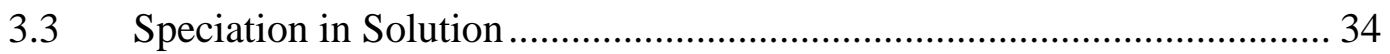

3.3.1 Stability constants: titration of $\mathrm{Ln}^{3+}$ with $\mathrm{L}(\mathrm{Et})$............................ 36

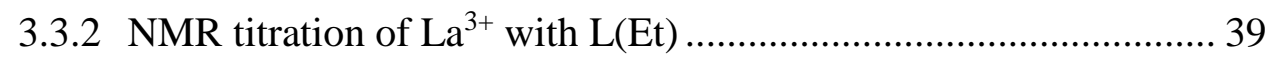

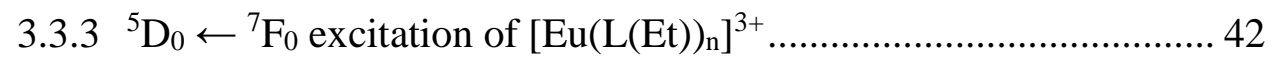

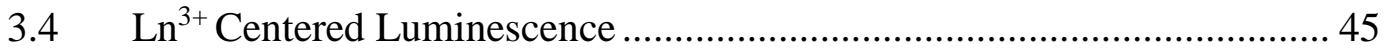

3.4.1 Confirmation of $\left[\mathrm{Ln}(\mathrm{L}(\mathrm{Et}))_{3}\right]^{3+}$ species in solution ....................... 45

3.4.2 $\left[\mathrm{Ln}(\mathrm{L}(\mathrm{Et}))_{3}\right]^{3+}$ luminescence, indirect excitation.......................... 47

3.4.3 Quantum yield and luminescence sensitization.............................. 50

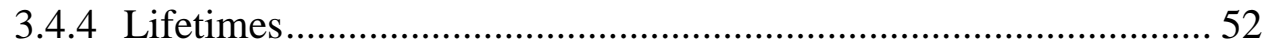

3.5 Circularly Polarized Luminescence …………………………………........ 54

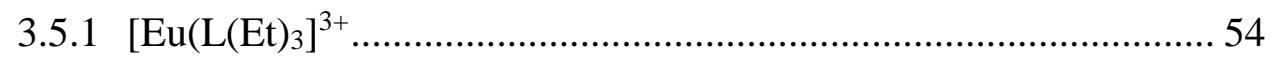

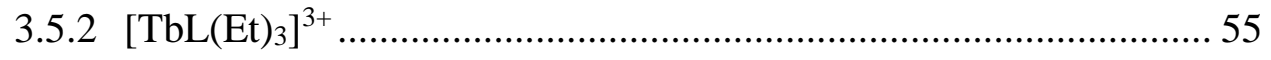

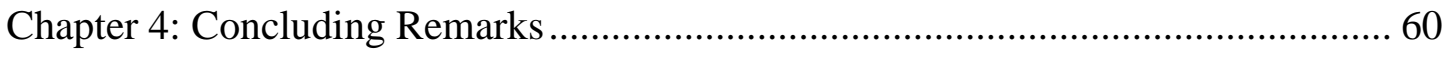

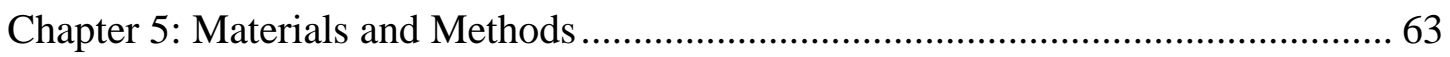

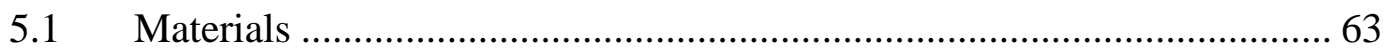

5.2 Electronic Spectra, Luminescence and Lifetimes Measurements.............. 63

5.3 Quantum Yield and Luminescence Sensitization ...................................... 64

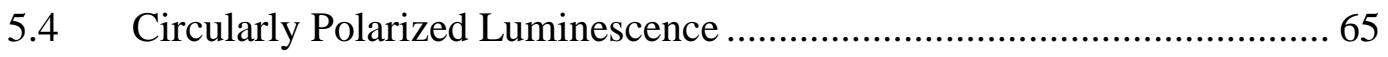

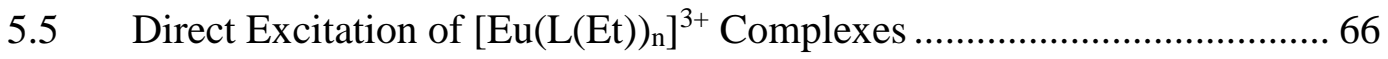

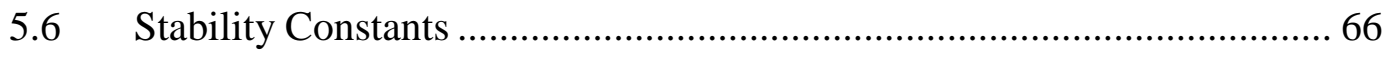

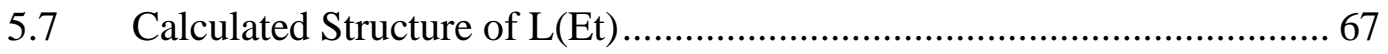

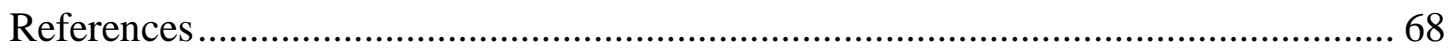




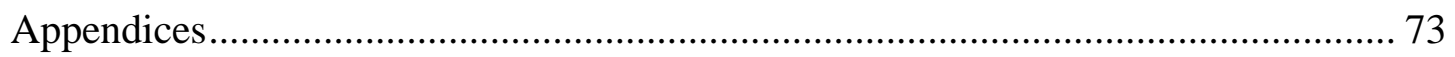

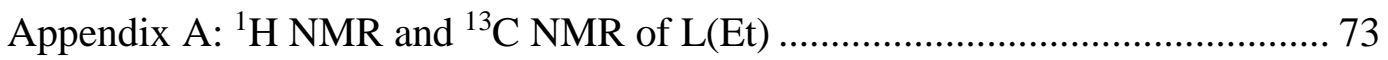

Appendix B: Calculated Bond Lengths and Bond Angles............................... 77

Appendix C: Supporting Information and Calculations ................................ 81 


\section{LIST OF FIGURES}

Figure 1. $\quad$ adrenaline, R enantiomer (left); S-epinephrine (right) ........................... 2

Figure 2. $\quad \mathrm{R}$ thalidomide (left); $\mathrm{S}$ thalidomide (right) ..................................... 3

Figure 3. Generic structure of a 9-coordinate $\mathrm{Ln}^{3+}$ complex with $\Delta$ symmetry (left), and $\Lambda$ symmetry (right) ..................................................... 4

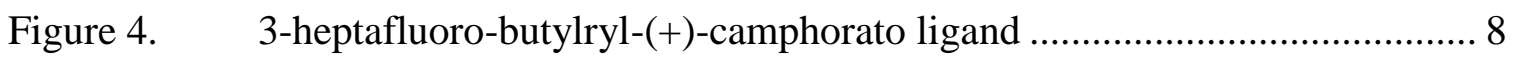

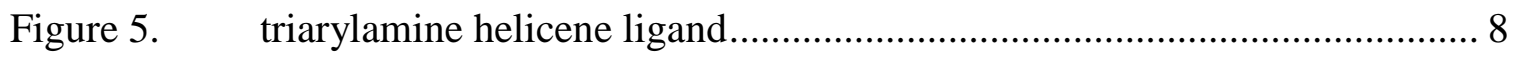

Figure 6. Simplified Energy Diagram, Antenna Effect, Ligand to Metal Energy

Transfer. ...................................................................................... 11

Figure 7. L(bap) - bis(benzimidazole)pyridine moiety .................................. 14

Figure 8. L(bap-1) - bis(benzimidazole)pyridine with methyl substituents ............ 14

Figure 9. L(bap-5) - bis(benzimidazole)pyridine with methyl and ethyl

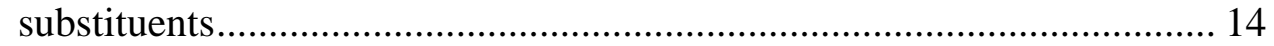

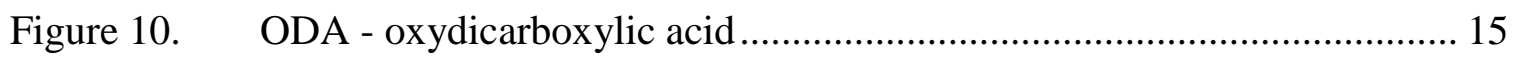

Figure 11. L(L8) - tripodal nonadentate receptor .............................................. 15

Figure 12. L L(tpm) - bis2,2',2",2'"-[(4'-phenyl-2,2':6',2"-terpyridine-6,6"-diyl) bis(methylenenitrilo)]tetrakis(acetic acid) ....................................... 16

Figure 13. $\quad$ L(N-tpm) - 2-(4-Aminobut-1-yl)-bis2,2',2",2'"-[(4'-phenyl-2,2': 6',2"-terpyridine-6,6"-diyl)bis(methylenenitrilo)]tetrakis(acetic acid) ..... 16

Figure 14. $\quad \mathrm{L}(\mathrm{Et})-R, R$ enantiomer of N,N'-bis(1-phenylpropyl)-2,6-pyridine

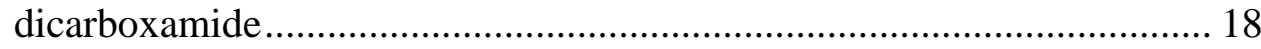

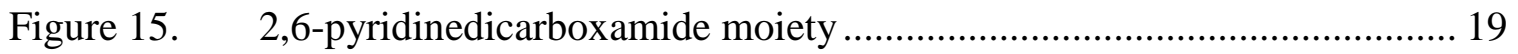

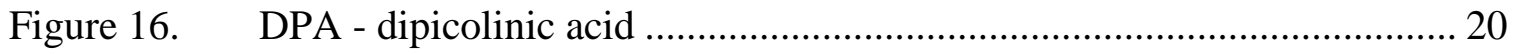

Figure 17. $\quad L(4 p)-R$ enantiomer 3-[2,6-bis(diethylcarbamoyl)

pyridine-4-yl]-N-(tert-butoxycarbonyl)alanine methyl ester ................. 21 
Figure 18. L(hh1) - $R$ enantiomer of pyridine-2,6-dicarboxylic acid-[1-naphthalen-1-yl-ethyl)-amide]

Figure 19. $\quad \mathrm{L}(\mathrm{hh} 2)$ - $R$ enantiomer of pyridine-2,6-dicarboxylic acid-[1-naphthalen-2-yl-ethyl)-amide]

Figure 20. $\quad \mathrm{L}(1 \mathrm{yl})-R, R$ enantiomer of pyridine-2,6-dicarboxylic acid bis-[1-naphthalen-1-yl-ethyl)-amide] 22

Figure 21. $\quad \mathrm{L}(2 \mathrm{yl})-R, R$ enantiomer of pyridine-2,6-dicarboxylic acid bis-[1-naphthalen-2-yl-ethyl)-amide] 22

Figure 22. $\quad \mathrm{L}(\mathrm{Me})$ - $R, R$ enantiomer of N,N'-bis(1-phenylethyl)-2,6-pyridine dicarboxamide 23

Figure 23. $\quad \mathrm{L}(\mathrm{Et})$ - $R, R$ enantiomer of N,N'-bis(1-phenylpropyl)-2,6-pyridine dicarboxamide 24

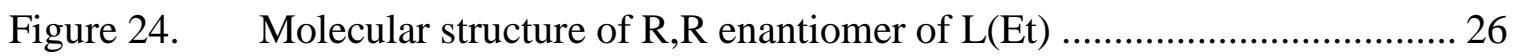

Figure 25. Molecular structure of S,S enantiomer of L(Et) …………………....... 26

Figure 26. Numbered structure of L(Et), R, R enantiomer ..................................... 27

Figure 27. Normalized electronic spectra of $\mathrm{L}(\mathrm{Et})$ and $\left[\mathrm{Ln}(\mathrm{L}(\mathrm{Et}))_{3}\right]^{3+}$ complexes in anhydrous acetonitrile at room temperature

Figure 28. Normalized steady-state emission spectrum of L(Et) (solid line) and $\left[\mathrm{Gd}(\mathrm{L}(\mathrm{Et}))_{3}\right]^{3+}$ (dotted line) in anhydrous acetonitrile at room temperature

Figure 29. Normalized time-resolved emission spectrum of L(Et) (solid line) and $\left[\mathrm{Gd}(\mathrm{L}(\mathrm{Et}))_{3}\right]^{3+}$ (dotted line) in anhydrous acetonitrile at $77 \mathrm{~K}$ 31

Figure 30. Titration of $\mathrm{Eu}^{3+}$ with $\mathrm{L}(\mathrm{Et})$ in anhydrous acetonitrile, time-resolved luminescence spectra 36

Figure 31. Intensity of luminescence versus R (ratio of Eu / L(Et) in solution in anhydrous acetonitrile) at selected wavelengths. 37

Figure 32. $\quad{ }^{1} \mathrm{H}$ NMR titration of $\mathrm{La}^{3+}$ with $\mathrm{S}, \mathrm{S}$ enantiomer of $\mathrm{L}(\mathrm{Et})$ in $\mathrm{CD}_{3} \mathrm{CN}$ 40 
Figure 33. $\quad{ }^{5} \mathrm{D}_{0} \leftarrow{ }^{7} \mathrm{~F}_{0}$ excitation spectra of various ratios $\mathrm{Eu}^{3+}:(\mathrm{L}(\mathrm{Et}))$ in anhydrous acetonitrile, from top to bottom: 1:10, 1:5, 1:3, 1:2, 1:1, $1: 0.5$

Figure 34. $\quad{ }^{5} \mathrm{D}_{0} \leftarrow{ }^{7} \mathrm{~F}_{0}$ excitation spectra of various concentrations of 1:5 mM $\mathrm{Eu}: \mathrm{L}(\mathrm{Et})$ in anhydrous acetonitrile

Figure 35. Steady-state (left) and time-resolved (right) luminescence excitation spectra of Eu:L(Et) in anhydrous acetonitrile, 1:0.5 to 1:10 Ratios. 46

Figure 36. Time-resolved luminescence in anhydrous acetonitrile at room temperature, normalized spectra of $\left[\mathrm{Ln}(\mathrm{L}(\mathrm{Et}))_{3}\right]^{3+}$ complexes 48

Figure 37. Time-resolved luminescence in anhydrous acetonitrile at $77 \mathrm{~K}$, normalized spectra of $\mathrm{L}(\mathrm{Et})$ and $\left[\mathrm{Ln}(\mathrm{L}(\mathrm{Et}))_{3}\right]^{3+}$ complexes. 48

Figure 38. Steady-state luminescence in anhydrous acetonitrile at room temperature, normalized spectra of $\mathrm{L}(\mathrm{Et})$ and $\left[\mathrm{Ln}(\mathrm{L}(\mathrm{Et}))_{3}\right]^{3+}$ complexes

Figure 39. Steady-state luminescence at $77 \mathrm{~K}$, normalized spectra of L(Et) and $\left[\mathrm{Ln}(\mathrm{L}(\mathrm{Et}))_{3}\right]^{3+}$ complexes in anhydrous acetonitrile 50

Figure 40. $\mathrm{CPL}$ of $\left[\mathrm{Eu}(\mathrm{L}(\mathrm{Et}))_{3}\right]^{3+} \mathrm{R}, \mathrm{R}$ enantiomer in anhydrous acetonitrile, left $={ }^{5} \mathrm{D}_{0} \rightarrow{ }^{7} \mathrm{~F}_{1}$ transition, right $={ }^{5} \mathrm{D}_{0} \rightarrow{ }^{7} \mathrm{~F}_{2}$ transition 55

Figure 41. $\quad \mathrm{CPL}$ of $\left[\mathrm{Tb}(\mathrm{L}(\mathrm{Et}))_{3}\right]^{3+} \mathrm{R}, \mathrm{R}$ enantiomer in anhydrous acetonitrile ${ }^{5} \mathrm{D}_{4} \rightarrow{ }^{7} \mathrm{~F}_{5}$ transition 57

Figure 42. $\quad{ }^{1} \mathrm{H}$ NMR of R,R enantiomer of L(Et) (300 MHz, Chloroform-d) ........... 73

Figure 43. $\quad{ }^{13} \mathrm{C}$ NMR R,R enantiomer of L(Et) $(75 \mathrm{MHz}$, Chloroform-d)................. 74

Figure 44. $\quad{ }^{1} \mathrm{H}$ NMR of S,S enantiomer of L(Et) (300 MHz, Chloroform-d) ............ 75

Figure 45. $\quad{ }^{13} \mathrm{C}$ NMR R,R enantiomer of L(Et) (75 MHz, Chloroform-d)................. 76

Figure 46. Lifetime Fit - scatter plot $=$ lifetimes data, solid line $=$ monoexponential and biexponential fit............................................... 83

Figure 47. Deconvoluted peaks, laser excitation spectrum of $6.67 \mathrm{mM} \mathrm{1:10}$ $\mathrm{Eu}: \mathrm{L}(\mathrm{Et})$ in anhydrous acetonitrile... 
Figure 48. Laser excitation spectra of various ratios of $\mathrm{Eu}: \mathrm{L}(\mathrm{Et})$ in anhydrous

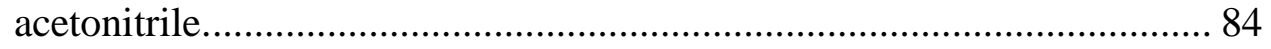




\section{LIST OF TABLES}

Table 1. Ligand Centered Absorbance Maxima ……......................................... 30

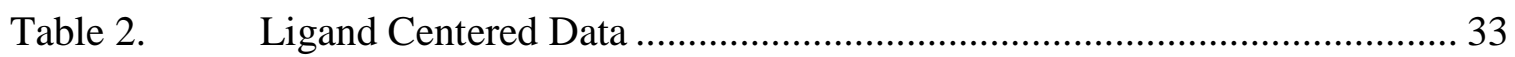

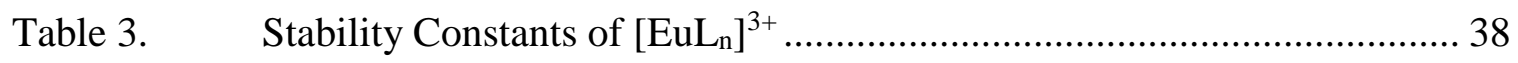

Table 4. $\quad\left[\mathrm{Eu}(\mathrm{L}(\mathrm{Et}))_{\mathrm{n}}\right]^{3+5} \mathrm{D}_{0} \leftarrow{ }^{7} \mathrm{~F}_{0}$ Excitation Maxima......................................... 44

Table 5. Lifetimes of various ratios and concentrations of $\mathrm{Eu}^{3+}: \mathrm{L}(\mathrm{Et})$ in

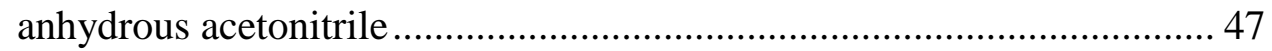

Table 6. Quantum Yield and Luminescence Sensitization values ........................... 51

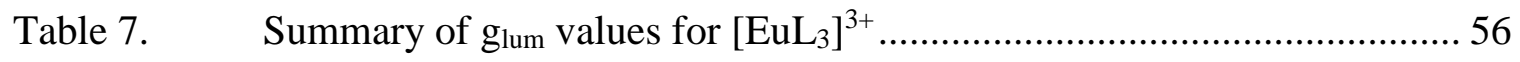

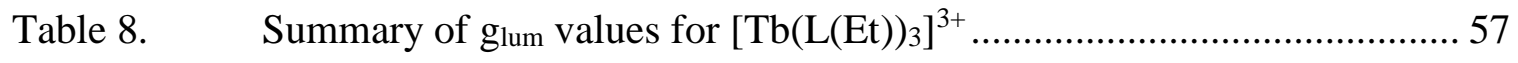




\section{LIST OF ABBREVIATIONS}

\begin{tabular}{|c|c|}
\hline $1 \pi \pi^{*}$ & singlet excited state \\
\hline${ }^{3} \pi \pi^{*}$ & triplet excited state \\
\hline$A_{M D, 0}$ & spontaneous emission probability of the $\mathrm{Eu}(5 \mathrm{D} 0 \rightarrow 7 \mathrm{~F} 1)$ transition \\
\hline$\beta$ & stability constant \\
\hline $\mathrm{CD}$ & circular dichroism \\
\hline CPL & circularly polarized luminescence \\
\hline DFT & density functional theory \\
\hline DPA & dipicolinic acid \\
\hline EDTA & ethylenediaminetetraacetic acid \\
\hline $\mathrm{g}_{\text {lum }}$ & luminescence dissymmetry ratio \\
\hline$I_{M D}$ & intensity of the $\mathrm{Eu}(5 \mathrm{D} 0 \rightarrow 7 \mathrm{~F} 1)$ transition \\
\hline ISC & intersystem crossing \\
\hline $\mathrm{I}^{\mathrm{T}} / \mathrm{I}^{\mathrm{S}}$ & ratio of triplet to singlet emission intensity \\
\hline$I_{t o t}$ & intensity of the total emission of the 5D0 level \\
\hline $\mathrm{L}(1 \mathrm{yl})$ & pyridine-2,6-dicarboxylic acid bis-[1-naphthalen-1-yl-ethyl)-amide] \\
\hline $\mathrm{L}(2 \mathrm{yl})$ & pyridine-2,6-dicarboxylic acid bis-[1-naphthalen-2-yl-ethyl)-amide] \\
\hline $\mathrm{L}(4 \mathrm{p})$ & $\begin{array}{l}\text { 3-[2,6-bis(diethylcarbamoyl)pyridine-4-yl]- } N \text {-(tert-butoxycarbonyl) } \\
\text { alaninemethyl ester }\end{array}$ \\
\hline L(bap) & bis(benzimidazole)pyridine, family of ligands \\
\hline L(bap-1) & bis(benzimidazole)pyridine with methyl substituents \\
\hline L(bap & bis(benzimidazole)pyridine with methyl and ethyl substituents \\
\hline
\end{tabular}


L(Et) $\quad N, N^{\prime}$-bis(1-phenylpropyl)-2,6-pyridinedicarboxamide

L(hh1) pyridine-2,6-dicarboxylic acid-[1-naphthalen-1-yl-ethyl)-amide]

L(hh2) pyridine-2,6-dicarboxylic acid-[1-naphthalen-2-yl-ethyl)-amide]

L(L8) tripodal nonadentate receptor

L(Me) N,N'-bis(1-phenylethyl)-2,6-pyridinedicarboxamide

$\mathrm{Ln}^{3+} \quad$ Lanthanide ion, +3 oxidation state

L(N-tpm) 2,2',2",2'"-[(4'-phenyl-2,2':6',2"-terpyridine-6,6"-diyl)bis (methylenenitrilo)]tetrakis(acetic acid)

L(tpm) 2-(4-Aminobut-1-yl)-2,2',2",2'"-[(4'-phenyl-2,2':

6',2"-terpyridine-6,6"-diyl)bis(methylenenitrilo)]tetrakis(acetic acid)

$\eta_{\text {sens }} \quad$ Luminescence sensitization

ODA oxydiacarboxylic acid

$\Phi \quad$ Quantum Yield

$Q^{E u}$

intrinsic luminescence quantum yield

$Q_{\text {tot }}^{E u} \quad$ Europium-centered luminescence quantum yield

$R \quad$ in titrations, the ratio of the concentration of $\mathrm{Ln}^{3+}$ to $\mathrm{L}$, or $\frac{\left[\mathrm{Ln}^{3+}\right]}{[L]}$

$\tau \quad$ lifetime of excited state

$\tau_{o b s} \quad$ Observed Lifetime of the Eu(5D0) level

$\tau_{R} \quad$ radiative lifetime 


\section{CHAPTER 1}

\section{INTRODUCTION}

\subsection{Chirality in Biological Molecules}

Biological systems have chirality in their very building blocks - the amino acids that make up the proteins in our bodies are almost all chiral. A chiral object is not superimposable on its own mirror image. Two organic molecules that are non-superimposable mirror images of each other, where all chiral carbon centers have opposite configurations ( $R$ or $S$ ), are enantiomers. Some receptors in the body are made of proteins that have a structure that preferentially binds one enantiomer of a signaling or messenger compound versus the other, the way that a left-handed glove fits more readily on a left versus a right hand. Due to this difference, one enantiomer of the compound will more effectively bind to the receptor and activate the pathway. ${ }^{1}$ Due to this difference in signaling, effective drug treatments will often contain one enantiomer of the chiral compound, the active enantiomer that will bind or have the desired activity in the body. In fact, since 1992, the U. S. Food and Drug Administration has set guidelines on chiral drugs, including study of the effects of different diastereomers and on the chiral composition of the drug. ${ }^{2}$ Knowing the ratio of the enantiomeric forms is important for dosage - an enantiomerically pure drug would deliver more active drug than a racemic mixture of the active and inactive enantiomers of the drug. In other cases, the two enantiomeric forms will have different activities; in extreme cases, one form is therapeutic while the other form is toxic. ${ }^{2}$ In these cases, it is important to have a method for detecting the presence of a racemic mixture or the excess of one enantiomer. 
4-(1-Hydroxy-2-(methylamino)ethyl)benzene-1,2-diol is an example of a chiral molecule where one enantiomer, the $R$ enantiomer, is biologically active. ${ }^{1}$ The $R$ enantiomer is the neurotransmitter adrenaline (Figure 1, left), also known as L-epinephrine, which plays an important role in many signaling pathways by binding to adrenergic receptors, leading to metabolic and bronchial changes. As epinephrine is often produced as a response to threats, and these changes aid in the response to danger, epinephrine is one of the neurotransmitters responsible for what is commonly referred to as the protective physical "fight or flight" response. ${ }^{1}$ In addition to being produced naturally in the body, epinephrine is also used as a drug, to treat a variety of cardiopulmonary conditions, such as asthma, ${ }^{3}$ croup, ${ }^{4}$ cardiac arrest, ${ }^{1}$ and anaphylactic conditions, including hymenoptera stings. ${ }^{5}$ Medical studies describing the effectiveness of treatment using epinephrine will specify the use of enantiomerically pure L-epinephrine or the racemic mixture of the two forms with different activity, where L-epinephrine preferentially binds to the adrenergic receptors, and the $S$ enantiomer of epinephrine (Figure 1, right) acts more slowly. ${ }^{2}$ For example, in the treatment of croup, some strategies use the faster action of the single enantiomer and others use the racemic mixture for the action of both forms. ${ }^{6,7}$
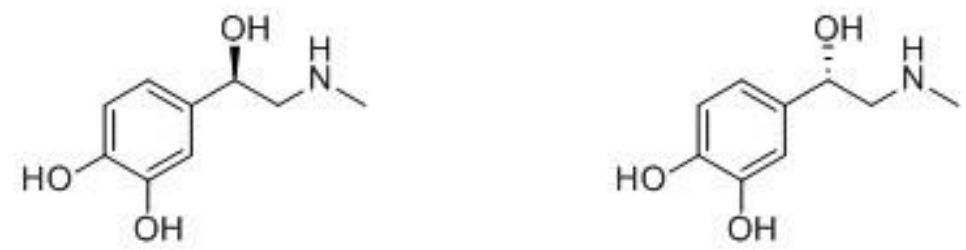

Figure 1. adrenaline, $R$ enantiomer (left); $S$-epinephrine (right)

The difference between L-epinephrine and D-epinephrine is relatively minor, but that is not always the case. The difference between the activity of the $R$ and $S$ enantiomers of 
thalidomide led to tragedy in the late 1950s, when it was used to treat morning sickness in pregnant women. The $R$ enantiomer (Figure 2, left) is therapeutic, and can be used to treat a variety of other diseases, including cancer. The $S$ enantiomer is a mutagen, and led to birth defects (Figure 2, right). ${ }^{2}$
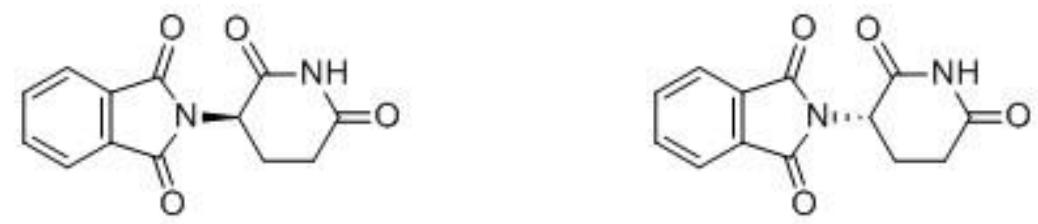

Figure 2. $R$ thalidomide (left); $S$ thalidomide (right)

Due to these differences in the activity of different enantiomers of the same compound, it is important to have methods for detecting the difference between chiral compounds.

\subsection{Symmetry}

As previously mentioned, an example of chirality is the way that left and right hands are mirror images of each other, but are not identical. A chiral carbon center is an $\mathrm{sp}^{3}$ hybridized carbon with tetrahedral geometry, where all four of the $\sigma$ bonded groups are different. $R$ or $S$ configuration at the chiral carbon center can be determined using Cahn-Ingold-Prelog priority rules. ${ }^{8}$ Chirality is not limited to organic molecules. Metal complexes can have a chiral environment, where the chiral structure is due to the arrangement of the ligand molecules around the metal center. If the ligands are bound in such a way that they form a "right handed" structure, the complex has $\Delta$ symmetry (Figure 3, left), and if the ligands are bound such that they form a "left handed" structure, the complex has $\Lambda$ symmetry (Figure 3 , right). ${ }^{8}$ 

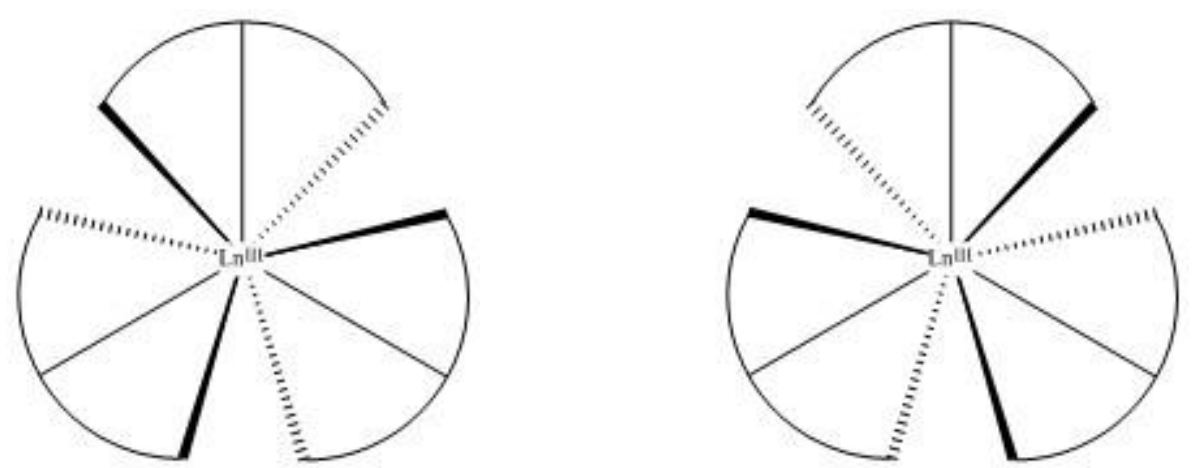

Figure 3. Generic structure of a 9 -coordinate $\mathrm{Ln}^{3+}$ complex with $\Delta$ symmetry (left), and $\Lambda$ symmetry (right)

Determining chirality becomes more complicated as structures become more complex. Molecules can be categorized by symmetry into point groups. Point groups are mathematical groups that contain a complete set of all the symmetry operations that can be performed on a molecule in that point group. ${ }^{9}$ A symmetry operation is simply a movement of the molecule into a position where it is equivalent to its original state before the symmetry operation was carried out. ${ }^{9}$ An example of a symmetry operation would be reflection across a mirror plane, and the associated symmetry element would be the mirror plane. ${ }^{9}$

If a molecule is chiral, its point group will not contain a mirror plane. ${ }^{9}$ If one of the symmetry elements is a mirror plane of symmetry, the molecule will be superimposable on its mirror image, and by definition it would be achiral. The improper axis of rotation, $\mathrm{S}_{\mathrm{n}}$ contains a mirror plane and an axis of rotation and can be reduced to a mirror plane or a center of inversion, so a molecule that has an improper axis of rotation cannot be chiral. $^{9}$

The ligands of interest are tridentate and form 9-coordinate 1:3 $\mathrm{Ln}^{3+}$ :ligand complexes which exhibit $\mathrm{D}_{3}$ symmetry. Generic structures for the $\Lambda$ and $\Delta$ forms are 
illustrated in Figure 3. The character table for the $\mathrm{D}_{3}$ point group includes the symmetry elements identity, $2 \mathrm{C}_{3}$ axes, and $3 \mathrm{C}_{2}$ axes - note that there are no mirror planes, point of inversions, or improper axes of rotation. ${ }^{9}$ Thus, these complexes with $\mathrm{D}_{3}$ symmetry are chiral. The ligands can be arranged around the lanthanide metal center with either a "right handed" or "left handed" helical twist, resulting in complexes with either $\Delta$ symmetry or $\Lambda$ symmetry. These $\Lambda$ and $\Delta$ structures can be studied using chiroptical spectroscopy techniques, including circularly polarized luminescence, as discussed in the next section.

\subsection{Chiroptical Spectroscopy Techniques}

There are a variety of methods for determining the structure of compounds, e.g. NMR, X-ray crystallography, and there are also methods that are particularly suited for determining chiroptical properties, for example, circular dichroism for determining the structure of proteins, ${ }^{10}$ circularly polarized luminescence spectroscopy for observing the excited state of a complex or an organic compound. ${ }^{11}$

One method of determining chirality of organic compounds uses a specific trait of chiral enantiomers, namely their differing optical activity. Two optically active enantiomers rotate light in opposite directions, either left or right, depending on whether it is the laevorotatory enantiomer or the dextrorotatory enantiomer. This rotation of light can be measured using a polarimeter. The experimentally determined optical activity of a compound, whether laevorotatory or dextrorotatory, is different from the structurally determined $R$ vs. $S$ handedness of a compound. As of now there is no reliable correlation between optical activity and structure. ${ }^{11-13}$

\subsubsection{Circularly polarized light and circular dichroism. While optical rotation}


can be used to determine the chirality of molecules like glyceraldehyde, it is not as useful when structures become more complex. Circularly polarized light is useful for characterization of more complex molecules, like proteins and metal ligand complexes. Plane polarized light contains circularly polarized components, where the field rotates as the wave travels, which results in a change in direction but not magnitude. If the left and right circularly polarized components are equal, the result is plane polarized light. However, if a chiral compound preferentially absorbs or emits left or right circularly polarized light, the result is a net circular polarization of light. ${ }^{10}$

Circular dichroism (CD) is a measure of the net absorption of circularly polarized light. ${ }^{10,14}$ It can be defined as the difference in absorption of left circularly polarized light $\left(A^{l}\right)$ and absorption of right circularly polarized light $\left(A^{r}\right),(1)$, and can only be measured at the sample's absorption bands.

$$
C D=A^{l}-A^{r}
$$

$\mathrm{CD}$ is a powerful tool. It can be used to study compounds that are intrinsically chiral, with an absolute chiral configuration, and can also be used to study the conformation of compounds. ${ }^{10} \mathrm{CD}$ can be used to study the ground state of a chiral complex. ${ }^{11}$ The difference in absorption of circularly polarized light can be measured from chiral center or the chiral environment of the chromophore, as chiral structures near the chromophore may affect the absorption of circularly polarized light. ${ }^{10}$ Absorption in specific regions of the spectrum can correspond to structures present, which makes it a useful tool for studying protein structure. For example, the structure of proteins in solution can be studied using CD, where absorption in the $\sim 260$ - $320 \mathrm{~nm}$ region corresponds to aromatic 
amino acid side chains, and certain types of secondary structures will give CD spectra with an identifiable shape ${ }^{15} \mathrm{CD}$ even allows for detection of some cofactors that show an absorption when they are bound to a chiral binding site in the protein. ${ }^{15}$

\subsubsection{Circularly polarized luminescence. The net emission of circularly polarized} light, on the other hand, can be measured with circularly polarized luminescence (CPL), the "emission analog" of $\mathrm{CD} \cdot{ }^{16}$ In the same way that $\mathrm{CD}$ can only be measured at the sample's absorbance bands, CPL can only be measured at the sample's emission bands. CPL studies luminescence emission and measures the net polarization in the luminescence from chiral molecules. It is used to study the excited state of the chiral compound, and chiral complexes as well as organic molecules can be studied. ${ }^{10,11}$

A CPL active compound would exhibit a difference in the luminescence intensity $(\Delta I)$ of left circularly polarized light $\left(I_{\mathrm{L}}\right)$ and luminescence intensity of right circularly polarized light $\left(I_{R}\right)(2) .{ }^{11}$

$$
\Delta I \equiv I_{l}-I_{r}
$$

Intensities are measured by counting photons. In circularly polarized luminescence spectroscopy, the ratio is generally measured, because measuring the absolute difference is difficult. ${ }^{16}$ The luminescence dissymmetry ratio, or the $g_{l u m}$, is the ratio of the difference between intensity of left $\left(I_{L}\right)$ and intensity of right $\left(I_{R}\right)$ circularly polarized light (3). ${ }^{16}$

$$
g_{\text {lum }}=\frac{\left(I_{L}-I_{R}\right)}{\frac{1}{2}\left(I_{L}+I_{R}\right)} .
$$

If the $g_{\text {lum }}$ value is 0 , there is no circular polarization, which means either the 
compound is without chiral properties or exists as a racemic mixture. The maximum $g_{\text {lum }}$ value is \pm 2 , which would mean maximum circular polarization. ${ }^{16}$ Generally, organic systems have $g_{\text {lum }}$ values in the $10^{-4}$ to $10^{-3}$ range, while $\mathrm{Ln}^{3+}$ systems have $g_{\text {lum }}$ values in the $10^{-2}$ to $10^{-1}$ range. ${ }^{11}$ The value of the $g_{\text {lum }}$ depends on a variety of factors, including the chiral environment that is present, whether there is a mixture of two diastereomers in solution, and features of the transition being measured. One of the highest observed $g_{l u m}$ values is +1.38 for $\mathrm{Eu}^{3+}: 3$-heptafluoro-butylryl-(+)-camphorato-ligands (Figure 4), ${ }^{17,18}$ and more common $g_{l u m}$ values are smaller, for example $1 \times 10^{-3}$ for triarylamine helicines (Figure 5). ${ }^{13,19}$

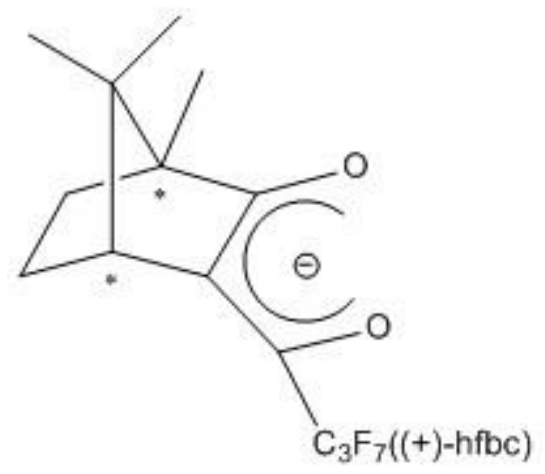

Figure 4. 3-heptafluoro-butylryl-(+)-camphorato ligand

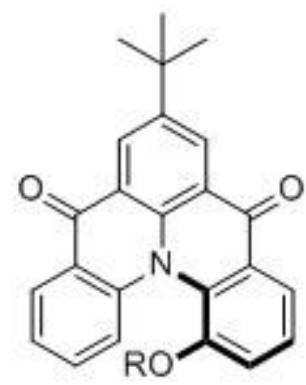

Figure 5. triarylamine helicene ligand

Magnetic dipole allowed and electric dipole forbidden transitions tend to give larger $g_{\text {lum }}$ values. ${ }^{11}$ This can be explained mathematically, as $g_{l u m}$ can be related to the 
molecular transitions by using Fermi's golden rule, ${ }^{11,16}$ giving the following relationship:

$$
g_{\text {lum }}(\lambda)=4 \operatorname{Re}\left[\frac{\vec{\mu}^{g n} \cdot \vec{m}^{g n}}{\left|\vec{\mu}^{g n}\right|^{2}+\left|\vec{m}^{g n}\right|^{2}}\right]
$$

As $\vec{\mu}^{g n}$ is the electric dipole transition moment, and $\vec{m}^{g n}$ is the magnetic dipole transition moment, $g_{\text {lum }}$ contains a ratio of the imaginary magnetic dipole transition moment, $m^{g n}$, and the electric dipole transition moment, $\mu^{g n} .{ }^{16}$ Having a small value in the denominator would give a larger $g_{l u m}$ value, and since $\vec{m}^{g n}$ is usually larger than $\vec{\mu}^{g n},{ }^{11}$ if $\left|\vec{\mu}^{g n}\right|^{2}$ is small, the $g_{\text {lum }}$ value would be predicted to be larger.

As mentioned earlier, $\mathrm{Ln}^{3+}$ systems tend to exhibit larger $g_{\text {lum }}$ values than organic systems. This is because certain emissive transitions of $\mathrm{Ln}^{3+}$ ions are both magnetic dipole allowed and electric dipole forbidden, making them ideal for CPL. For example, the $f \rightarrow f$ transitions between $f$ orbitals of lanthanides are Laporte forbidden. The Laporte rule states that parity conserving transitions are forbidden, that is, electronic transitions between orbitals with the same symmetry are forbidden. Thus, these $f \rightarrow f$ transitions have the desired property of being electric dipole forbidden transitions. ${ }^{16}$ It is important to note experimentally, these transitions are often weakly allowed, that is, if there is some distortion of the symmetry of the orbitals, vibrational coupling may perturb the symmetry enough that the transitions are weakly allowed. ${ }^{11}$ The other requirement is that the transitions are magnetic dipole allowed. Magnetic dipole allowed transitions obey the following selection rules:

$$
\text { no change in direction of spin, }{ }^{13}
$$




$$
\Delta J=0, \pm 1 \text { except where } J=0 \rightarrow J=0
$$

where $\Delta \mathrm{J}$ is the change in the total angular momentum quantum number, ${ }^{8}$ and the total angular momentum quantum number is a combination of the orbital angular momentum and the spin, ${ }^{13}$

$$
\Delta M_{j}=0, \pm 1
$$

where $\mathrm{M}_{j}$ is the projection of the total angular momentum along the axis. ${ }^{13}$

\subsection{Lanthanide Complexes}

\subsubsection{General traits of $\mathbf{4} f$-block metals and the antenna effect. The lanthanides,}

Ln, or rare earth elements, are $f$-block metals with atomic numbers between 57 (lanthanum) and 71 (lutetium). They prefer the $\mathrm{Ln}^{3+}$ oxidation state. ${ }^{20}$ The $f$ orbitals are deep-lying and shielded by higher filled orbitals,${ }^{21}$ so they do not play a major role in coordination to the ligands and are not as affected by bound ligands or by the solvent. ${ }^{20}$ Therefore the luminescence spectrum is characteristic of the metal center, corresponding to its $f-f$ transitions. ${ }^{22}$ This shielding also means that the $f-f$ transitions are sharp, ${ }^{20}$ and may have long decay times. ${ }^{21} \mathrm{Eu}^{3+}$ and $\mathrm{Tb}^{3+}$ typically have long luminescent lifetimes in the range of milliseconds. ${ }^{22}$

The $f \rightarrow f$ transitions are Laporte forbidden, ${ }^{22}$ and as a consequence lanthanides are weak absorbers of light. A way to counteract this is through the "antenna effect", where ligands, often aromatic organic molecules, are coordinated to a lanthanide ion. The bound ligand absorbs a photon, undergoes some ligand centered energy transitions, and then energy is transferred from the ligand excited states to the metal acceptor levels of the coordinated lanthanide metal center. ${ }^{13}$ This energy transfer from the ligand to the metal is 
Laporte allowed, and therefore, indirectly exciting through coordinated ligands is an effective way to counteract the weak absorbance of the lanthanide $f \rightarrow f$ transitions.

However, there are some caveats. The required energy transitions are not $100 \%$ efficient, and involve the loss of energy through radiative or non-radiative decay. Radiative transitions involve the absorbance or emission of a photon, and those that do not involve a photon are referred to as nonradiative transitions. ${ }^{21}$ Figure 6 illustrates these energy transitions.

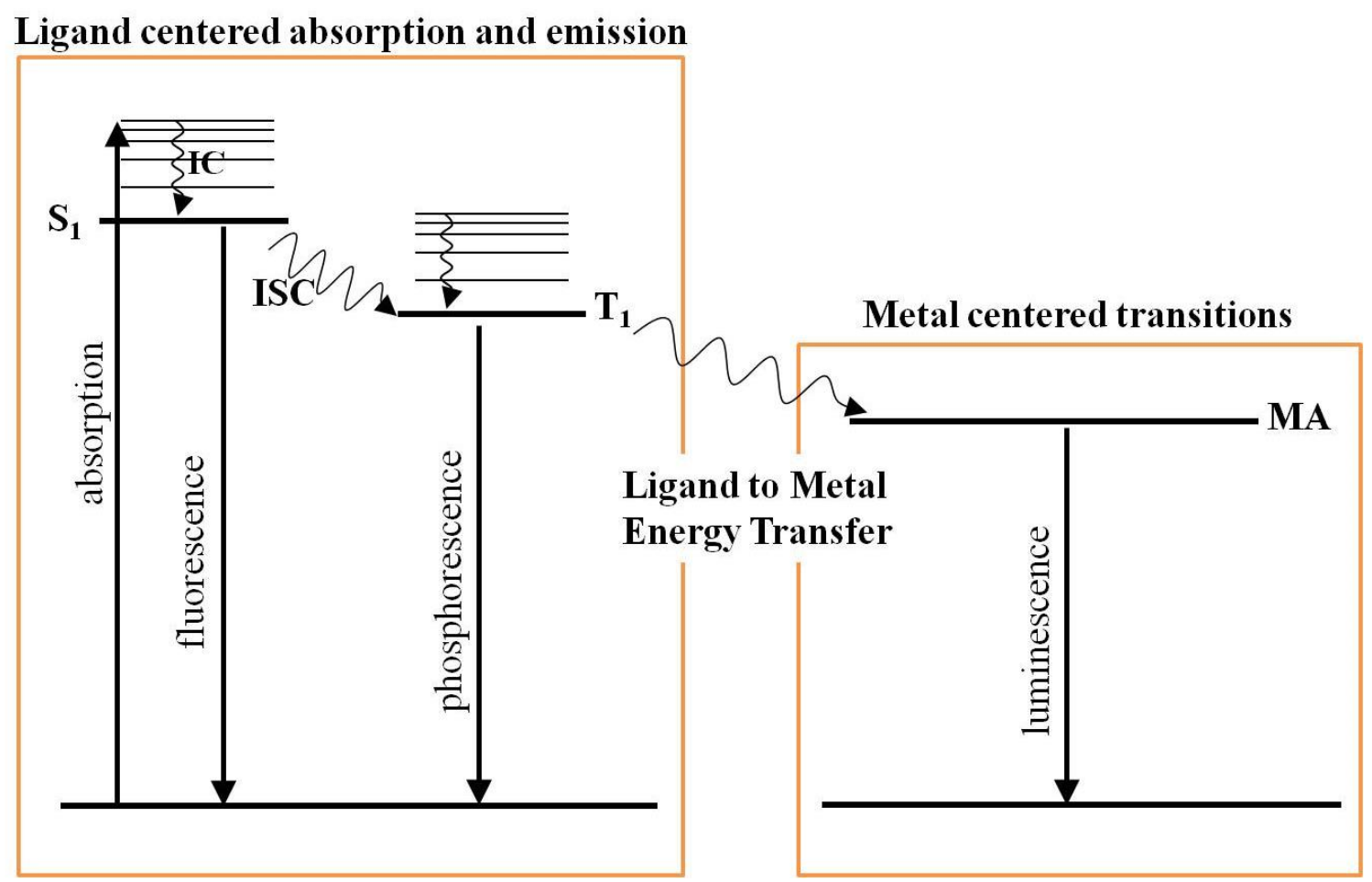

Figure 6. Simplified Energy Diagram, Antenna Effect, Ligand to Metal Energy Transfer. IC = Internal Conversion, $S_{1}=$ Excited singlet state, $T_{1}=$ Excited triplet State, ISC $=$ Intersystem Crossing, MA = Metal Acceptor Levels

After the ligand is excited, there may be non-radiative decay through vibration to the lowest vibrational level of the electronic ground state. Alternatively, an electron that is excited to a higher energy state may drop down to the LUMO, the lowest energy 
unoccupied orbital, $\pi^{*}$, through internal conversion (IC). IC does not involve a change in spin multiplicity - the spin state stays the same. Energy is converted into vibrational energy (heat), and through IC transitions down to the ${ }^{1} \pi \pi^{*}$ singlet state. ${ }^{21}$ At this point, there may be some loss of energy through emission from the ${ }^{1} \pi \pi^{*}$ excited singlet states, which is referred to as fluorescence for organic molecules. If there is no loss, the next step is a transition from the singlet ${ }^{1} \pi \pi^{*}$ excited state to the triplet ${ }^{3} \pi \pi^{*}$ excited state, with a change in overall spin multiplicity, through a process called intersystem crossing (ISC). ${ }^{21}$

The ideal gap for an efficient energy transfer $\Delta \mathrm{E}\left({ }^{1} \pi \pi^{*}-{ }^{3} \pi \pi^{*}\right)$ is $5,000 \mathrm{~cm}^{-1} \cdot{ }^{23}$ Here is another chance for radiative loss, through emission from the excited triplet state, ${ }^{3} \pi \pi^{*}$, or phosphorescence. ${ }^{21}$ If there is no loss, there is then ligand to metal energy transfer from the triplet ${ }^{3} \pi \pi^{*}$ excited state to the metal acceptor levels. Ideally, the ligand excited states and the metal acceptor levels are close enough for efficient transfer of energy, but far enough to avoid back transfer from the metal to the ligand. The ideal gap between the ligand excited states and the metal acceptor states is $2,500-3,500 \mathrm{~cm}^{-1}{ }^{23}$

\subsection{2 $\mathbf{L n}^{3+}$ :ligand coordination complexes. Upon either direct excitation or} indirect excitation (through the antenna effect, ), $\mathrm{Ln}^{3+}$ complexes may exhibit luminescence. The luminescent properties of some $\mathrm{Ln}^{3+}$ ions (e.g., $\mathrm{Eu}^{3+}$ and $\mathrm{Tb}^{3+}$ ) contribute to making them suitable for use in spectroscopy. These include characteristic luminescence bands, sensitivity to the metal environment, and long luminescent lifetimes. ${ }^{24}$ In addition, as previously described, certain transitions are magnetic dipole allowed and electric dipole forbidden, leading to larger $g_{\text {lum }}$ values, which makes some 
luminescent $\mathrm{Ln}^{3+}$ complexes useful for CPL studies.

Lanthanide ions are hard Lewis acids, and so prefer hard ligands, especially $\mathrm{O}$ donors and $\mathrm{N}$ donors, but do not strictly follow hard/soft rules. ${ }^{20}$ Ligands add until sterically saturated, and tend to form 8-12 coordinate complexes. Bound ligand will displace solvent molecules, and the coordination of ligand has the benefit of protecting $\mathrm{Ln}^{3+}$ from quenching by solvent. ${ }^{13}$ Coordinated solvent molecules will often reduce the luminescence due to nonradiative quenching from the solvent. Solvents such as water or methanol have - $\mathrm{OH}$ oscillators, and acetonitrile has $\mathrm{CH}$ oscillators, which can all lead to vibrational quenching. However, if the ligands coordinate to the metal center until sterically filled, the ligands shield the metal from solvent molecules, preventing these quenching processes. ${ }^{13}$ Thus, observing strong luminescence may signify that ligands have bound until sterically saturated and solvent molecules are excluded. As the lifetime of the excited state, $\tau$, correlates with the probability of radiative and non-radiative decay, ${ }^{25}$ an increase in the observed lifetime is another indication of a reduction in non-radiative quenching.

These complexes are quite labile compared with their transition metal counterparts, and therefore if there is a racemic mixture of $\Delta$ and $\Lambda$ structures in solution, traditional techniques for isolating a single diastereomer will not work as well with the lanthanide complexes. Control of the structure of $\mathrm{Ln}^{3+}$ coordination complexes is possible through other approaches, including macrocyclic ligands, podands, and multidentate ligands. ${ }^{26} \mathrm{~A}$ study of the bis(benzimidazole)pyridine, L(bap), family of ligands (Figure 7) showed that keeping the central tridentate aromatic system consistent, and changing substituents at the 
various - $\mathrm{R}$ positions on the ligands had a large effect on the structure of the $\left[\operatorname{Ln}(\mathrm{L}(\text { bap }))_{3}\right]^{3+}$ complexes, even when the changes to the ligands were relatively small.

Figure 7. L(bap) - bis(benzimidazole)pyridine moiety

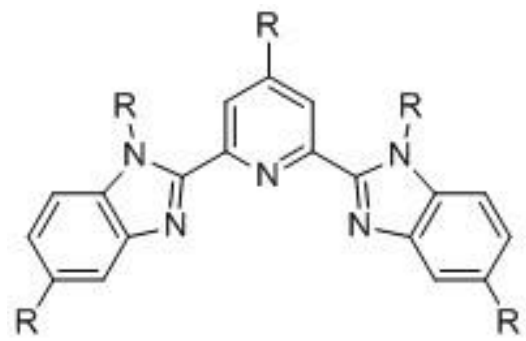

The bis(benzimidazole)pyridine ligand with methyl substituents, L(bap-1) (Figure 8), is structurally very similar to the bis(benzimidazole)pyridine ligand with methyl and ethyl substituents, L(bap-5) (Figure 9).

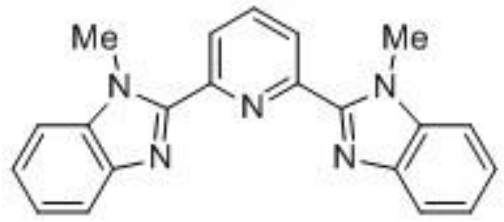

Figure 8. L(bap-1) - bis(benzimidazole)pyridine with methyl substituents

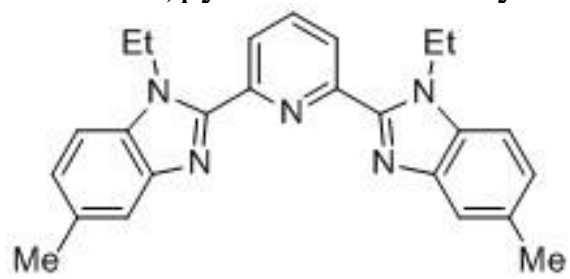

Figure 9. L(bap-5) - bis(benzimidazole)pyridine with methyl and ethyl substituents However, the $\left[\mathrm{Eu}\left(\mathrm{L}(\text { bap-1) })_{3}\right]^{3+}\right.$ complex is a pseudo- $\mathrm{D}_{3}$ structure, and the $\left[\mathrm{Eu}(\mathrm{L}(\text { bap-5 }))_{3}\right]^{3+}$ complex is a pseudo- $\mathrm{C}_{3}$ structure. Small structural changes in the ligands have a large effect on the association between the ligand and the $\mathrm{Ln}^{3+}$ center, leading to a larger effect on the symmetry on the resulting coordination complexes.

The symmetry of the coordination complex is important when making chiroptical comparisons between structures. Like $\left[\mathrm{Eu}(\mathrm{L}(\mathrm{bap}-1))_{3}\right]^{3+}$, coordination complexes of 
oxydiacarboxylic acid (ODA) (Figure 10) with $\mathrm{Eu}^{3+}$ have a $\mathrm{D}_{3}$ structure.<smiles>O=C(O)COCC(=O)O</smiles>

Figure 10. ODA - oxydicarboxylic acid

CPL active crystals of pure $\Delta$-[Eu(ODA $\left.)_{3}\right]^{3+}$ complex can be obtained, with a $g_{\text {lum }}$ sign pattern of (-) for the ${ }^{5} \mathrm{D}_{0} \rightarrow{ }^{7} \mathrm{~F}_{1}$ transition and (-,+) for the ${ }^{5} \mathrm{D}_{0} \rightarrow{ }^{7} \mathrm{~F}_{2}$ transition. ${ }^{27}$

Like $\left[\mathrm{Eu}\left(\mathrm{L}(\text { bap-5) })_{3}\right]^{3+}\right.$, coordination complexes of the chiral tripodal nonadentate receptor, $\mathrm{L}(\mathrm{L} 8)$, (Figure 11) with $\mathrm{Eu}^{3+}$ have a $\mathrm{C}_{3}$ structure.

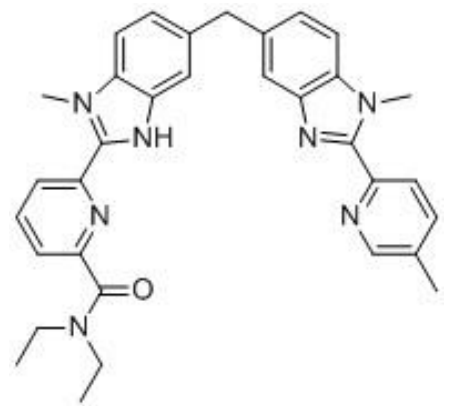

Figure 11. L(L8) - tripodal nonadentate receptor

CPL active, enantiomerically pure $\Delta \Delta-\left[\operatorname{Eu}(\mathrm{L}(\mathrm{L} 8))_{3}\right]^{3+}$ complex crystals can be obtained, with a $g_{\text {lum }}$ sign pattern of (+) for the ${ }^{5} \mathrm{D}_{0} \rightarrow{ }^{7} \mathrm{~F}_{1}$ and (-) for the ${ }^{5} \mathrm{D}_{0} \rightarrow{ }^{7} \mathrm{~F}_{2}$ transition. ${ }^{28}$ The sign patterns of the ODA and L(L8) complexes do not correlate with each other, and Gawryszewska et al. noted that the chiral environment at the $\mathrm{Eu}^{3+}$ center is likely too different due to the different symmetry of the complexes (distorted $\mathrm{D}_{3}$ vs $\mathrm{C}_{3}$ ), which means that a rule cannot be made for correlation of sign pattern and $\Delta$ or $\Lambda$ structure between these different symmetry structures. ${ }^{27}$

The structure of the ligand may also affect the electronic properties of the ligand and in turn, the electronic properties of the ligand may have an effect on the properties of the $\left[\mathrm{LnL}_{\mathrm{n}}\right]^{3+}$ complexes. An early study of a family of chelating ligands where structural 
changes lead to different photophysical properties focuses on the way the position of the ligand bands effect the photophysical properties of the $\mathrm{Eu}^{3+}$ and $\mathrm{Tb}^{3+}$ complexes. ${ }^{29}$ Transfer of energy occurs between the lowest triplet state of the ligand to the resonance level of $\mathrm{Ln}^{3+} \cdot{ }^{29}$ The position of the triplet state of the ligand was calculated using phosphorescence spectra of the $\left[\mathrm{GdL}_{\mathrm{n}}\right]^{3+}$ complexes, as the $\mathrm{Gd}^{3+}$ acceptor bands are not accessible for energy transfer from ligand excited states and thus any observed luminescence would be ligand centered. Even relatively small structural changes may lead to a change in photophysical properties. Two relatively similar structures studied are 2,2',2",2'"-[(4'-phenyl-2,2':6',2"-terpyridine-6,6"-diyl)bis(methylenenitrilo)]tetrakis(acetic acid), L(tpm) (Figure 12), and 2-(4-Aminobut-1-yl)-2,2',2",2'"-[(4'-phenyl-2,2':6',2"-ter pyridine-6,6"-diyl)bis(methylenenitrilo)]tetrakis(acetic acid), L(N-tpm) (Figure 13). ${ }^{29}$

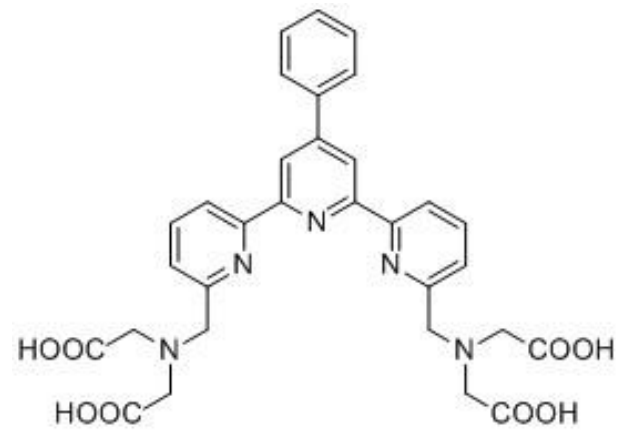

Figure 12. L(tpm) - bis2,2',2",2'"-[(4'-phenyl-2,2':6',2"-terpyridine-6,6"-diyl)bis (methylenenitrilo)]tetrakis(acetic acid)

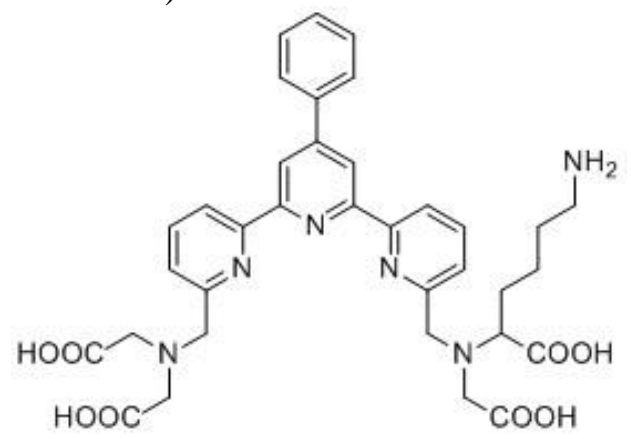

Figure 13. L(N-tpm) - 2-(4-Aminobut-1-yl)-bis2,2',2",2'"-[(4'-phenyl-2,2':6',2"-ter pyridine-6,6"-diyl)bis(methylenenitrilo)]tetrakis(acetic acid) 
Latva et al. observed changes in the photophysical properties of the ligands and complexes resulting from this structural change in the ligands. For example, there is a small difference in the excitation maxima of the $\mathrm{Tb}^{3+}$ :ligand complexes, and a small shift in the energy of the triplet state, but the quantum yield of the $[\mathrm{EuL}(\mathrm{tpm})]^{3+}$ and $[\mathrm{TbL}(\mathrm{tpm})]^{3+}$ complexes is twice that of the $[\mathrm{EuL}(\mathrm{N}-\mathrm{tpm})]^{3+}$ and $[\mathrm{TbL}(\mathrm{N}-\mathrm{tpm})]^{3+}$ complexes. The luminescence lifetime of the $[\mathrm{EuL}(\mathrm{tpm})]^{3+}$ complex is slightly lower than the lifetime of the $[\mathrm{EuL}(\mathrm{N}-\mathrm{tpm})]^{3+}$ complex, while the luminescence lifetime of the $[\mathrm{TbL}(\mathrm{tpm})]^{3+}$ complex is three times higher than the lifetime of the $[\mathrm{TbL}(\mathrm{N}-\mathrm{tpm})]^{3+}$ complex. $^{29}$

These changes in the properties of the $\mathrm{Ln}^{3+}$ :ligand coordination complexes show that, when designing an $\mathrm{Ln}^{3+}$ :ligand system, it is important to consider that relatively small structural changes to the ligands may have far reaching effects on the $\mathrm{Ln}^{3+}$ complex. 


\section{CHAPTER 2}

\section{$2.1 \quad$ Objectives of Project}

\section{RESEARCH GOAL}

There is currently no method of predicting absolute chiral structure from chiroptical properties. ${ }^{11-13}$ A family of ligands derived from a 2,6-pyridine dicarboxamide moiety may be a step towards chiral probes which display a consistent relationship between structure and spectroscopy. These ligands form labile $\left[\mathrm{LnL}_{3}\right]^{3+}$ complexes (where $\mathrm{Ln}^{3+}$ includes $\mathrm{Eu}^{3+}, \mathrm{Tb}^{3+}$, and $\mathrm{Gd}^{3+}$ ) with $\mathrm{D}_{3}$ symmetry. Previous studies have shown that using one enantiomer of chiral ligand may induce the formation of a single diastereomer of the $\left[\mathrm{LnL}_{3}\right]^{3+}$ complex, and there may be a relationship between structure of the complex $(\Lambda$ and $\Delta$ ) and the sign of the CPL (+ and -). ${ }^{11,30,3132}$

$N, N$ '-bis(1-phenylpropyl)-2,6-pyridinedicarboxamide (Figure 14), heretofore to be referred to as $\mathrm{L}(\mathrm{Et})$, is a chiral ligand which is structurally similar to the aforementioned family of ligands.

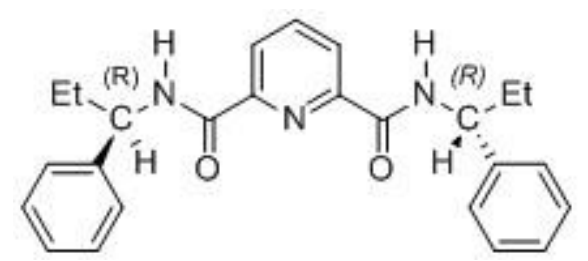

Figure 14. L(Et) - $R, R$ enantiomer of $N, N^{\prime}$-bis(1-phenylpropyl)-2,6-pyridine dicarboxamide

Minor structural changes in the ligand may have a larger impact on the photophysical and chiral properties of the $\left[\mathrm{LnL}_{3}\right]^{3+}$ complexes. A detailed study of the photophysical, structural, and chiroptical properties of $\mathrm{L}(\mathrm{Et})$ and $\left[\mathrm{Ln}(\mathrm{L}(\mathrm{Et}))_{3}\right]^{3+}$ complexes, and comparison with the properties of related ligands and $\left[\mathrm{LnL}_{3}\right]^{3+}$ complexes is required for a broader understanding of the behavior of these complexes, and the relationship between 
structure and chiroptical properties holds across similar ligand systems. We hypothesis that we can make a correlation between chiral structure of the ligand, the complex, and the sign of CPL signal.

\subsection{A Promising Family of Ligands}

Ligands derived from a 2,6-pyridine dicarboxamide moiety (Figure 15) have a variety of interesting properties which make them promising in the development of luminescent chiral probes ${ }^{11,33}$ and self assembly structures. ${ }^{34}$

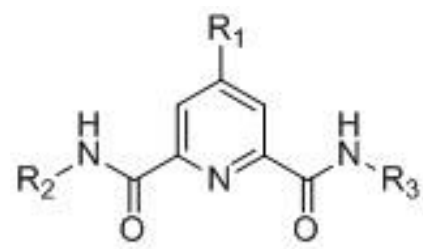

Figure 15. 2,6-pyridinedicarboxamide moiety

The properties of the ligands can be modified by changing the substituents at the $\mathrm{R}_{1}$, $\mathrm{R}_{2}$ or $\mathrm{R}_{3}$ positions. The coordination of these ligands to $\mathrm{Ln}^{3+}$ ions generally follows a predictable pattern. ${ }^{34}$ Generally, 3 tridentate ligands coordinate to the metal center to the form of a 9-coordinate complex where the lanthanide ion is shielded from solvent by the ligand. The resulting 1:3 $\mathrm{Ln}^{3+}$ :ligand complexes generally have $\mathrm{D}_{3}$ symmetry and can be indirectly excited through the antenna effect. ${ }^{11}$

Early studies of the structurally similar but simpler dipicolinic acid, DPA, (Figure 16) also known as 2,6-pyridine-dicarboxylate, and $\left[\operatorname{Ln}(\mathrm{DPA})_{3}\right]^{3+}$ complexes showed that 3 equivalent ligands must be coordinated to the metal center in order to form the complex with $\mathrm{D}_{3}$ symmetry. ${ }^{12,35}$ 


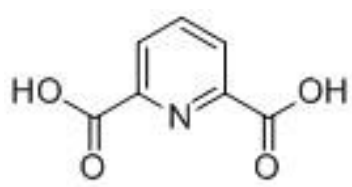

Figure 16. DPA - dipicolinic acid

Complexes with only one or two ligands bound to the $\mathrm{Ln}^{3+}$ center do not have $\mathrm{D}_{3}$ symmetry, as solvent molecules coordinate to the $\mathrm{Ln}^{3+}$ center and symmetry is lost. As DPA is achiral, the only chirality in the complexes results from the chiral environment at the metal center, from the arrangement of the ligands to form a structure with either $\Delta$ or $\Lambda$ helicity. ${ }^{11,12}$ Previous studies have found that the DPA complexes exist as a racemic mixture of $\Lambda$ and $\Delta$ metal complexes in solution. ${ }^{11}$ Exciting the sample with circularly polarized light results in a measurable $\mathrm{g}_{\text {lum }}$ value, where left circular polarized excitation and right circular polarized excitation give $\mathrm{g}_{l u m}$ of equal magnitude but opposite sign. ${ }^{16,35}$ This mixture can be perturbed by the addition of chiral molecules in solution (the "Pfeiffer effect"), ${ }^{36}$ to induce the formation of an excess of either $\Delta$ or $\Lambda$ results in a net circular polarization in the luminescence. The resulting sample has a measurable $\mathrm{g}_{l u m}$ value. ${ }^{37}$ However, changing the excitation polarization will change the $\mathrm{g}_{\text {lum }}$ value, indicating that there are multiple species of different symmetry in solution. ${ }^{11}$

\subsection{Comparison of Chiral 2,6-pyridine dicarboxamide Ligands}

Chirality can be introduced in the ligand itself, by attaching a chiral substituent at the $\mathrm{R}_{1}, \mathrm{R}_{2}$ or $\mathrm{R}_{3}$ position of the 2,6-pyridine dicarboxamide moiety. The $R, S$ structure will be meso, but the $R, R$ and $S, S$ structures will be chiral. Using a single enantiomer of the ligand (i.e. $R, R$ vs $S, S$ ) may induce a chiral environment, where one enantiomer preferentially forms the $\Lambda$ metal complex, and the other enantiomer preferentially forms 
the $\Delta$ metal ligand complex. ${ }^{11,12}$ An early study of

3-[2,6-bis(diethylcarbamoyl)pyridine-4-yl]- $N$-(tert-butoxycarbonyl)alanine methyl ester, ${ }^{33}$ heretofore to be known as L(4p), (Figure 17) showed that using a single enantiomer of $\mathrm{L}(4 \mathrm{p})$ induced the formation of an excess of one diastereomer of the $\left[\mathrm{LnL}_{3}\right]^{3+}$ complex in solution.<smiles>CCN(CC)C(=O)c1cc(C[C@@H](NC(=O)OCC(C)(C)C)C(C)=O)cc(C(=O)N(CC)CC)n1</smiles>

Figure 17. L(4p) - $R$ enantiomer 3-[2,6-bis(diethylcarbamoyl)pyridine-4-yl]- $N$-(tert-but oxycarbonyl)alanine methyl ester

L(4p) has a chiral group (tert-butoxycarbonyl) attached at the 4-position of the pyridine ring, or the $\mathrm{R}_{1}$ position of the 2,6-pyridinedicarboxamide moiety in Figure 15.

The chiral group in $\mathrm{L}(4 \mathrm{p})$ is relatively distant from the coordinating region of the 2,6-pyridinedicarboxamide moiety. Ligands with a chiral substituent at $\mathrm{R}_{2}$ and/or $\mathrm{R}_{3}$, directly attached to the coordinating amide region were explored as a way to increase the chiral directing power of the ligand. Pyridine-2,6-dicarboxylic acid-[1-naphthalen-1-yl-ethyl)-amide], L(hh1), (Figure 18) ${ }^{38}$ and pyridine-2,6-dicarboxylic acid-[1-naphthalen-2-yl-ethyl)-amide], L(hh2), (Figure 19) ${ }^{39}$ have one chiral substituent attached at $\mathrm{R}_{2}$.<smiles></smiles>

Figure 18. L(hh1) - $R$ enantiomer of pyridine-2,6-dicarboxylicacid-[1-naph thalen-1-yl-ethyl)-amide] 


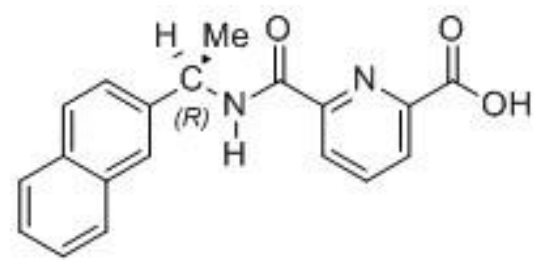

Figure 19. L(hh2) - $R$ enantiomer of pyridine-2,6-dicarboxylic acid-[1-naph thalen-2-yl-ethyl)-amide]

Lincheneau et al. describe L(hh1) and L(hh2) as "half helicates" because they have one chiral group at $\mathrm{R}_{2}$ and an achiral carboxylic acid group on the other side. ${ }^{38}$

Attaching chiral substituents at both $\mathrm{R}_{2}$ and $\mathrm{R}_{3}$, created ligands with twice the chiral centers as the "half helicates". Leonard et al. and Kotova et al., studied pyridine-2,6-dicarboxylic acid bis-[1-naphthalen-1-yl-ethyl)-amide], L(1yl) (Figure 20), ${ }^{40,41}$ which is structurally similar to L(hh1) (Figure 18), ${ }^{38}$ and pyridine-2,6-dicarboxylic acid ( $R, R$-bis-[-(1-naphthalen-2-yl-ethyl)-amide], L(2yl) (Figure 21), ${ }^{41}$ which is structurally similar to L(hh2) (Figure 19). ${ }^{39}$<smiles>[Y4][C@H](NC(=O)c1cccc(C(=O)NC(c2cccc3ccccc23)c2cccc3ccccc23)n1)c1cccc2ccccc12</smiles>

Figure 20. L(1yl) - $R, R$ enantiomer of pyridine-2,6-dicarboxylic acid bis-[1-naphthalen-1-yl-ethyl)-amide]<smiles>C[C@H](NC(=O)c1cccc(C(=O)N[C@H](C)c2ccc3ccccc3c2)n1)c1ccc2ccccc2c1</smiles>

Figure 21. L(2yl) - $R, R$ enantiomer of pyridine-2,6-dicarboxylic acid bis-[1-naphthalen-2-yl-ethyl)-amide] 
The $R, R$ enantiomer of $\mathrm{L}(1 \mathrm{yl})$ and $\mathrm{L}(2 \mathrm{yl})$ induced $\Delta$ chirality in the $1: 3 \mathrm{Ln}^{3+}$ :ligand complexes, and the $S, S$ enantiomer of $\mathrm{L}(1 \mathrm{yl})$ and $\mathrm{L}(2 \mathrm{yl})$ induced $\Lambda$ chirality. ${ }^{40}$ The induced helicity of the $\mathrm{Ln}^{3+}$ complexes increased compared with the "half helicate" complexes, and higher $\mathrm{g}_{\text {lum }}$ values were observed.

While $\mathrm{L}(1 \mathrm{yl})$ and $\mathrm{L}(2 \mathrm{yl})$ have strong directing powers, the naphthalenyl groups are quite bulky, which may have an effect on helical structure and formation of the complexes. Bonsall et al. and Hua et al., ${ }^{12,23}$ studied $N, N$ '-bis(1-phenylethyl)-2,6-pyridinedicarboxamide, L(Me), (Figure 22), which has a less bulky phenyl group at the chiral carbon center.

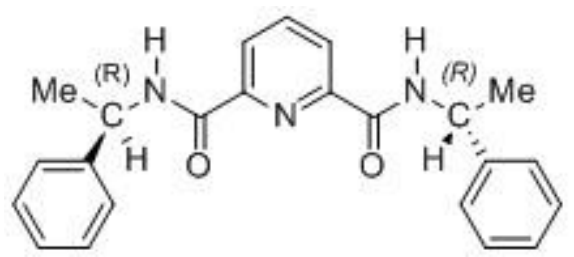

Figure 22. L(Me) - $R, R$ enantiomer of $N, N$ '-bis(1-phenylethyl)-2,6-pyridine dicarboxamide

Even with this change in structure, $\mathrm{L}(\mathrm{Me})$ also preferentially induces the formation of one diastereomer of the $\mathrm{Ln}^{3+}$ complex in solution, where the $R, R$ enantiomer induces $\Delta$ chirality, and the $S, S$ induces $\Lambda$ chirality. ${ }^{23}$

The ligand studied in this thesis, L(Et) (Figure 23), is structurally most similar to $\mathrm{L}(\mathrm{Me})$, where the only difference is that $\mathrm{L}(\mathrm{Et})$ contains an ethyl group at the chiral carbon centers and $\mathrm{L}(\mathrm{Me})$ has a methyl group at the chiral carbon centers. It will be interesting to observe whether this small structural change has an effect on the photophysical or chiroptical properties. 


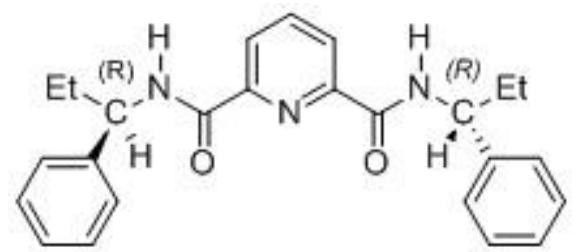

Figure 23. L(Et) - $R, R$ enantiomer of $N, N^{\prime}$-bis(1-phenylpropyl)-2,6-pyridine dicarboxamide

Photophysical characterization will allow for the determination of the luminescent properties of $\mathrm{L}(\mathrm{Et})$ and $\mathrm{Ln}^{3+}: \mathrm{L}(\mathrm{Et})$ complexes. Ideally, an effective luminescent probe would have a high quantum yield value and efficient energy transfer. It is also important to ensure that the $\left[\mathrm{Ln}(\mathrm{L}(\mathrm{Et}))_{3}\right]^{3+}$ species is formed in solution. Only the $1: 3$ species has $\mathrm{D}_{3}$ symmetry, where the 1:1 and 1:2 species do not. Therefore, investigation includes electronic spectra in the UV-Visible region, steady-state and time-resolved luminescence at room temperature and 77 Kelvin (indirect excitation), laser excitation (direct excitation), and luminescence titration to determine stability constants. CPL of the $\left.\left[\mathrm{Eu}(\mathrm{L}(\mathrm{Et}))_{3}\right]\right]^{3+}$ complex $\left({ }^{5} \mathrm{D}_{0} \rightarrow{ }^{7} \mathrm{~F}_{1}\right.$ and ${ }^{5} \mathrm{D}_{0} \rightarrow{ }^{7} \mathrm{~F}_{2}$ transitions $)$ as well as the $\left[\mathrm{Tb}(\mathrm{L}(\mathrm{Et}))_{3}\right]^{3+}$ complex $\left({ }^{5} \mathrm{D}_{4} \rightarrow{ }^{7} \mathrm{~F}_{5}\right.$ transition $)$ will be measured. These will be compared with previous studies of similar ligands to determine whether the correlation between the structure of the complex $(\Lambda$ and $\Delta)$ and the sign pattern of the CPL (+ and -) also holds true for $\mathrm{L}(\mathrm{Et})$. 


\section{CHAPTER 3}

\section{RESULTS AND DISCUSSION}

\subsection{Structure of $\mathrm{L}(\mathbf{E t})$}

3.1.1 Calculated molecular structure of $\mathbf{L}(\mathbf{E t})$. Calculated molecular structures of L(ET) were obtained by performing geometry optimization using density functional theory (DFT) $)^{42,43}$ on the system ${ }^{44-46}$ described in Chapter 5 . This method was used to determine the structure of $\mathrm{L}(\mathrm{Et})$ as an alternative to $\mathrm{x}$-ray, as it was difficult to obtain an X-ray quality crystal of L(Et). Previous studies of the structurally similar ligand L(Me) found that results obtained via X-ray and DFT were consistent, which confirms that this is a valid method of determining the structure of $\mathrm{L}(\mathrm{Et}) .{ }^{23}$ The conformation of the $R, R$ and $S, S$ enantiomers of $\mathrm{L}(\mathrm{Et})$ is important to consider because the geometry of the ligand may have an effect on the way that the ligands arrange around the metal center. While there are limitations to these predicted conformations, namely that it is a gas-phase molecular mechanics calculation and the actual behavior of the ligand in solution likely differs from the prediction, and that there are likely conformational and electronic changes that occur upon coordination of the ligand to the metal center, these predicted conformations do still offer some insight.

The structure obtained for the $R, R$ enantiomer $\mathrm{L}(\mathrm{Et})$ is shown in Figure 24 and the structure obtained for the $S, S$ enantiomer of $\mathrm{L}(\mathrm{Et})$ is shown in Figure 25. The bond lengths and angles of the $R, R$ and $S, S$ enantiomers of $\mathrm{L}(\mathrm{Et})$ are included in Appendix A. 


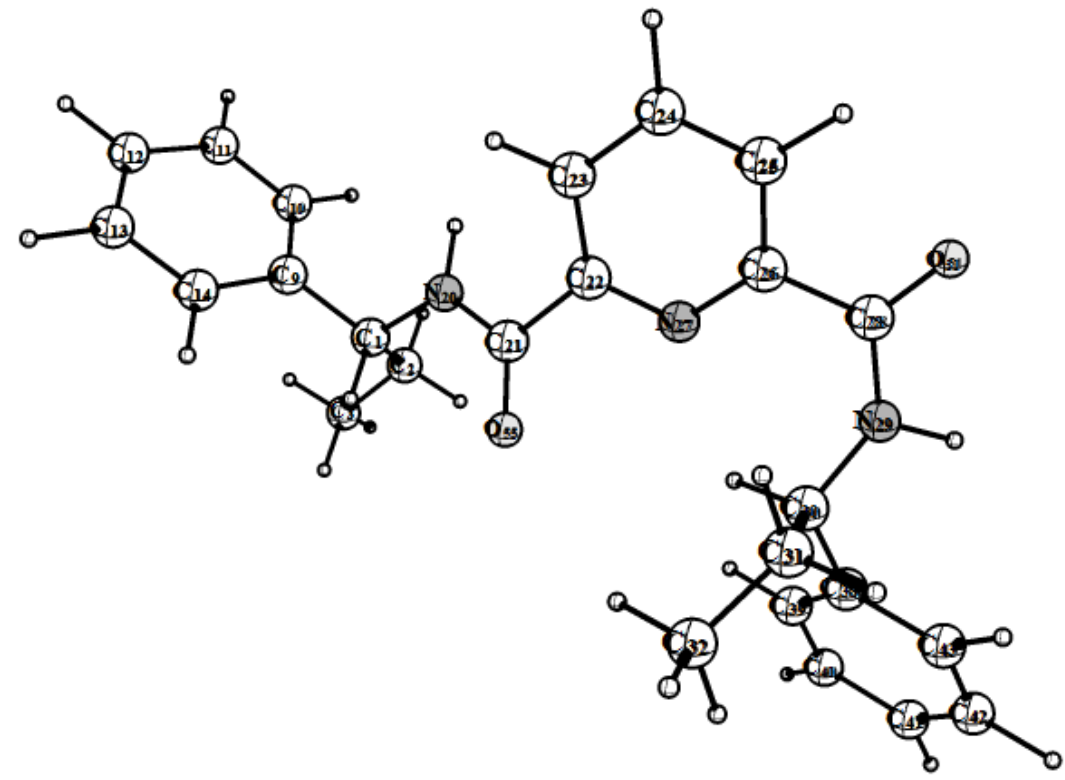

Figure 24. Molecular structure of $R, R$ enantiomer of $\mathrm{L}(\mathrm{Et})$

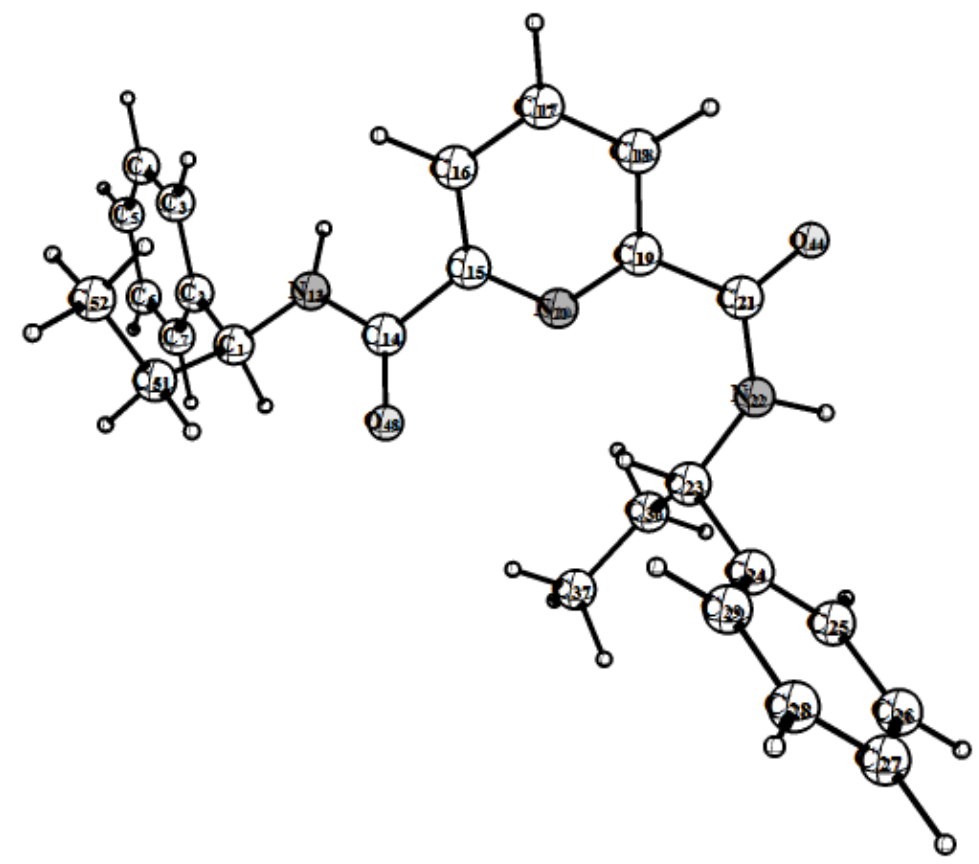

Figure 25. Molecular structure of $S, S$ enantiomer of L(Et)

The predicted conformations of the $R, R$ and $S, S$ enantiomers of $\mathrm{L}(\mathrm{Et})$ are mirror images of each other. Both structures have the carbonyl groups bent away from each other - C28 and C21 in Figure 24 and C14 and C21 in Figure 25 - and out of plane with 
the pyridine ring. The two phenyl groups are also out of plane with the pyridine ring and with each other - C9-14 and C38-43 in Figure 24 and C24-29 and C2-7 in Figure 25. This bent structure as well as the steric bulk of the phenyl groups will likely affect the arrangement of the ligands around the metal center. As there are three bulky ligands coordinated to the $\mathrm{Ln}^{3+}$ ion, they may need to distort their helical arrangement somewhat to relieve some steric strain, and therefore it is likely that the $\left[\mathrm{Ln}(\mathrm{L}(\mathrm{Et}))_{3}\right]^{3+}$ complex will have a perturbed $\mathrm{D}_{3}$ geometry, rather than the near $\mathrm{D}_{3}$ geometry Brittain observed in the $\left[\operatorname{Ln}(\mathrm{DPA})_{3}\right]^{3+}$ complex $^{35}$ with the far less bulky DPA ligands. This small structural change may have an effect on the CPL spectra of the $\left[\mathrm{Eu}(\mathrm{L}(\mathrm{Et}))_{3}\right]^{3+}$ and $\left[\mathrm{Tb}(\mathrm{L}(\mathrm{Et}))_{3}\right]^{3+}$ complexes.

3.1.2 NMR spectra of $\mathbf{L}(\mathbf{E t})$. The ${ }^{1} \mathrm{H}$ NMR and ${ }^{13} \mathrm{C}$ NMR spectra of the $R, R$ and $S, S$ enantiomers of $\mathrm{L}(\mathrm{Et})$ in $\mathrm{CDCl}_{3}$ are included in Appendix A, and confirm the structure of the L(Et) ligands. Analysis, including integration and labeling of the peaks, was performed in MestReNova. Figure 26 shows the numbering scheme used.

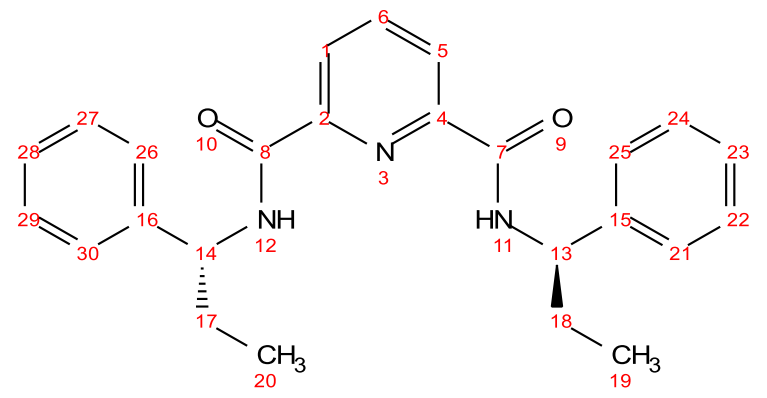

Figure 26. Numbered structure of $\mathrm{L}(\mathrm{Et}), R, R$ enantiomer

The ${ }^{1} \mathrm{H}$ NMR of the $R, R$ enantiomer of $\mathrm{L}(\mathrm{Et})$ shows peaks corresponding to the pyridine ring at $8.32 \mathrm{ppm}(\mathrm{H}$ on $\mathrm{C} 1, \mathrm{C} 5)$ and $8.0 \mathrm{ppm}(\mathrm{H}$ on $\mathrm{C} 6)$, as well as peaks corresponding to the $\mathrm{H}$ attached to $\mathrm{N} 11$ and N12 at $7.9 \mathrm{ppm}$. Also present is a multiplet at 
$7.36 \mathrm{ppm}$ corresponding to the phenyl rings (C21-25 and C26-30), peaks at $5.07 \mathrm{ppm}$ corresponding to the $\mathrm{H}$ directly attached to the chiral centers $(\mathrm{C} 13, \mathrm{C} 14)$, as well as peaks corresponding to the aliphatic carbons at $1.95 \mathrm{ppm}(\mathrm{C} 17, \mathrm{C} 18)$ and $1.92(\mathrm{C} 19, \mathrm{C} 20)$. The ${ }^{13} \mathrm{C}$ NMR of the $R, R$ enantiomer of $\mathrm{L}(\mathrm{Et})$ shows peaks corresponding to the carbonyl carbons $(\mathrm{C} 7, \mathrm{C} 8)$ at $162.8 \mathrm{ppm}$, the pyridine ring at $148.8 \mathrm{ppm}(\mathrm{C} 4)$ and $125.2 \mathrm{ppm}(\mathrm{C} 1$, C5), at 126.66-136.3 corresponding to the phenyl rings (C15,16, C21-25 and C26-30), a peak at $55.3 \mathrm{ppm}$ corresponding to the chiral centers $(\mathrm{C} 13, \mathrm{C} 14)$, and peaks corresponding to the aliphatic carbons at $29.4 \mathrm{ppm}(\mathrm{C} 17, \mathrm{C} 18)$ and $19.2 \mathrm{ppm}(\mathrm{C} 19, \mathrm{C} 20)$. The positions of the peaks are relatively identical between the $R, R$ enantiomer of $\mathrm{L}(\mathrm{Et})$ and the $S, S$ enantiomer of $\mathrm{L}(\mathrm{Et})$, as expected for enantiomers.

\subsection{Ligand Centered Absorbance and Emission}

Investigation of the ligand of interest, $\mathrm{L}(\mathrm{Et})$, began with photophysical characterization of $\mathrm{L}(\mathrm{Et}) .\left[\mathrm{Gd}(\mathrm{L}(\mathrm{Et}))_{3}\right]^{3+}$ complexes could be used to observe the effects of complexation on the positions of the ligand bands, as the observed luminescence is ligand centered because the $\mathrm{Gd}^{3+}$ acceptor bands are not accessible for energy transfer from ligand excited states. Previous studies of the structurally similar ligand $\mathrm{L}(\mathrm{Me})$ found that the photophysical properties of the $R, R$ enantiomer and the $S, S$ enantiomer were

similar. ${ }^{23}$ Therefore, photophysical studies of only the $R, R$ enantiomer of $\mathrm{L}(\mathrm{Et})$ are described in the following photophysical studies.

The spectrum of $\mathrm{L}(\mathrm{Et})$ has broad absorbance maxima around 228, 275 and $285 \mathrm{~nm}$, which are likely associated with pyridinedicarboxamide $n \rightarrow \pi^{*}$ and $\pi \rightarrow \pi^{*}$ transitions. ${ }^{23,37}$ The maxima are somewhat redshifted for $\left[\mathrm{Gd}(\mathrm{L}(\mathrm{Et}))_{3}\right]^{3+}$, indicating that 
complexation has occurred, and the position of the transitions has shifted. This shift upon complexation is also observed in other $\left[\mathrm{Ln}(\mathrm{L}(\mathrm{Et}))_{3}\right]^{3+}$ complexes, e.g. $\left[\mathrm{Eu}(\mathrm{L}(\mathrm{Et}))_{3}\right]^{3+}$ and $\left[\mathrm{Tb}(\mathrm{L}(\mathrm{Et}))_{3}\right]^{3+}$. Electronic spectra of $\mathrm{L}(\mathrm{Et})$ and $\left[\mathrm{Ln}(\mathrm{L}(\mathrm{Et}))_{3}\right]^{3+}$ complexes in solution are shown in Figure 27.

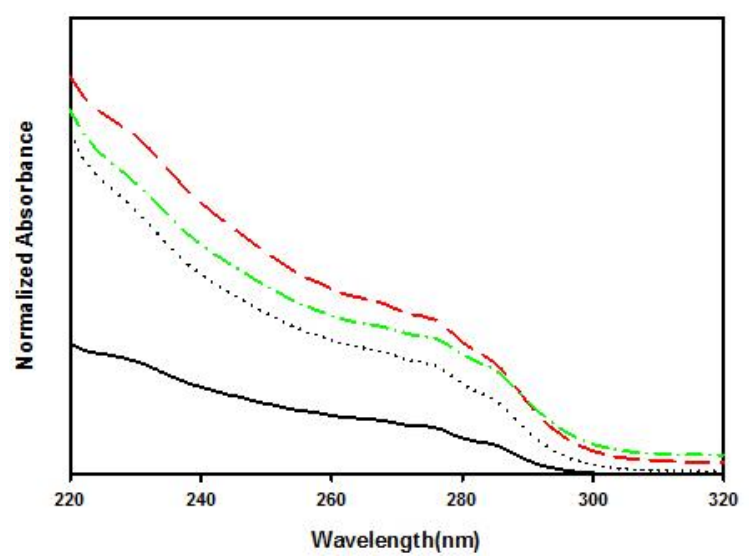

Figure 27. Normalized electronic spectra of $\mathrm{L}(\mathrm{Et})$ and $\left[\mathrm{Ln}(\mathrm{L}(\mathrm{Et}))_{3}\right]^{3+}$ complexes in anhydrous acetonitrile at room temperature. $\mathrm{L}(\mathrm{Et})$ - solid line, $\mathrm{Ln}^{3+}=\mathrm{Gd}^{3+}$ - dotted line, $\mathrm{Eu}^{3+}$ - dashed line, $\mathrm{Tb}^{3+}$ - dash-dot line

As $L(E t)$ is structurally very similar to $L(M e)$, only differing in an ethyl group versus a methyl group at the chiral centers, it is likely that these pyridinedicarboxamide centered transitions would be similarly positioned for both compounds, and in fact, the observed absorbance maxima for the $\pi \rightarrow \pi^{*}$ transition for $\mathrm{L}(\mathrm{Me}), 276$ and $284 \mathrm{~nm},{ }^{23}$ are only slightly redshifted compared with those of $\mathrm{L}(\mathrm{Et}), 275$ and $285 \mathrm{~nm}$. In contrast, the absorbance maxima for the $n \rightarrow \pi^{*}$ and $\pi \rightarrow \pi^{*}$ transitions of $\mathrm{L}(1 \mathrm{yl}), \mathrm{L}(2 \mathrm{yl}), \mathrm{L}(\mathrm{hh} 1)$ and $\mathrm{L}(\mathrm{hh} 2)$ have a larger shift compared to the bands of $\mathrm{L}(\mathrm{Et})$. This makes sense as $\mathrm{L}(1 \mathrm{yl})$, $\mathrm{L}(2 \mathrm{yl}), \mathrm{L}(\mathrm{hh} 1)$, and $\mathrm{L}(\mathrm{hh} 2)$ are more electronically different from $\mathrm{L}(\mathrm{Et})$ than $\mathrm{L}(\mathrm{Me})$, especially in the aromatic groups present. $\mathrm{L}(\mathrm{Et})$ and $\mathrm{L}(\mathrm{Me})$ have the central 2,6-pyridine dicarboxamide moiety as well as two phenyl groups, one attached at each chiral carbon 
center, and the maximum around $285 \mathrm{~nm}$ is associated with the phenyl groups. ${ }^{23} \mathrm{~L}(1 \mathrm{yl})$ and L(2yl) also have the central 2,6-pyridine dicarboxamide moiety, but they have two naphthyl groups instead of two phenyl groups, one attached at each chiral carbon center, and the maximum around $281 \mathrm{~nm}$ is likely associated with the naphthyl group. ${ }^{41} \mathrm{~L}(\mathrm{hh} 1)$ and $\mathrm{L}(\mathrm{hh} 2)$ have the central 2,6-pyridine dicarboxamide moiety and only one aromatic group (naphthyl) attached at its only chiral carbon center. ${ }^{38,39}$ The largest difference from $\mathrm{L}(\mathrm{Et})$ is seen in the electronic spectrum of $\mathrm{L}(4 \mathrm{p})$, where the pyridine transitions are observed at $267 \mathrm{~nm} .{ }^{33}$ This difference makes sense as L(4p) has a substituent directly attached to the pyridine at the 4-position, in contrast to L(Et) which is unsubstituted at this position. The absorbance maxima for related ligands is summarized in Table 1.

Table 1. Ligand Centered Absorbance Maxima

\begin{tabular}{c|ccc|ccc}
\hline Species & \multicolumn{3}{|c|}{$\mathrm{L}(\mathrm{nm})$} & \multicolumn{2}{c}{$\left[\mathrm{LnL}_{3}\right]^{3+}(\mathrm{nm})$} \\
$\mathrm{L}(\mathrm{Et})$ & 228 & 275 & 285 & 230 & 276 & 285 \\
$\mathrm{~L}(\mathrm{Me})^{23}$ & - & 276 & 284 & - & 277 & 286 \\
$\mathrm{~L}(4 \mathrm{p})^{33}$ & 243 & 267 & 242 & 279 \\
$\mathrm{~L}(11 \mathrm{y})^{40,4}$ & 223 & 280 & 220 & 280 \\
$\mathrm{~L}(2 \mathrm{ly})^{41}$ & 223 & 275 & 220 & 275 \\
$\mathrm{~L}(\mathrm{hh} 1)^{38}$ & - & - & 223 & 281 \\
$\mathrm{~L}(\mathrm{hh} 2)^{39}$ & - & - & 220 & 270 \\
\hline
\end{tabular}

Ligand centered emission of $\mathrm{L}(\mathrm{Et})$ and $\left[\mathrm{Gd}(\mathrm{L}(\mathrm{Et}))_{3}\right]^{3+}$ also showed the effects of complexation. The excitation maximum of $\mathrm{L}(\mathrm{Et})$ is around $280 \mathrm{~nm}$, whereas the excitation maximum of $\left[\mathrm{Ln}(\mathrm{L}(\mathrm{Et}))_{3}\right]^{3+}$ complexes is around $310 \mathrm{~nm}$. The change in the excitation maximum is explored in more detail in the discussion of speciation in section 3.4.2. Room temperature fluorescence emission from the ${ }^{1} \pi \pi^{*}$ excited singlet state is shown in Figure 28. 


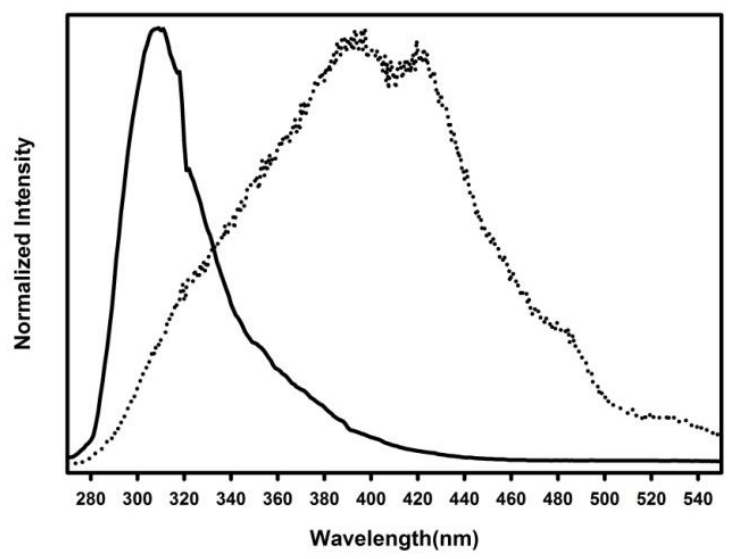

Figure 28. Normalized steady-state emission spectrum of $\mathrm{L}(\mathrm{Et})$ (solid line) and $\left[\mathrm{Gd}(\mathrm{L}(\mathrm{Et}))_{3}\right]^{3+}$ (dotted line) in anhydrous acetonitrile at room temperature

The fluorescence band of $\mathrm{L}(\mathrm{Et})$ consists of a broad band, centered around 315 - $330 \mathrm{~nm}$, while the fluorescence band of $\left[\mathrm{Gd}(\mathrm{L}(\mathrm{Et}))_{3}\right]^{3+}$ is redshifted, centered around $400 \mathrm{~nm}$. This change in the position of the singlet excited state of the ligand in the 1:3 Gd:L(Et) solutions is indicative of the formation of the complex. ${ }^{23}$

As the ligand does not exhibit observable phosphorescence at room temperature, in order to observe its triplet state emission, the sample must be cooled to $77 \mathrm{~K}$ to reduce nonradiative decay. The observed emission (Figure 29) corresponds to phosphorescence from the ${ }^{3} \pi \pi^{*}$ excited triplet state.

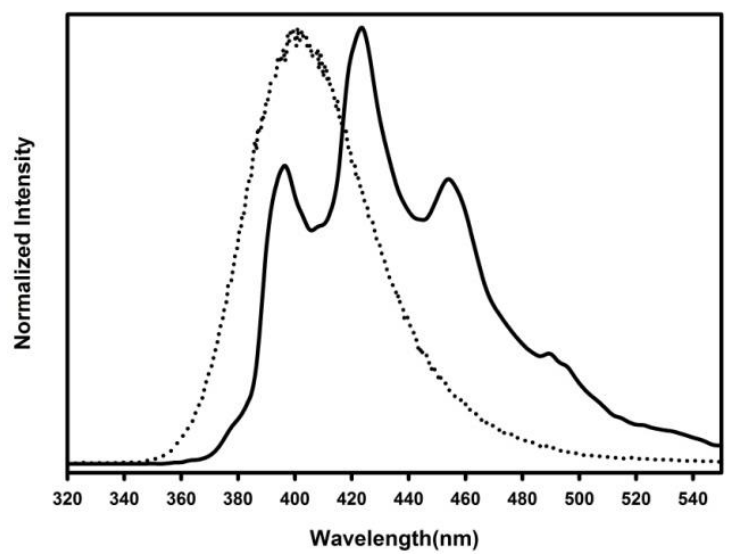

Figure 29. Normalized time-resolved emission spectrum of L(Et) (solid line) and $\left[\mathrm{Gd}(\mathrm{L}(\mathrm{Et}))_{3}\right]^{3+}$ (dotted line) in anhydrous acetonitrile at $77 \mathrm{~K}$ 
The phosphorescence band of $\mathrm{L}(\mathrm{Et})$ is centered around $415 \mathrm{~nm}$, while the phosphorescence band of $\left[\mathrm{Gd}(\mathrm{L}(\mathrm{Et}))_{3}\right]^{3+}$ is blueshifted, centered around $390 \mathrm{~nm}$.

As with the singlet state, the change in the position of the triplet excited state of the ligand in the 1:3 $\mathrm{Gd}(\mathrm{Et})$ solutions are indicative of the formation of the complex. ${ }^{23}$ The energy gap between the singlet and the triplet state $\Delta \mathrm{E}\left({ }^{1} \pi \pi^{*}-{ }^{3} \pi \pi^{*}\right)$ was $8,250 \mathrm{~cm}^{-1}$ for the ligand, and decreased significantly after complexation with gadolinium, to $6,402 \mathrm{~cm}^{-1}$. $\Delta \mathrm{E}\left({ }^{1} \pi \pi^{*}-{ }^{3} \pi \pi^{*}\right)$ of the gadolinium complex is closer to the ideal, which is in the range of $5,000 \mathrm{~cm}^{-1}$. However, $\Delta \mathrm{E}\left({ }^{1} \pi \pi^{*}-{ }^{3} \pi \pi^{*}\right)$ of the gadolinium complex with $\mathrm{L}(\mathrm{Et})$ is still further from the ideal than that of the $1: 3 \mathrm{Gd}(\mathrm{Me})$ complex. While $\Delta \mathrm{E}\left({ }^{1} \pi \pi^{*}-{ }^{3} \pi \pi^{*}\right)$ is $6,402 \mathrm{~cm}^{-1}$ for $\left[\mathrm{Gd}(\mathrm{L}(\mathrm{Et}))_{3}\right]^{3+}$, it is $5,070 \mathrm{~cm}^{-1}$ for $\left[\mathrm{Gd}(\mathrm{L}(\mathrm{Me}))_{3}\right]^{3+},{ }^{23}$ and $\Delta \mathrm{E}\left({ }^{1} \pi \pi^{*}-{ }^{3} \pi \pi^{*}\right)$ is 8,250 for $\mathrm{L}(\mathrm{Et})$, and $4,190 \mathrm{~cm}^{-1}$ for $\mathrm{L}(\mathrm{Me}){ }^{23}$

As $\Delta \mathrm{E}\left({ }^{1} \pi \pi^{*}-{ }^{3} \pi \pi^{*}\right)$ for the gadolinium complex is closer to $\Delta \mathrm{E} \approx 5,000 \mathrm{~cm}^{-1}$, considered the ideal for an efficient intersystem crossing, or ISC, energy transfer, ${ }^{47}$ it is predicted that the ISC is more efficient in the gadolinium complex. If true, this would be reflected in the magnitude of the triplet to singlet emission intensity, $\mathrm{I}^{T} / \mathrm{I}^{S}$. $\mathrm{I}^{T} / \mathrm{I}^{S}$ of $\mathrm{L}(\mathrm{Et})$ is $4.25 \times 10^{-3}$, while $\mathrm{I}^{\mathrm{T}} / \mathrm{I}^{\mathrm{S}}$ for $\left[\mathrm{Gd}(\mathrm{L}(\mathrm{Et}))_{3}\right]^{3+}$ is $4.04 \times 10^{-2} . \mathrm{I}^{\mathrm{T}} / \mathrm{I}^{\mathrm{S}}$ is 10 times greater for the gadolinium complex, suggesting an increase in the efficiency of the intersystem crossing (ISC) from the lowest excited singlet state to the lowest triplet state of the ligand when it is complexed to the lanthanide. As the $\Delta \mathrm{E}\left({ }^{1} \pi \pi^{*}-{ }^{3} \pi \pi^{*}\right)$ of the $\left[\mathrm{Gd}(\mathrm{L}(\mathrm{Me}))_{3}\right]^{3+}$ complex is closer to the ideal value of $5,000 \mathrm{~cm}^{-1}$ than the $\Delta \mathrm{E}\left({ }^{1} \pi \pi^{*}-{ }^{3} \pi \pi^{*}\right)$ of $\left[\mathrm{Gd}(\mathrm{L}(\mathrm{Et}))_{3}\right]^{3+}$, it also makes sense that $\mathrm{I}^{\mathrm{T}} / \mathrm{I}^{\mathrm{S}}$ would be higher for the $\left[\mathrm{Gd}(\mathrm{L}(\mathrm{Me}))_{3}\right]^{3+}$. These values are summarized in Table 2. 
Table 2. Ligand Centered Data ${ }^{1}$

\begin{tabular}{c|c|c|c|c}
\hline Species & $\begin{array}{c}\Delta \mathrm{E}\left({ }^{1} \pi \pi^{*}-{ }^{3} \pi \pi^{*}\right) \\
\left(\mathrm{cm}^{-1}\right)\end{array}$ & $\mathrm{I}^{T} / \mathrm{I}^{S}$ & $\begin{array}{c}\text { IST } \\
\left(\text { from } S^{*} \text { to } T^{*}\right)\end{array}$ & $\begin{array}{c}\Phi^{\mathrm{F}} \\
(\%)\end{array}$ \\
\hline $\mathrm{L}(\mathrm{Et})$ & 8250 & $4.3 \times 10^{-3}$ & 0.55 & 22 \\
$\mathrm{~L}(\mathrm{Me})^{23}$ & 4190 & $4.0 \times 10^{-3}$ & - & 21 \\
{$\left[\mathrm{Gd}(\mathrm{L}(\mathrm{Et}))_{3}\right]^{3+}$} & 6402 & $4.0 \times 10^{-2}$ & 3.2 & 2.8 \\
{$\left[\mathrm{Gd}(\mathrm{L}(\mathrm{Me}))_{3}\right]^{3+23}$} & 5070 & $4.7 \times 10^{-2}$ & - & 2.2 \\
{$\left[\mathrm{La}(\mathrm{L}(4 \mathrm{p}))_{3}\right]^{3+33}$} & 6800 & $8 \times 10^{-3}$ & - & 0.055 \\
{$\left[\mathrm{Lu}(\mathrm{L}(4 \mathrm{p}))_{3}\right]^{3+33}$} & 7545 & $4.7 \times 10^{-3}$ & - & 0.065 \\
\hline
\end{tabular}

This correlation between a more favorable $\Delta \mathrm{E}\left({ }^{1} \pi \pi^{*}-{ }^{3} \pi \pi^{*}\right)$ and a higher $\mathrm{I}^{\mathrm{T}} / \mathrm{I}^{\mathrm{S}}$ also holds true with $\mathrm{L}(4 \mathrm{p})$, where there is a change to the substituent attached to the pyridine. As the ligand itself is "essentially non-luminescent" ${ }^{33}$, Muller et al. could only measure these values for the complexes, and they studied complexes of $\mathrm{L}(4 \mathrm{p})$ with $\mathrm{La}^{3+}$ and $\mathrm{Lu}^{3+} \cdot{ }^{33} \Delta \mathrm{E}\left({ }^{1} \pi \pi^{*}-{ }^{3} \pi \pi^{*}\right)$ of the $\left[\mathrm{La}(\mathrm{L}(4 \mathrm{p}))_{3}\right]^{3+}$ complex was $6,800 \mathrm{~cm}^{-1}$, closer to 5,000 $\mathrm{cm}^{-1}$ than $\Delta \mathrm{E}\left({ }^{1} \pi \pi^{*}-{ }^{3} \pi \pi^{*}\right)$ of the $\left[\operatorname{Lu}(\mathrm{L}(4 \mathrm{p}))_{3}\right]^{3+}$ complex, which was $7,545 \mathrm{~cm}^{-1}$. This correlated to a higher $\mathrm{I}^{\mathrm{T}} / \mathrm{I}^{\mathrm{S}}$ for the $\left[\mathrm{La}(\mathrm{L}(4 \mathrm{p}))_{3}\right]^{3+}$ complex of $8 \times 10^{-3}$ compared with $4.7 \times 10^{-3}$ for the $\left[\mathrm{Lu}(\mathrm{L}(4 \mathrm{p}))_{3}\right]^{3+}$ complex. $^{33}$

The quantum yield, $\Phi$, which is a measure of a fluorophore's emission efficiency, ${ }^{21}$ of $\mathrm{L}(\mathrm{Et})$ was determined using a concentration and an excitation wavelength where Lambert-Beer is obeyed. ${ }^{21}$ In addition to these requirements, it was important to ensure that the quantum yield of $\left[\mathrm{Gd}(\mathrm{L}(\mathrm{Et}))_{3}\right]^{3+}$, and all following $\left[\mathrm{LnL}_{3}\right]^{3+}$ complexes, was determined in conditions that ensure the formation of the desired $\left[\mathrm{Gd}(\mathrm{L}(\mathrm{Et}))_{3}\right]^{3+}$ complex where the $\mathrm{Gd}^{3+}$ ion is coordinated to 3 ligand molecules. This is discussed in further

\footnotetext{
${ }^{1}$ The uncertainty of the $\mathrm{I}^{T} / \mathrm{I}^{S}$, IST, and $\Phi$ values is estimated to be $10 \%$.
} 
detail in the section on speciation, 3.3. $\Phi_{\mathrm{L}(\mathrm{Et})}$ was determined to be $22 \%$, which is very close to the quantum yield of $\mathrm{L}(\mathrm{Me}) 21 \% .^{23}$ The luminescence from the ligand is much weaker once it is complexed to gadolinium. The fluorescence quantum yield of $\mathrm{L}(\mathrm{Et})$ is approximately 10 times greater than the quantum yield of $\left[\mathrm{Gd}(\mathrm{L}(\mathrm{Et}))_{3}\right]^{3+}$, which was 2.8\%. This is consistent with the $\mathrm{L}(\mathrm{Me})$, which also shows a tenfold drop in the quantum yield of $\left[\mathrm{Gd}(\mathrm{L}(\mathrm{Me}))_{3}\right]^{3+}$, compared with the ligand alone. The luminescence from the $\mathrm{L}(4 \mathrm{p})$ ligand is also weak when it is complexed, as the fluorescence quantum yield of $\left[\mathrm{La}(\mathrm{L}(4 \mathrm{p}))_{3}\right]^{3+}$ is $0.055 \%$ and $\left[\mathrm{Lu}(\mathrm{L}(4 \mathrm{p}))_{3}\right]^{3+}$ is $0.065 \% .{ }^{33}$

\subsection{Speciation in Solution}

In the previous section, the effects of complexation on the position of the ligand bands was studied by comparison of photophysical properties of L(Et) and the $\left[\mathrm{Gd}(\mathrm{L}(\mathrm{Et}))_{3}\right]^{3+}$ complex. For the $\left[\mathrm{Gd}(\mathrm{L}(\mathrm{Et}))_{3}\right]^{3+}$ complex, and the other $\left[\mathrm{Ln}(\mathrm{L}(\mathrm{Et}))_{3}\right]^{3+}$ complexes studied, the speciation changes as the ratio of ligand to metal increases. The species formed will be the lanthanide ion coordinated to 1, 2, or 3 ligand molecules, forming 1:1, 1:2, and 1:3 complexes of $\mathrm{Ln}^{3+}: \mathrm{L}(\mathrm{Et})$, respectively. The formation of the $\left[\operatorname{Ln}(\mathrm{L}(\mathrm{Et}))_{n}\right]^{3+}$ complexes follow the equilibria described in equations (5), (6), and (7).

$$
\begin{aligned}
& L n^{3+}+L(E t) \rightleftharpoons[L n(L(E t))]^{3+} \quad \beta_{1} \\
& L n^{3+}+2 L(E t) \rightleftharpoons\left[L n(L(E t))_{2}\right]^{3+} \quad \beta_{2} \\
& L n^{3+}+3 L(E t) \rightleftharpoons\left[L n(L(E t))_{3}\right]^{3+} \quad \beta_{3}
\end{aligned}
$$

$\beta_{\mathrm{n}}$ are cumulative stability constants for the formation of the complex with $n$ ligands coordinated to the $\mathrm{Ln}^{3+}$ ion, as described in equations (8), (9), (10): 


$$
\begin{gathered}
\beta_{1}=\frac{\left[[\operatorname{Ln} L(E t)]^{3+}\right]}{\left[\operatorname{Ln}^{3+}\right][L(E t)]} \\
\beta_{2}=\frac{\left[\left[\operatorname{Ln}(L(E t))_{2}\right]^{3+}\right]}{\left[\operatorname{Ln}^{3+}\right][L(E t)]^{2}} \\
\beta_{3}=\frac{\left[\left[\operatorname{Ln}(L(E t))_{3}\right]^{3+}\right]}{\left[\operatorname{Ln}^{3+}\right][L(E t)]^{3}}
\end{gathered}
$$

These species were studied using solutions of varying ratios of $\mathrm{L}(\mathrm{Et})$ and $\left[\mathrm{Ln}\left(\mathrm{NO}_{3}\right)_{3}\right] \cdot n \mathrm{H}_{2} \mathrm{O}$ in anhydrous acetonitrile. Anhydrous solvents were used to reduce decomplexation due to water directly bound to the lanthanide metal center and quenching due to water indirectly connected or present in the outer sphere. Spectroscopic measurements (including lifetime measurements, direct excitation spectra) were taken to determine the species present at various ratios of europium to ligand in solution. The formation of the complex can be observed in a variety of ways: a shift in ligand centered excitation, an increase in metal centered emission due to the antenna effect, and/or a sharp increase in lifetime. Luminescence titrations of $\mathrm{Eu}\left(\mathrm{NO}_{3}\right)_{3}$ with $\mathrm{L}(\mathrm{Et})$ in anhydrous acetonitrile under argon were performed in order to determine stability constants.

Additionally, NMR titration of $\mathrm{La}\left(\mathrm{CF}_{3} \mathrm{SO}_{3}\right)_{3}$ with $\mathrm{L}(\mathrm{Et})$ confirmed that using an excess of ligand will drive the coordination of 3 ligands to the metal center, but no further - the four ligand complex is not formed. In the presence of an excess of ligand, peaks correlating with the free ligand were observed in addition to peaks correlating with the 1:3 species. As L(Et) is a bulky ligand, therefore it is unlikely that a four ligand complex, $\left[\operatorname{Ln}(\mathrm{L}(\mathrm{Et}))_{4}\right]^{3+}$, would be formed for steric reasons. Further discussion of the luminescence titrations is in section 3.3.1, and discussion of the NMR titrations is in 
section 3.3.2. For this reason, in order to form the desired complex in solution, all $\left[\mathrm{Ln}(\mathrm{L}(\mathrm{Et}))_{3}\right]^{3+}$ solutions used in luminescence measurements and CPL measurements were prepared with an excess of ligand, unless otherwise stated.

\subsubsection{Stability constants: titration of $\mathbf{L n}^{3+}$ with $\mathbf{L}(\mathbf{E t})$. The stability constants, $\beta_{n}$,} for the formation of the various species of $\left[\mathrm{Ln}(\mathrm{L}(\mathrm{Et}))_{n}\right]^{3+}$ were determined through luminescence titrations. The complex was indirectly excited and the metal centered emission was taken, allowing for observation of the changing metal environment as the species in solution changed. As the ligand does not phosphoresce at room temperature, the observed luminescence is solely a result of the metal emission. An example of the resulting time-resolved luminescence spectra for a titration of $\mathrm{Eu}^{3+}$ into $\mathrm{L}(\mathrm{Et})$ (Figure 30) illustrates the change in the bands as the titration progressed.

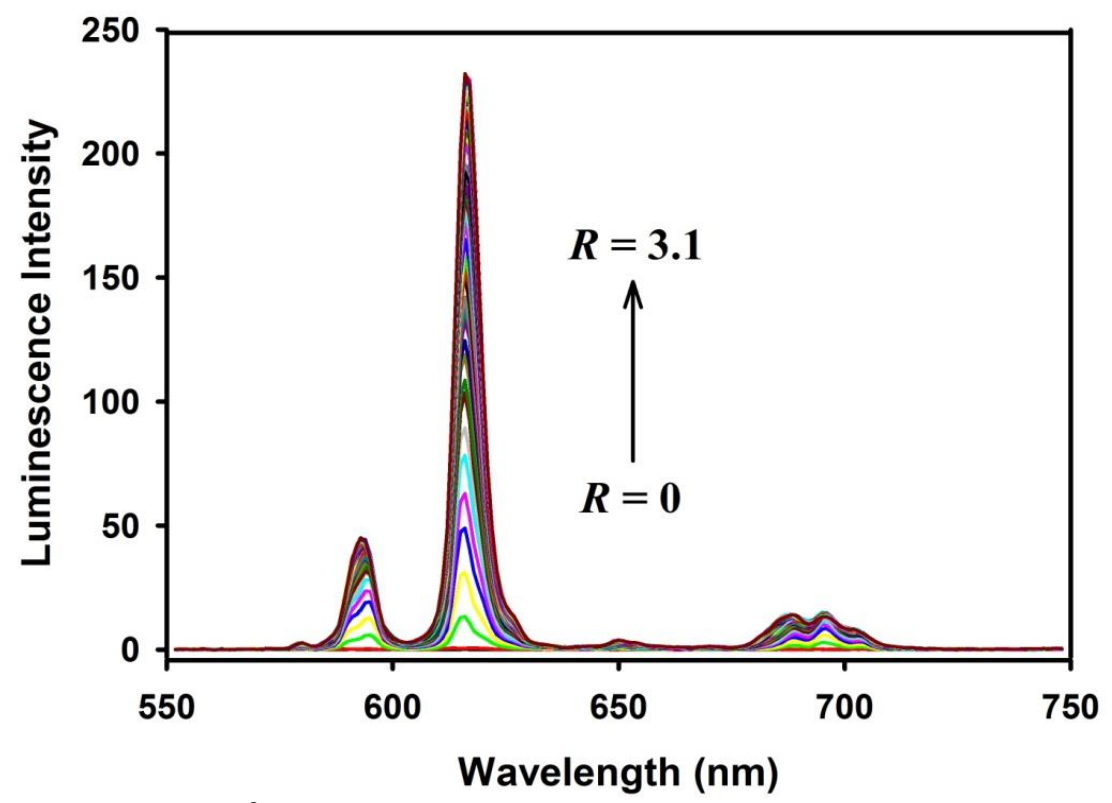

Figure 30. Titration of $\mathrm{Eu}^{3+}$ with $\mathrm{L}(\mathrm{Et})$ in anhydrous acetonitrile, time-resolved luminescence spectra. Increasing intensity as $R$ increases, indicated by arrow. Different shaded lines represent spectra taken during titration

Note that the ${ }^{5} \mathrm{D}_{0} \rightarrow{ }^{7} \mathrm{~F}_{2}$ transition ( $\left.610-625 \mathrm{~nm}\right)$ of $\mathrm{Eu}^{3+}$, which is sensitive to the metal 
environment, exhibits a change in intensity and shape as the ratio of $\mathrm{Eu}^{3+}$ to $\mathrm{L}(\mathrm{Et})$ changes during the titration. This change in intensity is illustrated in a plot of $R$, the ratio of $\mathrm{Eu}^{3+} / \mathrm{L}(\mathrm{Et})$, versus the luminescence intensity (Figure 31).

$$
\text { Eu:L(Et) Ratio vs. Intensity }
$$

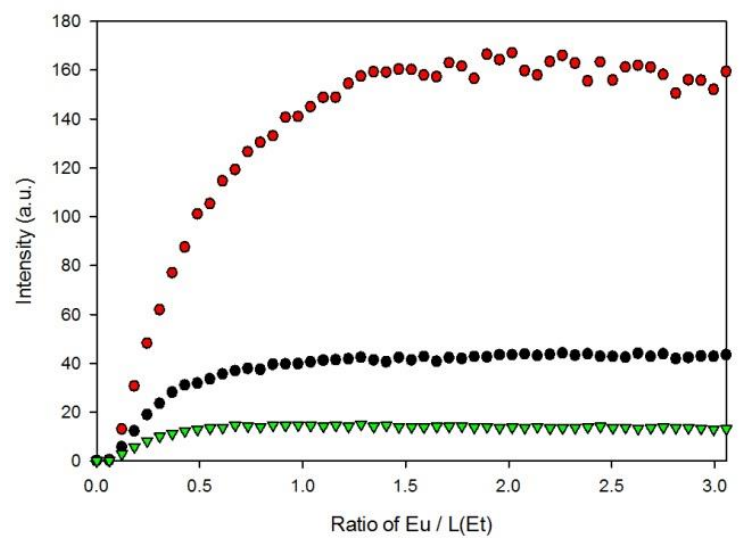

Figure 31. Intensity of luminescence versus $R$ (ratio of $\mathrm{Eu} / \mathrm{L}(\mathrm{Et})$ in solution in anhydrous acetonitrile) at selected wavelengths. Selected $\lambda_{\mathrm{em}}$ are $591 \mathrm{~nm}$ (middle line, black circles), $616 \mathrm{~nm}$ (upper line, red circles), and $695 \mathrm{~nm}$ (lowest line, green triangles), with $\lambda_{\mathrm{ex}}=296 \mathrm{~nm}$. Data taken from titration of $\mathrm{Eu}\left(\mathrm{NO}_{3}\right)_{3}$ into $\mathrm{L}(\mathrm{Et})$, as described in Figure 30 .

Analysis of $R$ versus intensity shows two breaks, the first at $R=0.37$, similar to the break found at $R=0.33$, for the $\mathrm{Eu}^{3+}$ to $\mathrm{L}(\mathrm{Me})$ titration, attributed to the $\left[\mathrm{Eu}(\mathrm{L}(\mathrm{Et}))_{3}\right]^{3+}$ complex. ${ }^{23}$ The positions of the second break are also similar, around $R=0.55$ for the $\mathrm{Eu}^{3+}$ to $\mathrm{L}(\mathrm{Et})$ titration, and at 0.5 for the $\mathrm{Eu}^{3+}$ to $\mathrm{L}(\mathrm{Me})$ titration, attributed to the $1: 2$ complex. $^{23}$

This titration data was fitted to the following equilibria ((11), (12), (13)), using Hyperquad2006 software with refinement and single species correction for $\mathrm{Eu}^{3+}$, and the stability constants were determined. Details of titration procedure, and further information about calculation of $\log \beta_{n}$ values can be found in Chapter 5 . The respective stability constants are $\log \beta_{1}, \log \beta_{2}$, and $\log \beta_{3}$. 


$$
\begin{aligned}
E u^{3+}+L(E t) & \rightleftharpoons[E u(L(E t))]^{3+} \quad \log \beta_{1} \\
E u^{3+}+2 L(E t) & \rightleftharpoons\left[E u(L(E t))_{2}\right]^{3+} \log \beta_{2} \\
E u^{3+}+3 L(E t) & \rightleftharpoons\left[E u(L(E t))_{3}\right]^{3+} \log \beta_{3}
\end{aligned}
$$

The $\log \beta$ values determined for $\mathrm{L}(\mathrm{Et})$ were $\log \beta_{1}=8.6, \log \beta_{2}=16.5$, and $\log \beta_{3}=$ 22.0. Note that these values are an average of two independent determinations. These values are consistent with the pattern observed in stability constants for formation of $\left[\mathrm{EuL}_{n}\right]^{3+}$ for other related ligands. Table 3 summarizes the stability constants for various $\left[\mathrm{EuL}_{n}\right]^{3+}$ species.

Table 3. Stability Constants of $\left[\mathrm{EuL}_{\mathrm{n}}\right]^{3+}$

\begin{tabular}{lccc}
\multicolumn{1}{c}{ Species } & $\log \beta_{1}$ & $\log \beta_{2}$ & $\log \beta_{3}$ \\
\hline $\mathrm{L}(\mathrm{Et})$ & $8.6(4)$ & $16.5(4)$ & $22.0(4)$ \\
$\mathrm{L}(\mathrm{Me})^{23}$ & $8.0(2)$ & $15.9(2)$ & $23.8(2)$ \\
$\mathrm{L}(4 \mathrm{p})^{33}$ & $8.2(4)$ & $14.6(5)$ & $19.7(5)$ \\
$\mathrm{L}(1 \mathrm{yl})^{40,41}$ & 6.8 & - & 20.0 \\
$\mathrm{~L}(2 \mathrm{yl})^{41}$ & 6.5 & 13.2 & 20.3 \\
$\mathrm{~L}(\mathrm{hh} 1)^{48}$ & 6.5 & - & 19.8 \\
\hline
\end{tabular}

The $\log \beta$ values are similar for the $\left[\mathrm{EuL}(\mathrm{Et})_{\mathrm{n}}\right]^{3+}$ and $\left[\mathrm{Eu}(\mathrm{L}(\mathrm{Me}))_{\mathrm{n}}\right]^{3+}$ complexes, with $\log$ $\beta_{3}$ lower for $\left[\mathrm{EuL}_{3}\right]^{3+}(22.0$ for $\mathrm{L}(\mathrm{Et})$ vs 23.8 for $\mathrm{L}(\mathrm{Me}))$. This makes sense given that $\mathrm{L}(\mathrm{Et})$ is slightly bulkier than $\mathrm{L}(\mathrm{Me})$, as $\mathrm{L}(\mathrm{Et})$ has ethyl groups attached at the chiral carbons as opposed to methyl groups for $\mathrm{L}(\mathrm{Me})$. Previous studies noted that steric hindrance had an effect on the formation of $\left[\mathrm{EuL}_{3}\right]^{3+}$ and other related complexes with $\mathrm{Eu}^{3+}$ and derivatives of 2,6-dicarboxamidopyridine. ${ }^{23} \mathrm{~L}(4 \mathrm{p})$ also has slightly lower $\log \beta$ values, with $\log \beta_{3}$ for $\left[\mathrm{EuL}_{3}\right]^{3+}$ being 22.0 for $\mathrm{L}(\mathrm{Et})$ vs $19.7 \mathrm{~b}$ for $\mathrm{L}(4 \mathrm{p})$. Even though $\mathrm{L}(4 \mathrm{p})$ is less bulky at the coordinating nitrogen groups of the 2,6-dicarboxamidopyridine 
moiety, a study of related ligands showed that the group attached at the 4-position of the pyridine ring has a steric and electronic destabilization effect. ${ }^{33} \mathrm{~L}(1 \mathrm{ly})$ and $\mathrm{L}(2 \mathrm{y})$ are much bulkier than $\mathrm{L}(\mathrm{Et})$ and $\mathrm{L}(\mathrm{Me})$ due to the larger naphthyl groups at the chiral centers, and they have lower $\log \beta$ values than both $\mathrm{L}(\mathrm{Et})$ and $\mathrm{L}(\mathrm{Me})$, further supporting this observation. The "half helicate" L(hh1) is very bulky at the chiral center, as it has a naphthyl group, but it is less bulky overall, because it only has one chiral center with the aromatic group. ${ }^{38,41}$ Interestingly, L(hh1) also has $\operatorname{lower} \log \beta$ values consistent with those of L(1ly) and L(2ly), ${ }^{38,40,41}$ suggesting that the bulkiness at the chiral center has a larger effect on the stability constant that the overall sterics of the compound.

\subsubsection{NMR titration of $\mathbf{L a}^{\mathbf{3 +}}$ with $\mathbf{L}(\mathbf{E t})$. In order to confirm the formation of the} 1:3 species in solution, an NMR titration of $\mathrm{La}^{3+}$ with $\mathrm{L}(\mathrm{Et})$ was performed in deuterated acetonitrile. Successive equivalents of the $S, S$ enantiomer of $\mathrm{L}(\mathrm{Et})$ were titrated with a solution of $\mathrm{La}\left(\mathrm{CF}_{3} \mathrm{SO}_{3}\right)_{3}$ to obtain ${ }^{1} \mathrm{H}$ NMR spectra of solutions where $R$, the ratio of the concentration of $\mathrm{La}^{3+}$ to the concentration of $\mathrm{L}(\mathrm{Et})$, varies from 1 to 1,1 to 2,1 to 3 , and 1 to 5 . As the titration proceeds, and the complex is formed, the position of the peaks associated with hydrogens close to the binding sites shift, and it is possible to see the appearance of the 1:1,1:2, and 1:3 complexes. The spectra obtained are shown in Figure 32, and the peaks corresponding to the different complexes are labeled in the figure. For reference, assignment of peaks in the ${ }^{1} \mathrm{H}$ NMR of $\mathrm{L}(\mathrm{Et})$ can be found in section 3.1.2, and the ${ }^{1} \mathrm{H}$ NMR spectrum is included in Appendix A. 

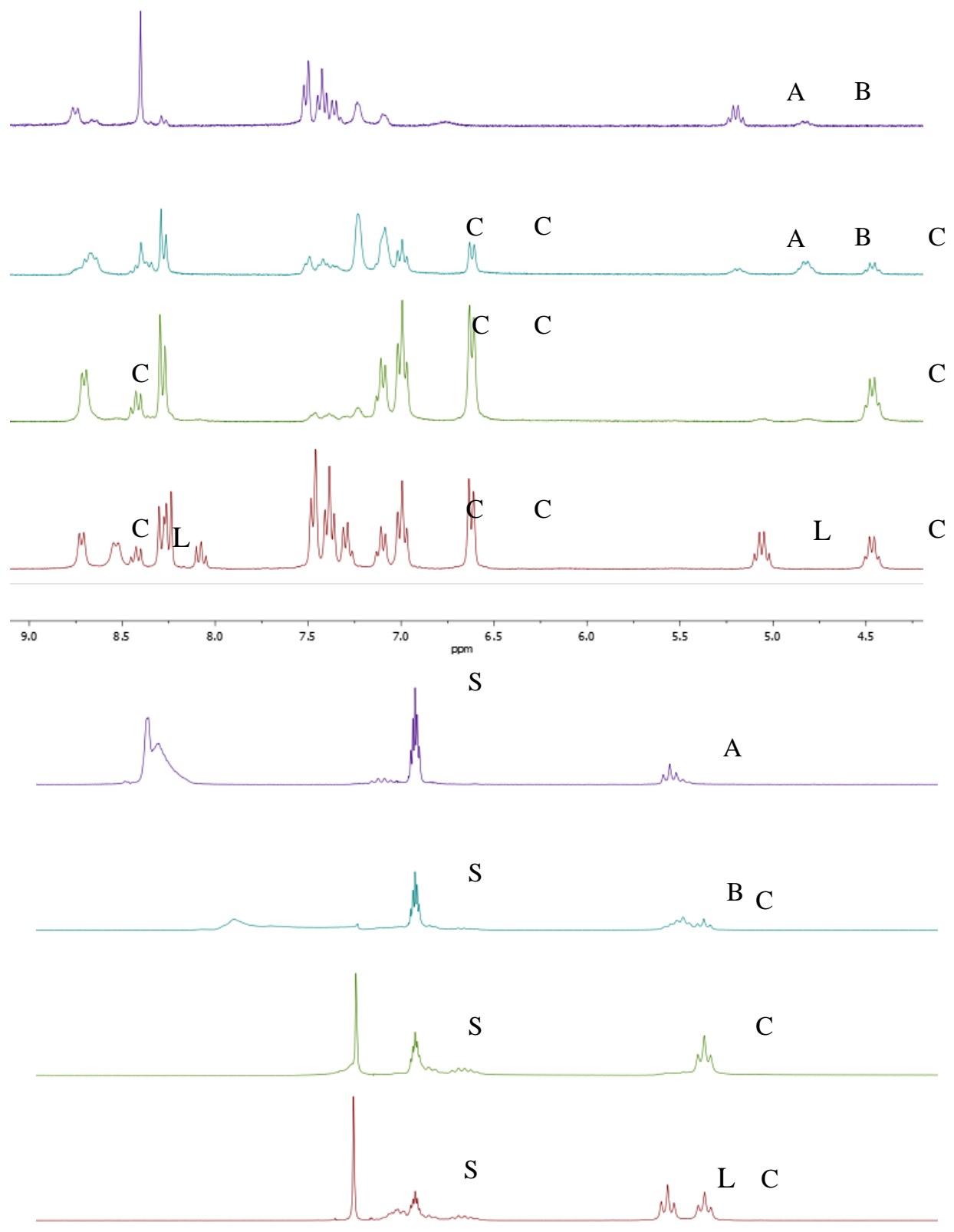

\begin{tabular}{lllllllllllllllllllllllllllllllllllllllll}
\hline 4 & 3.3 & 3.2 & 3.1 & 3.0 & 2.9 & 2.8 & 2.7 & 2.6 & 2.5 & 2.4 & 2.3 & 2.2 & 2.1 & 2.0 & 1.9 & 1.8 & 1.7 & 1.6 & 1.5 & 1.4 & 1.3 & 1.2 & 1.1 & 1.0 & 0.9 & 0.8 & 0.7 & 0.6 & 0.5 & 0.4 & 0.3 & 0.2 & 0.1 & 0.6
\end{tabular}

Figure 32. ${ }^{1} \mathrm{H}$ NMR titration of $\mathrm{La}^{3+}$ with $S, S$ enantiomer of $\mathrm{L}(\mathrm{Et})$ in $\mathrm{CD}_{3} \mathrm{CN}$

From top to bottom, $R=1, R=0.5, R=0.33, R=0.2$, where $R=\left[\mathrm{La}^{3+}\right] /[\mathrm{L}(\mathrm{Et})]$. Signals correlate to $\mathrm{L}=$ free ligand, $\mathrm{C}=1: 3$ species, $\mathrm{B}=1: 2$ species, $\mathrm{A}=1: 1$ species, $\mathrm{S}=$ solvent

One set of peaks corresponding to the $1: 3$ species can be seen in the spectrum for the solution with ratio $R=0.33$. The presence of one set of peaks for the $1: 3$ species is an indication that the three ligands bound to the metal center are equivalent and coordinated 
to the metal in the same way. If they were not equivalent, the individual ligands would have different shifts and multiple sets of peaks would be present. In conjunction with the lifetime values, longer than $1 \mathrm{~ms}$, which show that there are no solvent molecules coordinated to the metal center, this confirms the formation of the $\mathrm{D}_{3}$ complex. The direct excitation $g_{\text {lum }}$ results (discussed in section 3.5), which show that the $g_{\text {lum }}$ values are independent of the polarization of the excitation beam indicate the presence of a single diastereomer of the $\mathrm{D}_{3}$ complex when a single enantiomer of the ligand is used.

Two of the binding sites on the ligand are the amide oxygen atoms, and as the oxygen binds to the positively charged $\mathrm{La}^{3+}$ center, electron density is withdrawn from the amide nitrogen, leading to deshielding of the attached hydrogen. A doublet corresponding to the $1: 3$ species can be seen at $8.72 \mathrm{ppm}$ in the spectrum for the solution with ratio $R=0.33$. To probe into whether a 1:4 species forms, excess ligand is added, to a ratio $R=0.2$, where there is five times as much ligand as metal in solution. The amide peak does not shift, rather, the peak corresponding to the $1: 3$ species is present at $8.72 \mathrm{ppm}$ and a peak corresponding to the free ligand appears at $8.55 \mathrm{ppm}$. This indicates that additional ligands do not bind directly to the metal and instead have more of an outer sphere effect, consistent with the behavior of $\mathrm{L}(\mathrm{Me}){ }^{23}$

The peak corresponding to the hydrogen directly attached to the chiral center also shifts upon complexation, as the chiral center is also close to the binding sites. In the solution with ratio $R=1$, a peak corresponding to the $1: 1$ species is present at $5.21 \mathrm{ppm}$ and a peak corresponding to the $1: 2$ species is present at $4.84 \mathrm{ppm}$. In the solution with ratio $R=0.5$, the peaks corresponding to the $1: 1$ species and the $1: 2$ species are both 
present, along with a peak corresponding to the $1: 3$ species at $4.46 \mathrm{ppm}$. In the solution with ratio $R=0.33$, the $1: 3$ species peak is present, and in the solution with ratio $R=$ 0.2 , the $1: 3$ species peak is present, and a peak corresponding to the free ligand appears at $5.07 \mathrm{ppm}$.

3.3.3 ${ }^{\mathbf{5}} \mathbf{D}_{\mathbf{0}} \leftarrow{ }^{\mathbf{7}} \mathbf{F}_{\mathbf{0}}$ excitation of $\left[\mathbf{E u}(\mathbf{L}(\mathbf{E t}))_{n}\right]^{3+}$. Most of the photophysical studies are done with the usual method of indirectly exciting via the antenna effect, but it is also possible to study $\left[\mathrm{Eu}(\mathrm{L}(\mathrm{Et}))_{\mathrm{n}}\right]^{3+}$ speciation by directly exciting the europium center, which is very sensitive to its environment. The observation of the formation of different species in solution is possible with a specific emission and excitation transition of $\mathrm{Eu}^{3+} .{ }^{12}$, ${ }^{49}$ As mentioned previously in section 1.4.1, the Laporte forbidden $f$ - $f$ transitions are weak, so a laser was used as the direct excitation source. Emission was monitored at 615 $\mathrm{nm}$, which corresponds to the characteristic $\mathrm{Eu}^{3+}$ luminescent emission in the range of 610-625 nm of the ${ }^{5} \mathrm{D}_{0} \rightarrow{ }^{7} \mathrm{~F}_{2}$ transition. The ${ }^{5} \mathrm{D}_{0} \rightarrow{ }^{7} \mathrm{~F}_{2}$ transition is especially sensitive to the environment, as it is one of the "hypersensitive transitions" which follows the selection rule $\Delta \mathrm{J} \leq 2$, and this transition can be an indicator that the metal environment is chiral as it is "hypersensitive; absent if the ion lies on an inversion centre". ${ }^{49}$ The excitation range used is $578-582 \mathrm{~nm}$, which corresponds to the $\mathrm{Eu}^{3+}{ }^{5} \mathrm{D}_{0} \leftarrow{ }^{7} \mathrm{~F}_{0}$ transition. This is a very useful transition, because both the initial ${ }^{7} \mathrm{~F}_{0}$ state and the final excited ${ }^{5} \mathrm{D}_{0}$ state are nondegenerate, ${ }^{49}$ which means that for a "given chemical environment" ${ }^{49}$ the transition itself is nondegenerate and there is a single corresponding excitation peak. $\mathrm{Eu}^{3+}$ is the only $\mathrm{Ln}^{3+}$ ion with this unique transition. This allows for the observation of $\left[\mathrm{Eu}(\mathrm{L}(\mathrm{Et}))_{n}\right]^{3+}$ speciation, because each observed peak or shoulder must correspond to a 
different species.

As the ratio of $\mathrm{Eu}^{3+}$ to ligand changes, so do the species in solution, 1:1, 1:2, and 1:3 $\mathrm{Eu}^{3+}: \mathrm{L}(\mathrm{Et})$, forming as described in the equilibria (5), (6), (7). This is reflected in the observed peaks. In instances where there were overlapping peaks, for example in the 1:2 species solution, deconvolution was performed using Peakfit software. At the lowest ratio, 1:0.5 Eu:L(Et), the major peak has a maximum at $579.7 \mathrm{~nm}$, corresponding to the formation of the first species $[\mathrm{EuL}(\mathrm{Et})]^{3+}$. As the ratio increases to $1: 1$, then $1: 2$, the maximum shifts to 580.0, corresponding to the formation of the second species $\left[\mathrm{Eu}(\mathrm{L}(\mathrm{Et}))_{2}\right]^{3+}$. As the ratio increases further, to $1: 3,1: 5$, and $1: 10$, the 580.6 peak corresponding to the formation of the third species, $\left[\mathrm{Eu}(\mathrm{L}(\mathrm{Et}))_{3}\right]^{3+}$, is observed. Figure 33 illustrates the shift in maxima as the species in solution changes.

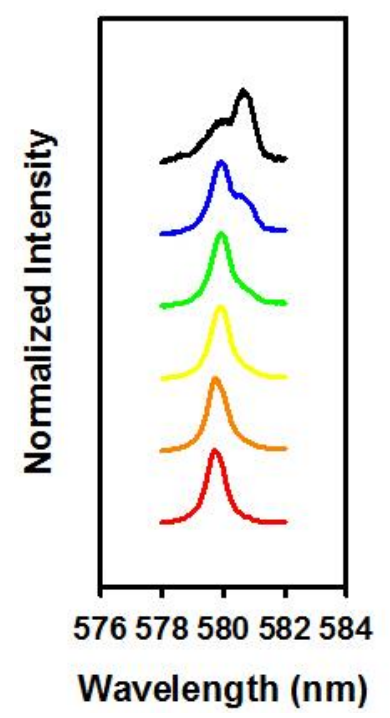

Figure $33 .{ }^{5} \mathrm{D}_{0} \leftarrow{ }^{7} \mathrm{~F}_{0}$ excitation spectra of various ratios $\mathrm{Eu}^{3+}:(\mathrm{L}(\mathrm{Et}))$ in anhydrous acetonitrile, from top to bottom: 1:10, 1:5, 1:3, 1:2, 1:1, 1:0.5

The $\left[\mathrm{Eu}(\mathrm{L}(\mathrm{Et}))_{3}\right]^{3+}$ species is the desired species with $\mathrm{D}_{3}$ symmetry, and it can be observed to form in solution with excess ligand. For this reason, studies of the 
photophysical and chiroptical properties of $\left[\operatorname{Ln}(\mathrm{L}(\mathrm{Et}))_{3}\right]^{3+}$ were performed using solutions with an excess of ligand to ensure that the desired complex is formed in solution.

It is also possible to observe the change in speciation due to change in concentration. As concentration increases, an increase in the presence of $\left[\mathrm{Eu}(\mathrm{L}(\mathrm{Et}))_{3}\right]^{3+}$ is observed, which follows Le Châtelier's principle, which states that increasing the concentration of reactants shifts the equilibrium towards formation of product. ${ }^{50}$ In the spectrum for the $2.00 \mathrm{mM}$ solution, the predominant peak is the $579.9 \mathrm{~nm}$ peak, corresponding to the $1: 2$ species, and a shoulder at $580.6 \mathrm{~nm}$ corresponding to the $1: 3$ species is present. In the spectrum for the $3.33 \mathrm{mM}$ solution, the $580.6 \mathrm{~nm}$ shoulder is more developed, and in the spectrum for the $6.67 \mathrm{mM}$ solution, there are two distinct peaks, the one at $579.9 \mathrm{~nm}$ corresponding to the $1: 2$ species and the one at $580.6 \mathrm{~nm}$ corresponding to the $1: 3$ species. The excitation spectra of these solutions of varying concentration are shown in Figure 34 .

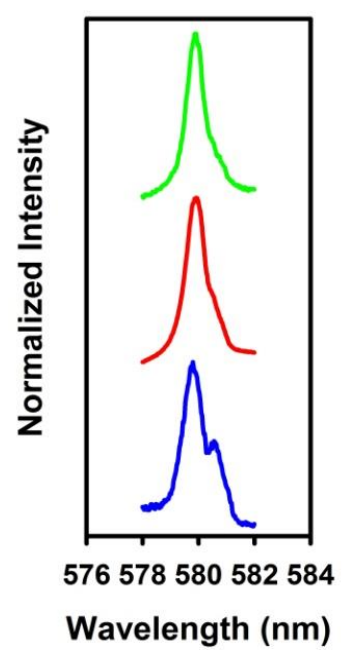

Figure 34. ${ }^{5} \mathrm{D}_{0} \leftarrow{ }^{7} \mathrm{~F}_{0}$ excitation spectra of various concentrations of $1: 5 \mathrm{mM}$ Eu:L(Et) in

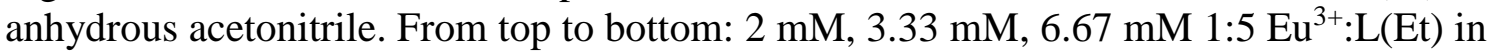
anhydrous acetonitrile. 
The general trend of the peak corresponding to the $1: 3 \mathrm{Eu}^{3+}: \mathrm{L}(\mathrm{Et})$ species having a longer wavelength compared with that of the $1: 1 \mathrm{Eu}^{3+}: \mathrm{L}(\mathrm{Et})$ species holds across different complexes as well, as summarized in Table 4.

Table 4. $\left[\mathrm{Eu}(\mathrm{L}(\mathrm{Et}))_{n}\right]^{3+5} \mathrm{D}_{0} \leftarrow{ }^{7} \mathrm{~F}_{0}$ Excitation Maxima ${ }^{2}$

\begin{tabular}{lccc}
\multicolumn{1}{c}{ Species } & $\begin{array}{c}1: 1 \text { complex } \\
(\mathrm{nm})\end{array}$ & $\begin{array}{c}1: 2 \text { complex } \\
(\mathrm{nm})\end{array}$ & $\begin{array}{c}1: 3 \text { complex } \\
(\mathrm{nm})\end{array}$ \\
\hline $\mathrm{L}(\mathrm{Et})$ & 579.7 & 580.0 & 580.6 \\
$\mathrm{~L}(\mathrm{Me})^{23}$ & 579.2 & 579.8 & 580.4 \\
\hline
\end{tabular}

However, the effect of a small structural difference on photophysical properties can be observed by comparing the structurally similar $\mathrm{L}(\mathrm{Et})$ and $\mathrm{L}(\mathrm{Me})$ systems. The positions of the observed excitation peaks for the $\left[\mathrm{Eu}(\mathrm{L}(\mathrm{Et}))_{n}\right]^{3+}$ species is shifted compared with the positions of the $\left[\mathrm{Eu}(\mathrm{L}(\mathrm{Me}))_{3}\right]^{3+}$ species, ${ }^{12}$ due to the change in ligand from $\mathrm{L}(\mathrm{Et})$ to $\mathrm{L}(\mathrm{Me})$.

\section{4 $\mathrm{Ln}^{3+}$ Centered Luminescence}

In contrast to $\mathrm{Gd}^{3+}$, the $\mathrm{Eu}^{3+}$ and $\mathrm{Tb}^{3+}$ metal acceptor bands are accessible for energy transfer from ligand excited states, so it is possible to observe metal centered emission through indirect excitation. The ligand transfers energy to the lanthanide through the antenna effect, and allows for observation of the metal environment through metal centered emission.

\subsubsection{Confirmation of $\left[\mathbf{L n}(\mathbf{L}(\mathbf{E t}))_{3}\right]^{3+}$ species in solution. Further confirmation} that an excess of ligand leads to the formation of the desired $\left[\mathrm{Eu}(\mathrm{L}(\mathrm{Et}))_{3}\right]^{3+}$ species was obtained by obtaining steady-state and time-resolved luminescence excitation spectra for

\footnotetext{
${ }^{2}$ The resolution is $0.1 \mathrm{~nm}$.
} 
solutions of $\mathrm{Eu}: \mathrm{L}(\mathrm{Et})$ with ratios ranging from 1:0.5 to 1:10. Emission was monitored at $615 \mathrm{~nm}$, corresponding to the characteristic $\mathrm{Eu}^{3+}{ }^{5} \mathrm{D}_{0} \rightarrow{ }^{7} \mathrm{~F}_{2}$ transition.

As the ratio of ligand to metal increases, the ligand centered excitation is redshifted, moving from $308 \mathrm{~nm}$ for the 1:0.5 ratio, to $318 \mathrm{~nm}$ for the $1: 10$ ratio. This shift is a sign that the predominant species in solution is changing as the ratio changes, which is consistent with the ligand centered measurements of $L(E t)$ and $\left[\mathrm{Gd}(\mathrm{L}(\mathrm{Et}))_{3}\right]^{3+}$, previously discussed in section 3.2, where the excitation maximum of the complex was redshifted compared with the ligand alone, as well as with the results obtained through ${ }^{5} \mathrm{D}_{0} \leftarrow{ }^{7} \mathrm{~F}_{0}$ excitation of $\left[\mathrm{Eu}(\mathrm{L}(\mathrm{Et}))_{n}\right]^{3+}$, previously discussed in section 3.3.3. Figure 35 (left) depicts this shift in steady-state luminescence excitation spectra, and Figure 35 (right) depicts this shift in the time-resolved luminescence excitation spectra.
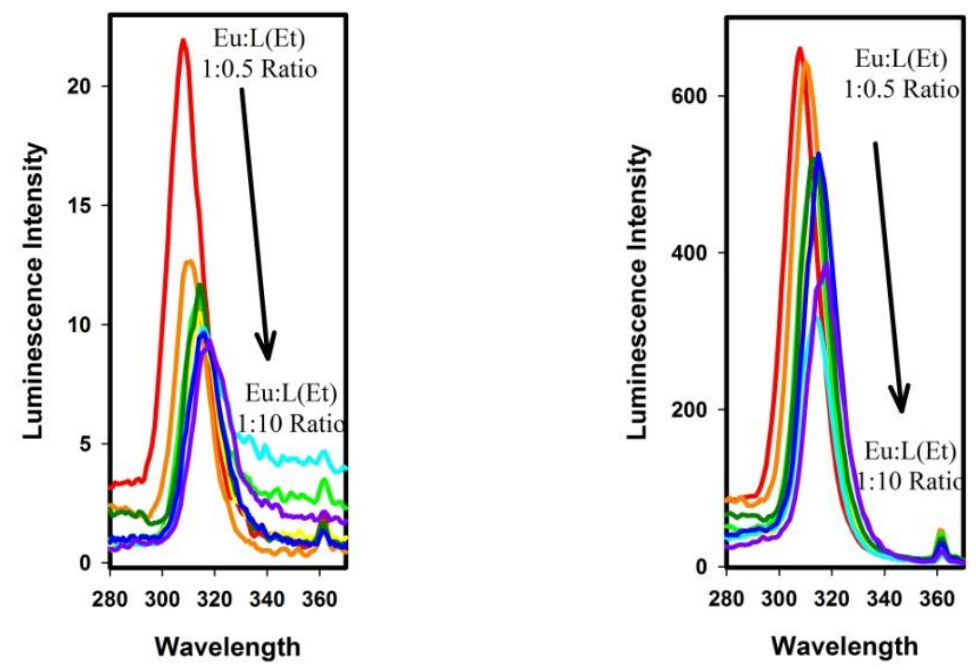

Figure 35. Steady-state (left) and time-resolved (right) luminescence excitation spectra of $\mathrm{Eu}: \mathrm{L}(\mathrm{Et})$ in anhydrous acetonitrile, 1:0.5 to 1:10 Ratios. Different shaded lines indicate changing ratio, decreasing intensity as ratio changes from 1:05 to 1:10, indicated by arrow.

In addition, lifetimes data taken of solutions of $\mathrm{Eu}^{3+}$ and $\mathrm{L}(\mathrm{Et})$ with varying molar 
ratios and concentration fit with earlier results determining that the desired $\left[\mathrm{Eu}(\mathrm{L}(\mathrm{Et}))_{3}\right]^{3+}$ species is formed in solution with excess ligand. As the ratio of ligand to metal increased, the overall trend was an increase in lifetime. As the concentration increased, the lifetime increases, and there is a sharp increase in the lifetime as the ratio of ligand to metal is increased. These trends of increasing lifetime are likely due to the formation of longer lifetime complexes of Eu:(L(Et)) as well as the displacement of solvent molecules by ligand, as this reduces quenching as discussed in section 1.4.1. The lifetimes results are summarized in Table 5.

Table 5. Lifetimes of various ratios and concentrations of $\mathrm{Eu}^{3+}: \mathrm{L}(\mathrm{Et})$ in anhydrous acetonitrile $^{3}$

\begin{tabular}{ccc}
\hline \multicolumn{3}{c}{ Lifetime $(\mathrm{ms})$} \\
\hline Ratio & \multicolumn{2}{c}{ Concentration $(\mathrm{M})$} \\
$\mathrm{Eu}^{3+}: \mathrm{L}(\mathrm{Et})$ & $2.00 \times 10^{-3}$ & $6.67 \times 10^{-3}$ \\
\hline $1: 0.5$ & 1.24 & 1.13 \\
$1: 1$ & 1.60 & 1.66 \\
$1: 2$ & 1.63 & 1.74 \\
$1: 3$ & 1.70 & 1.65 \\
$1: 5$ & 1.62 & 1.76 \\
\hline
\end{tabular}

Direct excitation spectra, indirect excitation spectra and lifetimes measurements taken of solutions of varying ratios and concentrations of $\mathrm{Eu}^{3+}: \mathrm{L}(\mathrm{Et})$ confirmed that the desired $\left[\mathrm{Eu}(\mathrm{L}(\mathrm{Et}))_{3}\right]^{3+}$ species is formed when there is an excess of ligand (1:5 or 1:10 ratio $\left.\mathrm{Eu}^{3+}: \mathrm{L}(\mathrm{Et})\right)$ and a higher concentration $(6.67 \mathrm{mM})$. Therefore, solutions with $6.67 \mathrm{mM}$ concentration and 1:5 or 1:10 $\mathrm{Ln}^{3+}: \mathrm{L}(\mathrm{Et})$ ratio were used to obtain the results for all of the $\left[\mathrm{Ln}(\mathrm{L}(\mathrm{Et}))_{3}\right]^{3+}$ species studied.

\subsection{2 $\left[\mathbf{L n}(\mathbf{L}(\mathbf{E t}))_{3}\right]^{3+}$ luminescence, indirect excitation. The presence of the}

\footnotetext{
${ }^{3}$ Uncertainty of $0.01 \mathrm{~ms}$
} 
characteristic emission bands ${ }^{22}$ in the luminescence spectra of $\left[\mathrm{Eu}(\mathrm{L}(\mathrm{Et}))_{3}\right]^{3+}$ and $\left[\mathrm{Tb}(\mathrm{L}(\mathrm{Et}))_{3}\right]^{3+}$ indicate that the complex has formed and energy is being transferred from the ligand to the metal via the antenna affect. ${ }^{13}$ The peaks corresponding to the longer lifetime Eu transitions (the ${ }^{5} \mathrm{D}_{0} \rightarrow{ }^{7} \mathrm{~F}_{J}$ transitions, for example, $J=1 \sim 590 \mathrm{~nm}, J=2 \sim 615$ $\mathrm{nm}, J=3 \sim 585 \mathrm{~nm}, J=4 \sim 700 \mathrm{~nm}$ ) can be observed in the time-resolved luminescence emission spectra taken at room temperature and $77 \mathrm{~K}$ (Figure 36 and Figure 37), with the $\sim 580 \mathrm{~nm}$ peak, corresponding to the sometimes weak nondegenerate ${ }^{5} \mathrm{D}_{0} \rightarrow{ }^{7} \mathrm{~F}_{0}$ transition, observable in the spectrum taken at $77 \mathrm{~K}$ (Figure 37).

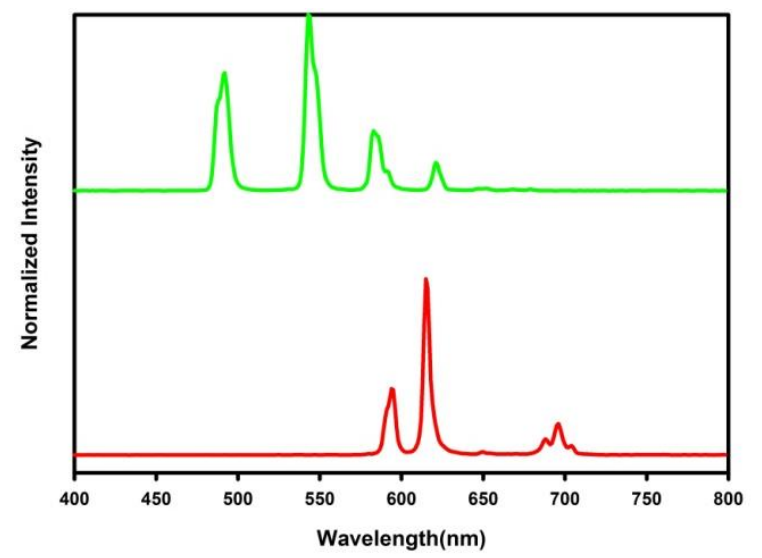

Figure 36. Time-resolved luminescence in anhydrous acetonitrile at room temperature, normalized spectra of $\left[\mathrm{Ln}(\mathrm{L}(\mathrm{Et}))_{3}\right]^{3+}$ complexes. From top to bottom, $\mathrm{Ln}^{3+}=\mathrm{Tb}^{3+}, \mathrm{Eu}^{3+}$

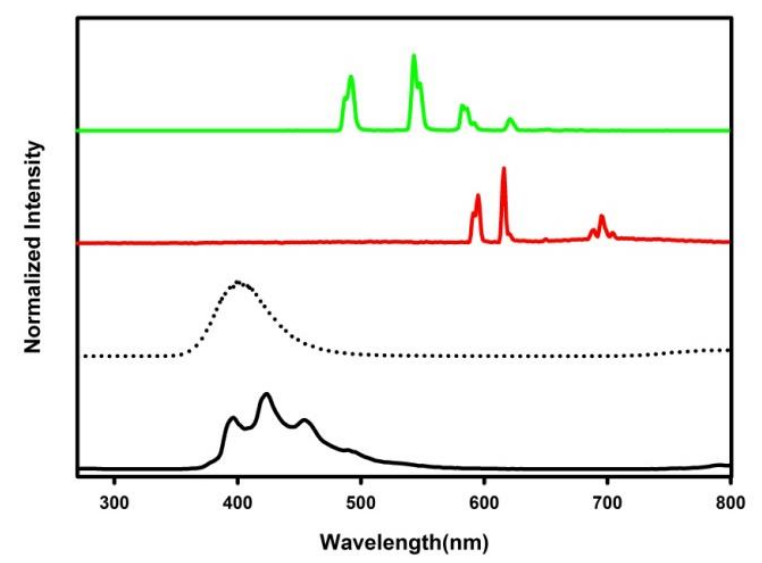

Figure 37. Time-resolved luminescence in anhydrous acetonitrile at $77 \mathrm{~K}$, normalized spectra of $\mathrm{L}(\mathrm{Et})$ and $\left[\mathrm{Ln}(\mathrm{L}(\mathrm{Et}))_{3}\right]^{3+}$ complexes. From top to bottom, $\left[\mathrm{Tb}(\mathrm{L}(\mathrm{Et}))_{3}\right]^{3+}$, $\left[\mathrm{Eu}(\mathrm{L}(\mathrm{Et}))_{3}\right]^{3+},\left[\mathrm{Gd}(\mathrm{L}(\mathrm{Et}))_{3}\right]^{3+}, \mathrm{L}(\mathrm{Et})$ 
The strongest peak at $615 \mathrm{~nm}$ corresponds to the ${ }^{5} \mathrm{D}_{0} \rightarrow{ }^{7} \mathrm{~F}_{2}$ transition. Other transitions are also visible, and the stronger peaks originate from ${ }^{5} \mathrm{D}_{0}$, notably the band around 590 $\mathrm{nm}$ corresponding to the ${ }^{5} \mathrm{D}_{0} \rightarrow{ }^{7} \mathrm{~F}_{1}$ transition, the small peak/shoulder around $580 \mathrm{~nm}$, corresponding to the ${ }^{5} \mathrm{D}_{0} \rightarrow{ }^{7} \mathrm{~F}_{0}$ transition, and peak and around $700 \mathrm{~nm}$ corresponding to the ${ }^{5} \mathrm{D}_{0} \rightarrow{ }^{7} \mathrm{~F}_{4}$ transition. Sometimes visible are the weaker peaks around $530 \mathrm{~nm}$ and 550 nm, corresponding to the ${ }^{5} \mathrm{D}_{1} \rightarrow{ }^{7} \mathrm{~F}_{0}$ and ${ }^{5} \mathrm{D}_{1} \rightarrow{ }^{7} \mathrm{~F}_{1}$ transitions.

In addition to the characteristic metal emission bands, the ligand emission bands may also be observed, which is an indication of incomplete transfer of energy in either ISC or ligand metal energy transfer. In the steady-state luminescence spectra at room temperature (Figure 38), the ligand band is present as a broad band around 330 - 360 $\mathrm{nm}$, and indicates singlet ${ }^{1} \pi \pi^{*}$ emission from the ligand.

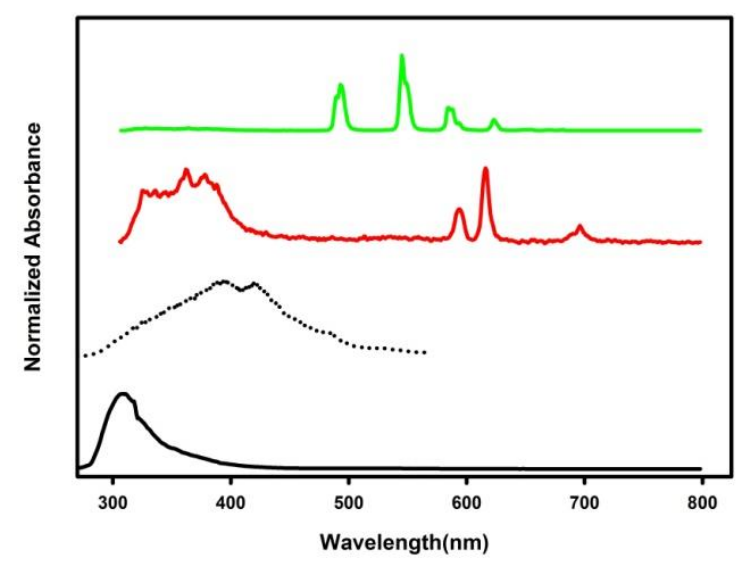

Figure 38. Steady-state luminescence in anhydrous acetonitrile at room temperature, normalized spectra of $\mathrm{L}(\mathrm{Et})$ and $\left[\mathrm{Ln}(\mathrm{L}(\mathrm{Et}))_{3}\right]^{3+}$ complexes. From top to bottom, $\left[\mathrm{Tb}(\mathrm{L}(\mathrm{Et}))_{3}\right]^{3+},\left[\mathrm{Eu}(\mathrm{L}(\mathrm{Et}))_{3}\right]^{3+},\left[\mathrm{Gd}(\mathrm{L}(\mathrm{Et}))_{3}\right]^{3+}, \mathrm{L}(\mathrm{Et})$

The presence of singlet ${ }^{1} \pi \pi^{*}$ emission indicates incomplete ISC transfer from the singlet ${ }^{1} \pi \pi^{*}$ to triplet ${ }^{3} \pi \pi^{*}$ state. The ${ }^{1} \pi \pi^{*}$ emission observed in the $\left[\mathrm{Eu}(\mathrm{L}(\mathrm{Et}))_{3}\right]^{3+}$ and $\left[\mathrm{Tb}(\mathrm{L}(\mathrm{Et}))_{3}\right]^{3+}$ complexes is redshifted compared to the ligand only emission, in line with 
the results obtained for $\left[\mathrm{Gd}(\mathrm{L}(\mathrm{Et}))_{3}\right]^{3+}$.

In steady-state luminescence emission spectra obtained at $77 \mathrm{~K}$ (Figure 39), both the singlet ${ }^{1} \pi \pi^{*}$ band and the triplet ${ }^{3} \pi \pi^{*}$ band may be observed, while only the triplet ${ }^{3} \pi \pi^{*}$ band is observed in time-resolved luminescence emission spectra at $77 \mathrm{~K}$ (Figure 37), due to the shorter lifetime of singlet ${ }^{1} \pi \pi^{*}$ emission.

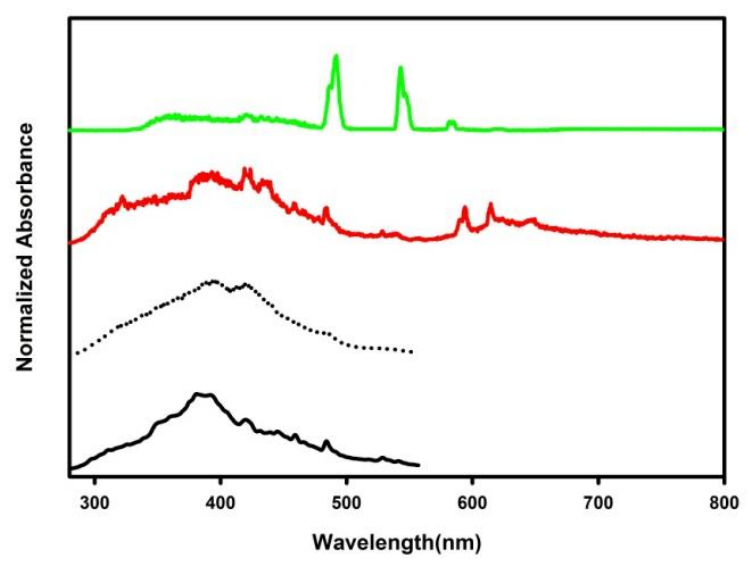

Figure 39. Steady-state luminescence at $77 \mathrm{~K}$, normalized spectra of $\mathrm{L}(\mathrm{Et})$ and $\left[\mathrm{Ln}(\mathrm{L}(\mathrm{Et}))_{3}\right]^{3+}$ complexes in anhydrous acetonitrile. From top to bottom, $\left[\mathrm{Tb}(\mathrm{L}(\mathrm{Et}))_{3}\right]^{3+}$, $\left[\mathrm{Eu}(\mathrm{L}(\mathrm{Et}))_{3}\right]^{3+},\left[\mathrm{Gd}(\mathrm{L}(\mathrm{Et}))_{3}\right]^{3+}, \mathrm{L}(\mathrm{Et})$

The presence of emission around $\sim 395-425 \mathrm{~nm}$, corresponding to triplet ${ }^{3} \pi \pi^{*}$ state emission, indicates incomplete ligand to metal energy transfer. The peak area of the ${ }^{3} \pi \pi^{*}$ emission band is smaller than the ${ }^{1} \pi \pi^{*}$ emission band, indicating that the ligand to metal energy transfer is relatively efficient, as confirmed by the $\mathrm{I}^{T} / \mathrm{I}^{S}$ measurement in section 3.2. Note that ligand bands are significantly more prominent in the $\left[\mathrm{Eu}(\mathrm{L}(\mathrm{Et}))_{3}\right]^{3+}$ spectrum than the $\left[\mathrm{Tb}(\mathrm{L}(\mathrm{Et}))_{3}\right]^{3+}$ spectrum, indicating that ligand to metal energy transfer is less efficient in $\left[\mathrm{Eu}(\mathrm{L}(\mathrm{Et}))_{3}\right]^{3+}$ versus $\left[\mathrm{Tb}(\mathrm{L}(\mathrm{Et}))_{3}\right]^{3+}$. This will have the effect of lowering the overall quantum yield of $\left[\mathrm{Eu}(\mathrm{L}(\mathrm{Et}))_{3}\right]^{3+}$, as discussed in the next section.

3.4.3 Quantum yield and luminescence sensitization. The quantum yield, $\Phi$, is a 
measure of a fluorophore's emission efficiency, ${ }^{21}$ and therefore, reflects the efficiency of transitions such as the previously discussed ISC. Additionally, for $\left[\mathrm{EuL}_{3}\right]^{3+}$ complexes, it is possible to measure the luminescence sensitization $\left(\eta_{\text {sens }}\right)$, which in this case is a measure of the efficiency by which the coordinated ligand transfers energy to the $\mathrm{Eu}^{3+}$. Further details about the calculations used to determine these values can be found in Chapter 5. The quantum yield values for $\left[\mathrm{LnL}_{3}\right]^{3+}$ complexes, and the luminescence sensitization values for $\left[\mathrm{EuL}_{3}\right]^{3+}$ complexes are summarized in Table 6.

Table 6. Quantum Yield and Luminescence Sensitization values ${ }^{4}$

\begin{tabular}{ccccc}
\hline Species & $\eta_{\text {sens }}$ & $\eta_{\text {sens }}$ & {$\left[\mathrm{EuL}_{3}\right]^{3+}$} & $\Phi$ \\
& & $\%$ & $\%$ & {$\left[\mathrm{TbL}_{3}\right]^{3+}$} \\
\hline $\mathrm{L}(\mathrm{Et})$ & $4.1 \times 10^{-5}$ & $4.1 \times 10^{-3}$ & 1.4 & 8.3 \\
$\mathrm{~L}(\mathrm{Me})^{23}$ & $4.0 \times 10^{-5}$ & $4.0 \times 10^{-3}$ & 1.0 & 8.6 \\
$\mathrm{~L}(4 \mathrm{p})^{33}$ & - & - & 0.22 & 1.2 \\
$\mathrm{~L}(1 \mathrm{yl})^{40,41}$ & $4.90 \times 10^{-2}$ & 4.90 & 7.3 & - \\
$\mathrm{L}(2 \mathrm{yl})^{41}$ & 0.117 & 11.7 & 1.9 & - \\
$\mathrm{L}(\mathrm{hh} 2)^{39}$ & 0.073 & 7.26 & 2.1 & - \\
\hline
\end{tabular}

The presence of ligand emission in the $\left[\mathrm{Ln}(\mathrm{L}(\mathrm{Et}))_{3}\right]^{3+}$ complex spectra indicates incomplete energy transfer, where the presence of singlet state emission indicates inefficient intersystem crossing and the presence of triplet state emission indicates incomplete energy transfer from ligand bands to metal acceptor bands. By inspection, when the ligand bands are more prominent in the $\left[\mathrm{Ln}(\mathrm{L}(\mathrm{Et}))_{3}\right]^{3+}$ complex spectrum, it is likely an indication of inefficient ISC and ligand metal energy transfer, and quantum yield values will likely be lower. For example, the ligand bands are more prominent in

\footnotetext{
${ }^{4}$ Estimated uncertainty in $\eta_{\text {sens }}$ and $\Phi$ values is $10 \%$
} 
the $\left[\mathrm{Eu}(\mathrm{L}(\mathrm{Et}))_{3}\right]^{3+}$ complex spectra compared with the $\left[\mathrm{Tb}(\mathrm{L}(\mathrm{Et}))_{3}\right]^{3+}$ complex spectra, and the $\left[\mathrm{Eu}(\mathrm{L}(\mathrm{Et}))_{3}\right]^{3+}$ complex had a relatively low quantum yield value of $1.4 \%$ compared with $8.1 \%$ for the $\left[\mathrm{Tb}(\mathrm{L}(\mathrm{Et}))_{3}\right]^{3+}$ complex. The related $\left[\mathrm{Eu}(\mathrm{L}(\mathrm{Me}))_{3}\right]^{3+}$ complex also had an incomplete intersystem crossing and ligand to metal energy transfer, and a lower quantum yield value for $\left[\mathrm{Eu}(\mathrm{L}(\mathrm{Me}))_{3}\right]^{3+}(1.0 \%)$ versus $\left[\mathrm{Tb}(\mathrm{L}(\mathrm{Et}))_{3}\right]^{3+}(8.6 \%){ }^{23}$ Although these quantum yield values are not especially high, it can be noted that the $\left[\operatorname{Ln}(\mathrm{L}(\mathrm{Et}))_{3}\right]^{3+}$ and $\left[\mathrm{Ln}(\mathrm{L}(\mathrm{Me}))_{3}\right]^{3+}$ complexes have a significantly higher quantum yield when compared to the respective $\left[\mathrm{Ln}(\mathrm{L}(4 \mathrm{p}))_{3}\right]^{3+}$ complexes - $\left[\mathrm{Eu}(\mathrm{L}(4 \mathrm{p}))_{3}\right]^{3+} 0.22 \%$ and $\left[\operatorname{Tb}(\mathrm{L}(4 \mathrm{p}))_{3}\right]^{3+} 1.2 \%$, largely due to more efficient energy transfer of ligand and complex transitions in the $\left[\mathrm{Ln}(\mathrm{L}(\mathrm{Et}))_{3}\right]^{3+}$ and $\left[\mathrm{Ln}(\mathrm{L}(\mathrm{Me}))_{3}\right]^{3+}$ complexes.

However, the efficiency of energy transfer is not the only factor contributing to the relatively low value of the quantum yield of the $\left[\mathrm{Eu}(\mathrm{L}(\mathrm{Et}))_{3}\right]^{3+}$ complexes. An additional explanation for the lower quantum yield of the $\left[\mathrm{Eu}(\mathrm{L}(\mathrm{Et}))_{3}\right]^{3+}$ complex is that europium is more susceptible than terbium to certain quenching processes. ${ }^{24}$ In addition, the luminescence sensitization value for $\mathrm{L}(\mathrm{Et}), \eta_{\text {sens }}$, is $4.1 \times 10^{-5}$, indicating weak efficiency. In comparison, for $\mathrm{L}(1 \mathrm{yl}) \eta_{\text {sens }}$ is the much higher value of 0.490 , which corresponds to the much higher quantum yield for $\left[\mathrm{Eu}(\mathrm{L}(1 \mathrm{yl}))_{3}\right]^{3+}, 7.3 \%,{ }^{41}$ compared with $\left[\mathrm{Eu}(\mathrm{L}(\mathrm{Et}))_{3}\right]^{3+}, 1.0 \%$. Kotova, et al. attribute the higher quantum yield value at least partially to the naphthalene groups attached to the chiral carbons, as they are more able to shield the $\mathrm{Eu}^{3+}$ centers than the phenyl groups attached to the chiral carbons of $\mathrm{L}(\mathrm{Et})$ and $\mathrm{L}(\mathrm{Me}){ }^{41}$

3.4.4 Lifetimes. Lifetimes values for $\left[\operatorname{Ln}(\mathrm{L}(\mathrm{Et}))_{3}\right]^{3+}$ species were obtained at room 
temperature and $77 \mathrm{~K}$. The $\left[\mathrm{Eu}(\mathrm{L}(\mathrm{Et}))_{3}\right]^{3+}$ lifetime values were $1.53 \mathrm{~ms}$ at room temperature, and $1.76 \mathrm{~ms}$ at $77 \mathrm{~K}$, and the observed lifetime for the $\left[\mathrm{Tb}(\mathrm{L}(\mathrm{Et}))_{3}\right]^{3+}$ species in acetonitrile was $1.85 \mathrm{~ms}$ at room temperature and $1.60 \mathrm{~ms}$ at $77 \mathrm{~K}$. The uncertainty of these values is $0.01 \mathrm{~ms}$. The lifetime values are higher at $77 \mathrm{~K}$ than at room temperature because there is less nonradiative decay due to vibration at $77 \mathrm{~K}$. There is a larger difference for the $\left[\mathrm{Ln}(\mathrm{L}(\mathrm{Et}))_{3}\right]^{3+}$ lifetimes at $77 \mathrm{~K}$ versus room temperature than for the $\left[\mathrm{Ln}(\mathrm{L}(\mathrm{Me}))_{3}\right]^{3+}$ lifetimes, which means that nonradiative decay processes have a larger effect on the $\left[\mathrm{Ln}(\mathrm{L}(\mathrm{Et}))_{3}\right]^{3+}$ complexes than the $\left[\mathrm{Ln}(\mathrm{L}(\mathrm{Me}))_{3}\right]^{3+}$ complexes. The observed lifetime for the $\left[\mathrm{Tb}(\mathrm{L}(\mathrm{Et}))_{3}\right]^{3+}$ species in acetonitrile was 1.85 at room temperature and 1.60 at $77 \mathrm{~K}$, and for the $\left[\mathrm{Tb}(\mathrm{L}(\mathrm{Me}))_{3}\right]^{3+}$ species was $1.95 \mathrm{~ms}$ at room temperature and $1.89 \mathrm{~ms}$ at $77 \mathrm{~K} .{ }^{23} \mathrm{The}\left[\mathrm{Eu}(\mathrm{L}(\mathrm{Et}))_{3}\right]^{3+}$ lifetime values were $1.53 \mathrm{~ms}$ at room temperature, and $1.76 \mathrm{~ms}$ at $77 \mathrm{~K}$, and the $\left[\mathrm{Eu}(\mathrm{L}(\mathrm{Me}))_{3}\right]^{3+}$ lifetime values were $1.75 \mathrm{~ms}$ at room temperature and $1.84 \mathrm{~ms}$ at $77 \mathrm{~K} .{ }^{23}$

The high lifetime values, greater than $1 \mathrm{~ms}$, are indicative of the preference for the species with 3 ligands coordinated to the metal center, without partial decomplexation or quenching due to solvent interaction, as the coordinated ligand molecules protect the metal center and therefore result in longer luminescent lifetimes. ${ }^{23}$ The lifetimes of the $\left[\mathrm{Ln}(\mathrm{L}(\mathrm{Et}))_{3}\right]^{3+}$ complexes are comparable to previously reported values, though the lifetimes of the $\mathrm{L}(\mathrm{Et})$ species are slightly lower than those of the $\mathrm{L}(\mathrm{Me})$ and $\mathrm{L}(1 \mathrm{yl})$ species, ${ }^{23,40,41}$ indicating that there may be some quenching of the $\mathrm{L}(\mathrm{Et})$ species. At room temperature, the observed lifetimes for the $\left[\mathrm{EuL}_{3}\right]^{3+}$ species are $1.53 \mathrm{~ms}$ for the $\mathrm{L}(\mathrm{Et})$ complex, $1.75 \mathrm{~ms}$ for the $\mathrm{L}(\mathrm{Me})$ complex, ${ }^{23} 1.85 \mathrm{~ms}$ for the $\mathrm{L}(1 \mathrm{yl})$ complex,${ }^{41} 401.79 \mathrm{~ms}$ 
for the L(2yl) complex, ${ }^{41} 1.76 \mathrm{~ms}$ for the $\mathrm{L}(\mathrm{hh} 1)$ complex ${ }^{48}$ and $1.95 \mathrm{~ms}$ for the $\mathrm{L}(\mathrm{hh} 2)$ complex. ${ }^{39}$ Uncertainty in these measurements is $0.01 \mathrm{~ms}$.

\subsection{Circularly Polarized Luminescence}

CPL spectra were measured for complex solutions of $\left[\mathrm{Ln}(\mathrm{L}(\mathrm{Et}))_{3}\right]^{3+}$ in anhydrous acetonitrile. As explained in Chapter 1, CPL involves the emission of circularly polarized luminescence from a chiral compound.

Two sources of chirality exist for the complexes studied. One is the helical arrangement of ligands around the metal center, where left handed helical arrangement of the ligands results in the formation of the $\Lambda$ structure, and right handed helical arrangement results in the formation of the $\Delta$ structure. An excess of one of the two forms ( $\Delta$ or $\Lambda$ ) could lead to CPL activity. Previous studies of complexes with achiral ligands, for example $\left.[\mathrm{LnDPA}]_{3}\right]^{3+}$ complexes, ${ }^{11}$ showed that a racemic mixture of $\Delta$ and $\Lambda$ structures formed in solution. Such a racemic mixture would lead to no CPL activity. Another source of chirality is the ligands themselves, for example the chiral pyridine dicarboxamide derivatives discussed in this work. The chirality of the ligand may induce the preferential formation of either the $\Delta$ or $\Lambda$ helical environment over the other. As this helical arrangement affects the chiral environment at the metal center, preferential formation of one helical structure would result in observable CPL activity.

3.5.1 $\left[\mathbf{E u}\left(\mathbf{L}(\mathbf{E t})_{3}\right]^{3+}\right.$. The ${ }^{5} \mathrm{D}_{0} \rightarrow{ }^{7} \mathrm{~F}_{1}$ (Figure 40, left) and ${ }^{5} \mathrm{D}_{0} \rightarrow{ }^{7} \mathrm{~F}_{2}$ ( Figure 20, right) transitions of $\left[\mathrm{Eu}\left(\mathrm{L}(\mathrm{Et})_{3}\right]^{3+}\right.$ show strong circularly polarized luminescence (CPL) activity. 

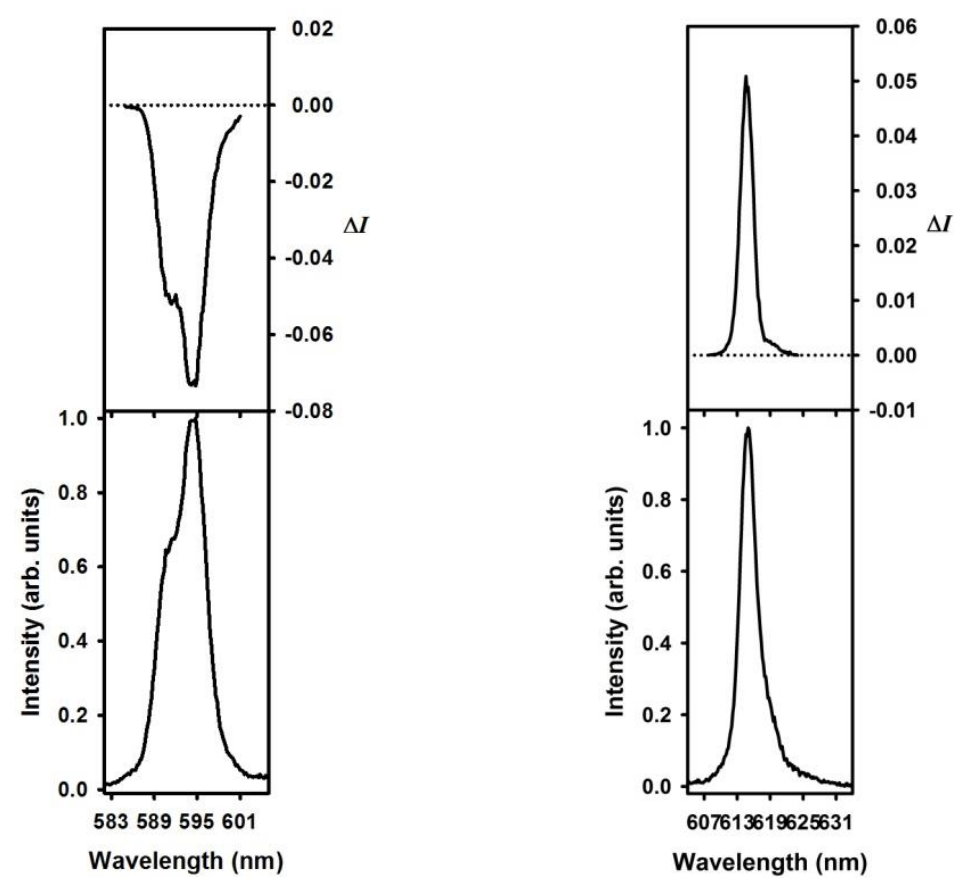

Figure 40. CPL of $\left[\mathrm{Eu}(\mathrm{L}(\mathrm{Et}))_{3}\right]^{3+} R, R$ enantiomer in anhydrous acetonitrile, left= ${ }^{5} \mathrm{D}_{0} \rightarrow{ }^{7} \mathrm{~F}_{1}$ transition, right $={ }^{5} \mathrm{D}_{0} \rightarrow{ }^{7} \mathrm{~F}_{2}$ transition

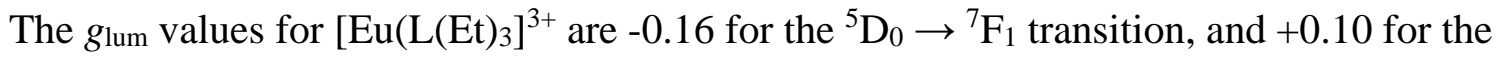
${ }^{5} \mathrm{D}_{0} \rightarrow{ }^{7} \mathrm{~F}_{2}$ transition. This sign pattern corresponds with the CPL sign pattern of the $\left[\mathrm{EuL}_{3}\right]^{3+}$ complexes with the ligands $\mathrm{L}(\mathrm{Me}), \mathrm{L}(1 \mathrm{yl}), \mathrm{L}(2 \mathrm{yl}), \mathrm{L}(\mathrm{hh} 1)$, and $\mathrm{L}(\mathrm{hh} 2)$, that is, (-) for the ${ }^{5} \mathrm{D}_{0} \rightarrow{ }^{7} \mathrm{~F}_{1}$ transition, and (+) for the ${ }^{5} \mathrm{D}_{0} \rightarrow{ }^{7} \mathrm{~F}_{2}$ transition. This indicates the $R, R$ enantiomer of these ligands induces the same chirality at the $\mathrm{Eu}^{3+}$ center of the complexes, with structural data from these studies showing that it is the $\Lambda$ structure..$^{23,38-41}$

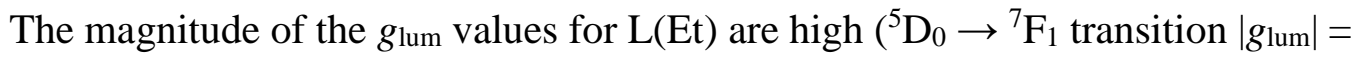
$0.16)$ and consistent with the high $g_{\text {lum }}$ values observed for the $\mathrm{L}(\mathrm{Me})\left(\left|g_{\mathrm{lum}}\right|=0.19\right)$, $\mathrm{L}(1 \mathrm{yl})\left(\left|g_{\mathrm{lum}}\right|=0.24\right)$ and L(2yl) $\left(\left|g_{\mathrm{lum}}\right|=0.16\right)$, which indicates that the chiral ligand induces the formation of the single $\Lambda$ diastereomer of the $\left[\mathrm{EuL}_{3}\right]^{3+}$ complex. ${ }^{23,41}{ }^{38-41} \mathrm{In}$ contrast, the ligand $\mathrm{L}(4 \mathrm{p})$, where the chiral group is more distant from the coordinating region of the 2,6-pyridinedicarboxamide moiety, induces only a small excess of one 
diastereomer of the $\left[\mathrm{EuL}_{3}\right]^{3+}$ complex in solution, thus resulting in weak CPL activity, $\left|g_{\operatorname{lum}}\right|=0.02 .^{11,33}$

Table 7 summarizes the CPL values for $\left[\mathrm{EuL}(\mathrm{Et})_{3}\right]^{3+}$, and compares them to the values for the $\left[\mathrm{Eu}(\mathrm{L})_{3}\right]^{3+}$ complexes of the other previously mentioned ligands $\mathrm{L}(\mathrm{Me})$, L(p4), L(1yl), L(2yl), L(hh1), and L(hh2).

Table 7. Summary of glum values for $\left[\mathrm{EuL}_{3}\right]^{3+6}$

\begin{tabular}{ccccccc}
\hline & \multicolumn{3}{c}{${ }^{5} \mathrm{D}_{0} \rightarrow{ }^{7} \mathrm{~F}_{1}$} & \multicolumn{3}{c}{${ }^{5} \mathrm{D}_{0} \rightarrow{ }^{7} \mathrm{~F}_{2}$} \\
Species & $\begin{array}{c}\text { Wavelength } \\
(\mathrm{nm})\end{array}$ & $\mathrm{g}_{\text {lum }}$ & $\begin{array}{c}\text { Wavelength } \\
(\mathrm{nm})\end{array}$ & $g_{\text {lum }}$ & $\begin{array}{c}\text { Wavelength } \\
(\mathrm{nm})\end{array}$ & $\mathrm{g}_{\text {lum }}$ \\
\hline $\mathrm{L}(\mathrm{Et})$ & 590.8 & -0.16 & 595.8 & -0.14 & 614.6 & 0.1036 \\
$\mathrm{~L}(\mathrm{Me})^{23}$ & 590.5 & -0.19 & 595.3 & -0.18 & 615.6 & 0.21 \\
$\mathrm{~L}(4 \mathrm{p})^{33}$ & 591 & -0.02 & - & - & - & - \\
$\mathrm{L}(1 \mathrm{yl})^{41} 40$ & 589.9 & -0.24 & 593.6 & -0.05 & 614.1 & 0.25 \\
$\mathrm{~L}(2 \mathrm{yl})^{41}$ & - & - & 595.59 & -0.16 & 619.02 & 0.17 \\
$\mathrm{~L}(\mathrm{hh} 1)^{38}$ & - & - & 600 & -0.15 & 619 & 0.06 \\
$\mathrm{~L}(\mathrm{hh} 2)^{39}$ & 589 & -0.15 & 592 & -0.17 & 614 & 0.10 \\
\hline
\end{tabular}

Indirect excitation through the ligand bands was used to take the CPL spectra in Figure 40. It is also possible to directly excite the europium center, and $g_{\text {lum }}$ values obtained via direct excitation of $\left[\mathrm{Eu}\left(\mathrm{L}(\mathrm{Et})_{3}\right]^{3+}\right.$ species were consistent with those obtained via indirect excitation, that is, the sign of the $g_{l u m}$ was $(+)$ for the ${ }^{5} \mathrm{D}_{0} \rightarrow{ }^{7} \mathrm{~F}_{2}$ transition. Additionally, the $g_{\text {lum }}$ values are consistent regardless of the direction of polarization of the excitation beam, $+0.0025(1)$ with a plane polarized excitation beam,$+0.0021(1)$ with left circular polarization in the excitation beam, and $+0.0023(2)$ with right circular polarization in the excitation beam. Since the CPL activity of the $\left[\mathrm{Eu}\left(\mathrm{L}(\mathrm{Et})_{3}\right]^{3+}\right.$ species is

\footnotetext{
${ }^{6}$ Uncertainty of $g_{\text {lum }}$ values is 0.01 , resolution of wavelengths is $0.1 \mathrm{~nm}$.
} 
independent of direct or indirect excitation and independent of the polarization of the excitation beam, this indicates that a single diastereomer of the metal complex is present in solution..$^{51}$

3.5.2 $\left[\mathbf{T b L}(\mathbf{E t})_{3}\right]^{3+}$. The CPL spectrum for the ${ }^{5} \mathrm{D}_{4} \rightarrow{ }^{7} \mathrm{~F}_{5}$ transition of $\left[\mathrm{TbL}(\mathrm{Et})_{3}\right]^{3+}$ (Figure 41) showed strong CPL activity.

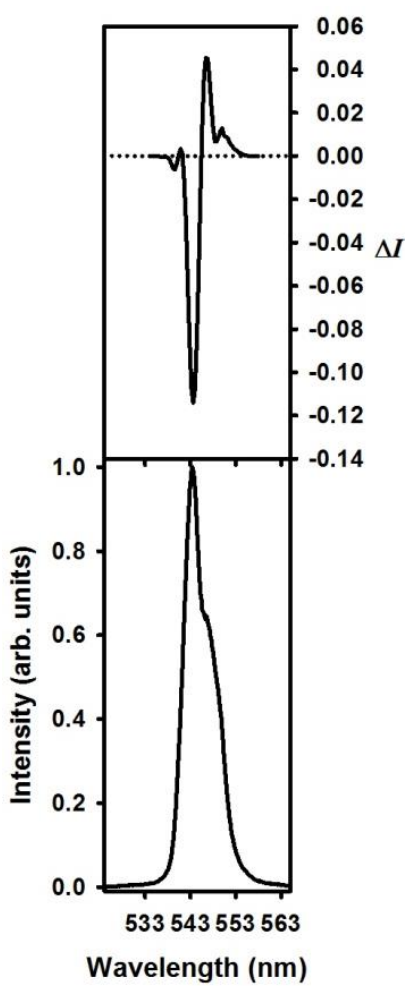

Figure 41. CPL of $\left[\mathrm{Tb}(\mathrm{L}(\mathrm{Et}))_{3}\right]^{3+} R, R$ enantiomer in anhydrous acetonitrile ${ }^{5} \mathrm{D}_{4} \rightarrow{ }^{7} \mathrm{~F}_{5}$ transition

As with the previously discussed $\left[\mathrm{EuL}(\mathrm{Et})_{3}\right]^{3+}$, the high $\left|g_{\text {lum }}\right|$ of 0.23 indicates that $\mathrm{L}(\mathrm{Et})-R, R$ induces the formation of a single diastereomer of the $\left[\mathrm{TbL}(\mathrm{Et})_{3}\right]^{3+}$ complex. In comparison, the $\left[\operatorname{TbL}(4 \mathrm{p})_{3}\right]^{3+}$ complex, where only a small excess of one diastereomer is formed, has a much weaker CPL activity with $\left|g_{\operatorname{lum}}\right|=0.01 .^{33}$ The results are summarized in Table 8. 
Table 8. Summary of $\mathrm{g}_{\text {lum }}$ values for $\left[\mathrm{Tb}(\mathrm{L}(\mathrm{Et}))_{3}\right]^{3+}$

$$
{ }^{5} \mathrm{D}_{4} \rightarrow{ }^{7} \mathrm{~F}_{5}
$$

\begin{tabular}{cc}
\hline $\begin{array}{c}\text { Wavelength } \\
(\mathrm{nm})\end{array}$ & $g_{\text {lum }}$ \\
\hline 539.2 & -0.11 \\
540.8 & 0.02 \\
543.6 & -0.23 \\
546.8 & 0.14 \\
551.2 & 0.08 \\
\hline
\end{tabular}

The strong CPL activity of the $\left[\mathrm{EuL}(\mathrm{Et})_{3}\right]^{3+}$ complex (section 3.5 .1 ) and the $\left[\mathrm{TbL}(\mathrm{Et})_{3}\right]^{3+}$ complex (section 3.5.2) supports our hypothesis that using only one enantiomer, $R, R$, of $\mathrm{L}(\mathrm{Et})$ will induce the formation of one chiral structure in solution, resulting in strong CPL activity. Additionally, comparison with other $\left[\mathrm{EuL}_{3}\right]^{3+}$ complexes of related ligands () shows the CPL sign pattern is consistent. This means that using the $R, R$ enantiomer results in the formation of a chiral $\left[\mathrm{EuL}_{3}\right]^{3+}$ structure with consistent chiroptical properties across similar ligand systems and $\mathrm{D}_{3}\left[\mathrm{LnL}_{3}\right]^{3+}$ complexes.

The chiral structure of the ligands induced the chiral $\Delta$ or $\Lambda$ helical environment of the metal complexes. The $\Delta$ and $\Lambda$ complexes have mirror image CPL spectra. There is a consistent correlation between the $\left[\mathrm{EuL}_{3}\right]^{3+}$ complexes and the CPL sign pattern - that is, $(-,-)$ then $(+)$ for the ${ }^{5} \mathrm{D}_{0} \rightarrow{ }^{7} \mathrm{~F}_{1}$ and ${ }^{5} \mathrm{D}_{0} \rightarrow{ }^{7} \mathrm{~F}_{2}$ transitions, which held across this family of ligands..$^{23,38-41}$ This is the mirror image of the pattern found across related ligands for the $\left[\mathrm{Eu}(\mathrm{L}-S, S)_{3}\right]^{3+}$ complexes of $(+,+)$ then $(-)$ for the ${ }^{5} \mathrm{D}_{0} \rightarrow{ }^{7} \mathrm{~F}_{1}$ and ${ }^{5} \mathrm{D}_{0} \rightarrow{ }^{7} \mathrm{~F}_{2}$ transitions. ${ }^{11}$ This shows that there is a correlation from chiral structure in the ligand to the chiral environment of the metal complex to the CPL signal, and is extremely 
promising, as it supports a relationship between structure and spectroscopy.

Studies of these $1: 3 \mathrm{Ln}^{3+}$ :ligand $\left[\mathrm{EuL}_{3}\right]^{3+}$ complexes will hopefully allow us to determine whether the relationship between structure and chiroptical properties holds, and obtain an overall idea of the behavior of these $\mathrm{Ln}^{3+}$ complexes. We hypothesis that we can make a correlation between chiral structure and sign of CPL signal. 


\section{CHAPTER 4}

\section{CONCLUDING REMARKS}

We have studied the photophysical and chiroptical properties of $\mathrm{L}(\mathrm{Et})$ and the chiral $\left[\mathrm{Ln}(\mathrm{L}(\mathrm{Et}))_{n}\right]^{3+}$ complexes it forms with $\mathrm{Ln}^{3+}$ ions, e.g. $\mathrm{Eu}^{3+}, \mathrm{Gd}^{3+}$, and $\mathrm{Tb}^{3+}$, in solution. Comparison of $\mathrm{L}(\mathrm{Et})$ with related ligands derived from the 2,6-pyridine dicarboxamide moiety, showed that the small structural change in the ligand did result in some changes in the properties of complexes of $\mathrm{Ln}^{3+}$ with the ligand, but that overall, the behavior of $\mathrm{L}(\mathrm{Et})$ and the chiral $\left[\mathrm{Ln}(\mathrm{L}(\mathrm{Et}))_{n}\right]^{3+}$ complexes it forms with $\mathrm{Ln}^{3+}$ ions, e.g. $\mathrm{Eu}^{3+}, \mathrm{Gd}^{3+}$, and $\mathrm{Tb}^{3+}$, in solution is consistent with the behavior of other structurally similar ligands. This is a promising result for the use of this family of ligands as luminescent probes, as studies of other families of ligands have shown that structural changes in the ligands may have larger consequences in the structure and properties of the $\mathrm{Ln}^{3+}$ :ligand complexes.

The $\left[\mathrm{Ln}(\mathrm{L}(\mathrm{Et}))_{3}\right]^{3+}$ species formed is consistent with other ligands in this family. The structural change in $\mathrm{L}(\mathrm{Et})$ results in a change in the stability constants for the formation of $[\mathrm{Eu}(\mathrm{L}(\mathrm{Et}))]^{3+},\left[\mathrm{Eu}(\mathrm{L}(\mathrm{Et}))_{2}\right]^{3+}$, and $\left[\mathrm{Eu}(\mathrm{L}(\mathrm{Et}))_{3}\right]^{3+}$, determined via luminescence titrations of $\mathrm{Eu}^{3+}: \mathrm{L}(\mathrm{Et})$, but using an excess of ligand drove the formation of the desired $\left[\mathrm{Eu}(\mathrm{L}(\mathrm{Et}))_{3}\right]^{3+}$ species, where three ligand molecules are coordinated to the metal center. ${ }^{1} \mathrm{H}$ NMR titrations of $\mathrm{La}^{3+}: \mathrm{L}(\mathrm{Et})$ showed the formation of the $\left[\mathrm{La}(\mathrm{L}(\mathrm{Et}))_{3}\right]^{3+}$ complex

with $\mathrm{D}_{3}$ symmetry, and the ${ }^{5} \mathrm{D}_{0} \leftarrow{ }^{7} \mathrm{~F}_{0}$ excitation spectra of the $\left[\mathrm{Eu}(\mathrm{L}(\mathrm{Et}))_{3}\right]^{3+}$ species and the long luminescent lifetimes of the $\left[\mathrm{Eu}(\mathrm{L}(\mathrm{Et}))_{3}\right]^{3+}$ and $\left[\mathrm{Tb}(\mathrm{L}(\mathrm{Et}))_{3}\right]^{3+}$ species further confirmed that the desired species was formed in solution, excluding solvent molecules from the inner coordination sphere. While changing the ligand results in a change in the 
quantum yield and luminescence sensitization values of the $\left[\mathrm{EuL}_{3}\right]^{3+}$ complexes, the values are not significantly reduced and the complex can still be indirectly excited via the antenna effect.

Using a single enantiomer of $\mathrm{L}(\mathrm{Et})$ induces the preferential formation of one chiral $\left[\mathrm{Ln}(\mathrm{L}(\mathrm{Et}))_{3}\right]^{3+}$ complex, consistent with the $\left[\mathrm{LnL}_{3}\right]^{3+}$ complexes formed with other ligands in this family. The $\left[\mathrm{Eu}(\mathrm{L}(\mathrm{Et}))_{3}\right]^{3+}$ complex with $(R, R)$ enantiomer of $\mathrm{L}(\mathrm{Et})$ exhibits strong CPL activity, where the magnitude of the $\mathrm{g}_{\text {lum }}$ is independent of the polarization of the excitation beam, and the sign is independent of whether direct or indirect excitation is used, which indicates that a single diastereomer of the chiral complex is formed in solution. ${ }^{11}$ In addition, the CPL sign patterns of complexes with $(R, R)$ enantiomer of $\mathrm{L}(\mathrm{Et})$ are consistent with the CPL sign pattern of related $\left[\mathrm{LnL}_{3}\right]^{3+}$ complexes with the $(R, R)$ enantiomer of the respective ligands. The sign pattern of the $\left[\mathrm{Eu}(\mathrm{L}(\mathrm{Et}))_{3}\right]^{3+}$ complex with the $(R, R)$ enantiomer of $\mathrm{L}(\mathrm{Et})$ is $(-,-)$ then $(+)$ for the ${ }^{5} \mathrm{D}_{0} \rightarrow{ }^{7} \mathrm{~F}_{1}$ and ${ }^{5} \mathrm{D}_{0} \rightarrow{ }^{7} \mathrm{~F}_{2}$ transitions, which is consistent with the results across the ligands studied within this family. Using the $(R, R)$ enantiomer of the ligand resulted in preferential formation of the $\Lambda$ diastereomer of the $\left[\mathrm{EuL}_{3}\right]^{3+}$ complexes and the CPL sign pattern of the $\left[\mathrm{EuL}_{3}\right]^{3+}$ complexes is the same as that of the $\left[\mathrm{Eu}(\mathrm{L}(\mathrm{Et}))_{3}\right]^{3+}$ complex, which are $(-,-)$ then $(+)$ for the ${ }^{5} \mathrm{D}_{0} \rightarrow{ }^{7} \mathrm{~F}_{1}$ and ${ }^{5} \mathrm{D}_{0} \rightarrow{ }^{7} \mathrm{~F}_{2}$ transitions. ${ }^{24,26,30,35-36}$

This correlation between chirality of the ligand to the stereochemistry of the metal complex to the CPL sign pattern is significant because it shows that, within this family of ligands, there is a relationship between structure and chiroptical properties. As of yet there is no simple method for predicting chiral structure using spectroscopy. Further 
study of this family of ligands and the $\left[\mathrm{LnL}_{3}\right]^{3+}$ complexes they form may lead to the development of exciting luminescent chiral probes. 


\section{CHAPTER 5}

\section{MATERIALS AND METHODS}

\subsection{Materials}

Prior to use, solid reagents were dried overnight under vacuum and heat. Lanthanide nitrate hydrates, $\mathrm{Ln}\left(\mathrm{NO}_{3}\right)_{3} \cdot n \mathrm{H}_{2} \mathrm{O}(\mathrm{Ln}=\mathrm{Eu}, \mathrm{Tb}, \mathrm{Gd})$ were obtained from Sigma Aldrich and used without further purification. HPLC grade solvents were dried before use and stored over activated molecular sieves. The $R, R$ enantiomer of $N, N^{\prime}$-bis(1-phenylpropyl)-2,6-pyridinedicarboxamide was synthesized via previously published methods. ${ }^{23}$ Masses were measured using an Ohaus Discovery DV215CD microscale and volumes were using a calibrated variable volume pipette. Lanthanide stock solutions of $\mathrm{Ln}\left(\mathrm{NO}_{3}\right)_{3}(\mathrm{Ln}=\mathrm{Eu}, \mathrm{Tb}, \mathrm{Gd})$ were standardized using buret titrations with known concentration solutions of ethylenediaminetetraacetic acid (EDTA) in the presence of ammonium acetate buffer and arsenazo III indicator to determine $\mathrm{Ln}^{3+}$ concentration. ${ }^{52}$

\subsection{Electronic Spectra, Luminescence and Lifetimes Measurements}

A Hewlett Packard 845A Diode Array Spectrophotometer and a Varian Cary 50 UV/visible spectrophotometer were used to measure electronic spectra in the UV-Visible region, always with baseline correction. All measurements were taken at room temperature and concentrations were chosen for which the Beer-Lambert law is obeyed. For more detail, see Appendix C.

Luminescence spectra were taken on a Varian Cary Eclipse fluorometer which uses a Xenon lamp as the excitation light source. Data were measured and recorded through the 
Cary Eclipse Scan Application 1.1(132), with Savitzsky-Golay type smoothing. Room temperature and $333 \mathrm{~K}$ temperature control were achieved with an attached Cary Single Cell Peltier Accessory and Quantum Northwest TLC Temperature Control. Steady-state luminescence measurements at $77 \mathrm{~K}$ were run on a Perkin-Elmer LS50B Luminescence Spectrometer and time-resolved luminescence measurements at $77 \mathrm{~K}$ were run on the Varian Cary Eclipse fluorometer, with an adjustment to accommodate a liquid nitrogen filled chamber. Lifetime measurements at room temperature, $333 \mathrm{~K}$, and $77 \mathrm{~K}$ were taken using the Varian Cary Eclipse fluorometer, with the same physical setup as the luminescence scans. Data were measured and recorded through the Cary Eclipse Lifetimes Application. Reported lifetimes values are an average of three runs. Luminescence spectra of $\mathrm{L}(\mathrm{Et})$ and $\left[\mathrm{Gd}(\mathrm{L}(\mathrm{Et}))_{3}\right]^{3+}$ were taken at $77 \mathrm{~K}$ in order to compare the change in $\Delta \mathrm{E}\left({ }^{3} \pi \pi^{*-1} \pi \pi^{*}\right)$ and efficiency of ISC upon complexation. For more detail on experimental methods and calculations, see Appendix.

\subsection{Quantum Yield and Luminescence Sensitization}

The quantum yield, $\Phi,{ }^{21}$ of $\mathrm{L}(\mathrm{Et})$ and $\left[\mathrm{Ln}(\mathrm{L}(\mathrm{Et}))_{3}\right]^{3+}$ complex was determined using $\mathrm{L}(\mathrm{Me})$ and the respective $\left[\mathrm{Ln}(\mathrm{L}(\mathrm{Me}))_{3}\right]^{3+}$ complexes as a reference. The quantum yield was calculated using the following equation, ${ }^{23}$ where "R" refers to the reference, "S" refers to the sample, the integral is the area under the emission spectra in wavelength units; $I$ is the intensity of the emission peak, $A$ is the absorbance at the excitation wavelength, and $n$ is the refractive index of the solution:

$$
\frac{\Phi_{S}}{\Phi_{R}}=\left(\frac{\int I_{S} d \lambda}{\int I_{R} d \lambda}\right)\left(\frac{I_{R, e x c}}{I_{S, e x c}}\right)\left(\frac{A_{R, \lambda_{e x c}}}{A_{S, \lambda_{e x c}}}\right)\left(\frac{n_{S}}{n_{R}}\right)^{2}
$$


Refractive index was taken using a Carl Zeiss 32048 Refractometer. The estimated error of the quantum yield using this method has been previously determined to be $10 \% .^{23}$

The luminescence sensitization was measured for $\left[\mathrm{EuL}(\mathrm{Et})_{3}\right]^{3+}$, and calculated using the following series of equations.

$$
Q^{E u}{ }_{t o t}=\eta_{I S C} \cdot \eta_{E t} \cdot Q^{E u}=\eta \operatorname{sens} \cdot Q^{E u}
$$

$$
\begin{aligned}
& \eta_{\text {sens }}=\text { luminescence sensitization } \\
& Q^{E u}{ }_{\text {tot }}=\text { Europium-centered luminescence } \Phi
\end{aligned}
$$

where $Q^{E u}=$ intrinsic luminescence quantum yield

$$
Q^{E u}=\frac{\tau_{o b s}}{\tau_{R}}
$$

$\tau_{\text {obs }}=$ Observed Lifetime of the $\mathrm{Eu}\left({ }^{5} \mathrm{D}_{0}\right)$ level

where $\tau_{R}=$ radiative lifetime

$$
\tau_{R}=\frac{1}{A_{M D, 0} \cdot n^{3}} \cdot\left(\frac{I_{M D}}{I_{\text {tot }}}\right)
$$

$A_{M D, 0}=$ spontaneous emission probability of the $E u\left({ }^{5} D_{0} \rightarrow{ }^{7} F_{1}\right)$ transition

$I_{M D}=$ intensity of the $E u\left({ }^{5} D_{0} \rightarrow^{7} F_{1}\right)$ transition

where $I_{\text {tot }}=$ intensity of the total emission of the ${ }^{5} D_{0}$ level

\subsection{Circularly Polarized Luminescence}

CPL and total luminescence spectra were taken on a custom built CPL instrument where the excitation source is a xenon arc lamp ignited at 1000W which excites the sample solution at an angle to the detector to avoid artifacts, and the resulting emission is passed through a linear polarizer to avoid artifacts in the final measurement. ${ }^{16}$ The 
monochromators adjust the excitation and emission wavelengths, with a resolution of 0.1 $\mathrm{nm}$. The net circular polarization is detected by a circular analyzer which includes a photo-elastic modulator (PEM), and the left and right circularly polarized light is detected using a "thermoelectrically cooled photomultiplier tube (PMT) operating in a differential photon counting mode". ${ }^{12}$ Digital counters then count the amount of left and right circularly polarized light, and the $g_{\text {lum }}$ values are calculated. The total luminescence spectrum was normalized and plotted against the CPL spectrum of the sets of $g_{\text {lum }}$ values collected across a transition.

\subsection{Direct Excitation of $[\mathrm{Eu}(\mathrm{L}(\mathbf{E t})) \mathrm{n}]^{3+}$ Complexes}

Direct excitation spectra of $\left[\mathrm{Eu}(\mathrm{L}(\mathrm{Et}))_{n}\right]^{3+}$ complexes were performed using an Argon dye laser excitation source, using rhodamine $6 \mathrm{G}$ dye and a voltage range from 3.44 - 3.47 $\mathrm{W}$. The resolution of the emission monochromator is $0.1 \mathrm{~nm}$, and the error in the wavelength is assumed to be equal to the resolution. Spectra were deconvoluted using PeakFit software, with Lorentzian line shapes. See Appendix C for more detail. Comparison of the deconvoluted peaks across samples with varying ratios of Eu and $\mathrm{L}(\mathrm{Et})$ allowed for the determination of the position of the peaks for the 1:1, 1:2 and 1:3 species.

\subsection{Stability Constants}

The values of $\beta_{n}$ were determined through luminescence titrations of $\mathrm{L}(\mathrm{Et})$ with $\mathrm{Eu}^{3+}$ and $\mathrm{Tb}^{3+}$ using an automatic titration system using a calibrated precision peristaltic pump. The system was kept under an argon atmosphere and homogenized with a magnetic stirrer for 15 minutes between additions. A Varian Cary Fluorometer with a $450 \mathrm{~W}$ 
Xenon arc lamp as the excitation source recorded a time-resolved luminescence spectrum after each addition. The stability constants were determined using Hyperquad2006 software. For luminescence titrations with $\mathrm{Eu}^{3+}$, the ${ }^{5} \mathrm{D}_{0} \rightarrow{ }^{7} \mathrm{~F}_{2}$ transition $(\sim 615 \mathrm{~nm})$ was used for analysis due to its sensitivity to the environment, as this transition is sensitive to the symmetry of its environment. ${ }^{53}$ The value reported is an average of two independent determinations.

\subsection{Calculated Structure of $L(E \mathbf{E t})$}

Computational chemistry calculations were performed on a Windows 7 64-bit PC with an Intel Centrino, Core i5 processor. The WebMO computational chemistry interface was used to run jobs, and the web server software used was Apache HTTP Server by The Apache Software Foundation. The Firefly Quantum Chemistry Package (Firefly QC), formerly known as PC Gamess, was used to perform geometric optimization of the ligand structures. Firefly QC is partially based on the GAMESS source code. ${ }^{44,45}$ The modeling method chosen for the geometry optimization was self-consistent field (SCF) density functional theory (DFT) using B3LYP and the 6-31G(d) basis set. ${ }^{23,54}$ Final output was confirmed to have reached the stationary point, where the SCF converged and there were no imaginary vibration modes. ${ }^{42,43}$ The bond angles and bond lengths were calculated from the optimized structures and the molecular visualization of the results were rendered using Gabedit. ${ }^{46}$ 


\section{REFERENCES}

(1) Voet, D. V., Judith. Biochemistry. 4th ed.; John Wiley \& Sons: Hoboken, NJ, 2010.

(2) Smith, S. W. Chiral toxicology: it's the same thing...only different. Toxicol. Sci. 2009, 110 (1), 4-30 DOI: 10.1093/toxsci/kfp097.

(3) Mondal, P.; Kandala, B.; Ahrens, R.; Chesrown, S. E.; Hendeles, L. Nonprescription racemic epinephrine for asthma. J Allergy Clin Immunol Pract 2014, 2 (5), 575-8 DOI: 10.1016/j.jaip.2014.02.014.

(4) Petrocheilou, A.; Tanou, K.; Kalampouka, E.; Malakasioti, G.; Giannios, C.; Kaditis, A. G. Viral croup: diagnosis and a treatment algorithm. Pediatr Pulmonol 2014, 49 (5), 421-9 DOI: 10.1002/ppul.22993.

(5) Casale, T. B.; Burks, A. W. Clinical practice. Hymenoptera-sting hypersensitivity. N Engl J Med 2014, 370 (15), 1432-9 DOI: 10.1056/NEJMcp1302681.

(6) Pitluk, J. D.; Uman, H.; Safranek, S. Clinical inquiries. What's best for croup? J Fam Pract 2011, 60 (11), 680-1.

(7) Klassen, T. P. Croup. A current perspective. Pediatr Clin North Am 1999, 46 (6), 1167-78.

(8) Housecroft, C. E.; Sharpe, A. G. Inorganic Chemistry. 4th ed.; Pearson Education Limited: Essex, 2012.

(9) Cotton, F. A. Chemical Applications of Group Theory. 3rd ed.; WileyInterscience: New York, 1990.

(10) Berova, N.; Polavarapu, P. L.; Nakanishi, K.; Woody, R. W. Comprehensive Chiroptical Spectroscopy. John Wiley \& Sons, Inc.: New York, 2011.

(11) Muller, G. In Luminescence of Lanthanide Ions in Coordination Compounds and Nanomaterials; de Bettencourt-Dias, A., Ed.; John Wiley \& Sons, Ltd.: 2014.

(12) Bonsall, S. D.; Houcheime, M.; Straus, D. A.; Muller, G. Optical isomers of N,N'bis(1-phenylethyl)-2,6-pyridinedicarboxamide coordinated to europium(III) ions as reliable circularly polarized luminescence calibration standards. Chem. Commun. 2007, 35 (35), 3676-8 DOI: 10.1039/b704346e.

(13) Muller, G. Luminescent chiral lanthanide(III) complexes as potential molecular probes. Dalton Transactions 2009, (44), 9692-9707 DOI: 10.1039/b909430j.

(14) Kelly, S. M.; Jess, T. J.; Price, N. C. How to study proteins by circular dichroism. 
Biochim. Biophys. Acta 2005, 1751 (2), 119-39 DOI:

10.1016/j.bbapap.2005.06.005.

(15) Kelly, S. M.; al., e. How to study proteins by circular dichroism. Biochimica et Biophysica Acta 2005, 119-139.

(16) Riehl, J. P.; Muller, G. In Handbook on the Physics and Chemistry of Rare Earths; Gschneidner, K. A. J., Bünzli, J.-C. G., Pecharsky, V. K., Ed.; Elsevier: 2005; Vol. 34, pp 289-354.

(17) Lunkley, J. L.; Shirotani, D.; Yamanari, K.; Kaizaki, S.; Muller, G. Extraordinary Circularly Polarized Luminescence Activity Exhibited by Cesium Tetrakis (3heptafluorobutylryl-(+)-camphorato) $\mathrm{Eu}$ (III) Complexes in $\mathrm{EtOH}$ and $\mathrm{CHCl} 3$ Solutions. J. Am. Chem. Soc. 2008, 130 (42), 13814.

(18) Shirotani, D.; Suzuki, T.; Kaizaki, S. Novel Configurational Structures of Sodium Tetrakis(3-heptafluorobutylryl-(+)-camphorato) Ln(III) Complexes with a Trapped $\mathrm{Na}+$ by $\mathrm{Na}+\cdots \mathrm{FC}$ Interactions in the Solid State and in Solution. Inorg. Chem. 2006, 45 (16), 6111-6113 DOI: 10.1021/ic0606633.

(19) Field, J. E.; Muller, G.; Riehl, J. P.; Venkataraman, D. Circularly polarized luminescence from bridged triarylamine helicenes. J. Am. Chem. Soc. 2003, 125 (39), 11808-11809.

(20) Crabtree, R. H. In The Organometallic Chemistry of the Transition Metals; 5th ed.; John Wiley \& Sons, Inc.: Hoboken, NJ, 2009; pp 439-447.

(21) Lakowicz, J. R. Principles of Fluorescence Spectroscopy. 3rd ed.; Springer Science: New York, NY, 2006.

(22) Bünzli, J.-C. G.; Choppin, G. R. Lanthanide probes in life, chemical, and earth sciences : theory and practice. Elsevier: Amsterdam, 1989.

(23) Hua, K. T.; Xu, J.; Quiroz, E. E.; Lopez, S.; Ingram, A. J.; Johnson, V. A.; Tisch, A. R.; de Bettencourt-Dias, A.; Straus, D. A.; Muller, G. Structural and photophysical properties of visible- and near-IR-emitting tris lanthanide(III) complexes formed with the enantiomers of N,N'-bis(1-phenylethyl)-2,6pyridinedicarboxamide. Inorg. Chem. 2012, 51 (1), 647-60 DOI: 10.1021/ic202094p.

(24) Bünzli, J.-C. G.; Eliseeva, S. V. In Lanthanide Luminescence; Hänninen, P., Härmä, H., Ed.; Springer: Berlin, Heidelberg, 2010; Vol. 7, pp 1-45.

(25) Binnemans, K. Interpretation of europium(III) spectra. Coord. Chem. Rev. 2015, 295, 1-45 DOI: 10.1016/j.ccr.2015.02.015. 
(26) Muller, G.; Bunzli, J. C.; Schenk, K. J.; Piguet, C.; Hopfgartner, G. Influence of bulky $\mathrm{N}$-substituents on the formation of lanthanide triple helical complexes with a ligand derived from bis(benzimidazole)pyridine: structural and thermodynamic evidence. Inorg. Chem. 2001, 40 (12), 2642-51.

(27) Gawryszewska, P.; Legendziewicz, J.; Ciunik, Z.; Esfandiari, N.; Muller, G.; Piguet, C.; Cantuel, M.; Riehl, J. P. On the determination of empirical absolute chiral structure: chiroptical spectrum correlations for D3 lanthanide (III) complexes. Chirality 2006, 18 (6), 406-12 DOI: 10.1002/chir.20270.

(28) Cantuel, M.; Bernardinelli, G.; Muller, G.; Riehl, J. P.; Piguet, C. The First Enantiomerically Pure Helical Noncovalent Tripod for Assembling NineCoordinate Lanthanide(III) Podates. Inorg. Chem. 2004, 43 (6), 1840-1849 DOI: 10.1021/ic035292u.

(29) Latva, M.; Takalo, H.; Mukkala, V.-M.; Matachescu, C.; Rodríguez-Ubis, J. C.; Kankare, J. Correlation between the lowest triplet state energy level of the ligand and lanthanide(III) luminescence quantum yield. J. Lumin. 1997, 75 (2), 149-169 DOI: 10.1016/s0022-2313(97)00113-0.

(30) Muller, G.; Riehl, J. P. Use of induced circularly polarized luminescence (CPL) from racemic $\mathrm{D}(3)$ lanthanide complexes to determine the absolute configuration of amino acids. J Fluoresc 2005, 15 (4), 553-8 DOI: 10.1007/s10895-005-2828-4.

(31) Piguet, C.; Bünzli, J.-C. G. In Handbook on the Physics and Chemistry of Rare Earths; Elsevier: 2010; Vol. 40, pp 301-553.

(32) Pandya, S.; Yu, J.; Parker, D. Engineering emissive europium and terbium complexes for molecular imaging and sensing. Dalton Trans 2006, (23), 2757-66 DOI: 10.1039/b514637b.

(33) Muller, G.; Schmidt, B.; Jiricek, J.; Hopfgartner, G.; Riehl, J. P.; Bunzli, J. C. G.; Piguet, C. Lanthanide triple helical complexes with a chiral ligand derived from 2,6-pyridinedicarboxylic acid. Journal of the Chemical Society-Dalton Transactions 2001, (18), 2655-2662 DOI: 10.1039/b102728j.

(34) Kitchen, J. A. Lanthanide-based self-assemblies of 2,6-pyridyldicarboxamide ligands: Recent advances and applications as next-generation luminescent and magnetic materials. Coord. Chem. Rev. 2017, 340, 232-246 DOI: 10.1016/j.ccr.2017.01.012.

(35) Brittain, H. G. Circularly Polarized Luminescence Studies of the Ternary Complexes Formed between Terbium(Iii), Pyridine-2,6-Dicarboxylic Acid, and Amino-Acids. J. Am. Chem. Soc. 1980, 102 (11), 3693-3698 DOI: DOI 10.1021/ja00531a005. 
(36) Coruh, N.; Hilmes, G. L.; Riehl, J. P. Use of the Pfeiffer Effect to Probe the Optical-Activity of Europium(Iii) Complexes with 2,6-Pyridinedicarboxylate. Inorg. Chem. 1988, 27 (20), 3647-3651 DOI: DOI 10.1021/ic00293a042.

(37) Ingram, A. J.; Dunlap, A. G.; Dipietro, R.; Muller, G. Speciation, luminescence, and alkaline fluorescence quenching of 4-(2-methylbutyl)aminodipicolinic acid (H2MEBADPA). J. Phys. Chem. A 2011, 115 (27), 7912-20 DOI: $10.1021 / \mathrm{jp} 201209 \mathrm{k}$.

(38) Lincheneau, C.; Destribats, C.; Barry, D. E.; Kitchen, J. A.; Peacock, R. D.; Gunnlaugsson, T. Lanthanide directed self-assembly synthesis and photophysical evaluation of chiral Eu(III) luminescent "half-helicates". Dalton Trans 2011, 40 (45), 12056-9 DOI: 10.1039/c1dt11225b.

(39) Kotova, O.; Blasco, S.; Twamley, B.; O'Brien, J.; Peacock, R. D.; Kitchen, J. A.; Martinez-Calvo, M.; Gunnlaugsson, T. The application of chiroptical spectroscopy (circular dichroism) in quantifying binding events in lanthanide directed synthesis of chiral luminescent self-assembly structures. Chemical Science 2015, 6 (1), 457-471 DOI: 10.1039/c4sc02474e.

(40) Leonard, J. P.; Jensen, P.; McCabe, T.; O'Brien, J. E.; Peacock, R. D.; Kruger, P. E.; Gunnlaugsson, T. Self-assembly of chiral luminescent lanthanide coordination bundles. J. Am. Chem. Soc. 2007, 129 (36), 10986-7 DOI: 10.1021/ja073049e.

(41) Kotova, O.; Kitchen, J. A.; Lincheneau, C.; Peacock, R. D.; Gunnlaugsson, T. Probing the effects of ligand isomerism in chiral luminescent lanthanide supramolecular self-assemblies: a europium "Trinity Sliotar" study. Chemistry 2013, 19 (48), 16181-6 DOI: 10.1002/chem.201303660.

(42) Parr, R. G. Density-Functional Theory of Atoms and Molecules. Oxford University Press, USA: New York, 1989.

(43) Jones, R. O.; Gunnarsson, O. The Density Functional Formalism, Its Applications and Prospects. Reviews of Modern Physics 1989, 61 (3), 689-746 DOI: DOI 10.1103/RevModPhys.61.689.

(44) Granovsky, A. A. Firefly version 8. http://classic.chem.msu.su/gran/firefly/index.html (03/06/2015),

(45) Schmidt, M. W.; Baldridge, K. K.; Boatz, J. A.; Elbert, S. T.; Gordon, M. S.; Jensen, J. H.; Koseki, S.; Matsunaga, N.; Nguyen, K. A.; Su, S. J.; Windus, T. L.; Dupuis, M.; Montgomery, J. A. General Atomic and Molecular ElectronicStructure System. J. Comput. Chem. 1993, 14 (11), 1347-1363 DOI: DOI $10.1002 / j c c .540141112$. 
(46) Allouche, A. R. Gabedit--a graphical user interface for computational chemistry softwares. J. Comput. Chem. 2011, 32 (1), 174-82 DOI: 10.1002/jcc.21600.

(47) Lanthanide Luminescence; Photophysical, Analytical and Biological Aspects. Springer-Verlag: Berlin Heidelberg, 2011; Vol. 7.

(48) Lincheneau, C.; Leonard, J. P.; McCabe, T.; Gunnlaugsson, T. Lanthanide directed self-assembly formations of $\mathrm{Tb}(\mathrm{III})$ and $\mathrm{Eu}(\mathrm{III})$ luminescent complexes from tryptophan based pyridyl amide ligands. Chem Commun (Camb) 2011, 47 (25), 7119-21 DOI: 10.1039/c1cc11326g.

(49) Bünzli, J.-C. G. In Lanthanide Probes in Life, Chemical and Earth Sciences; Bünzli, J.-C. G., Choppin, G. R., Ed.; Elsevier: Amsterdam, 1989; pp 219-293.

(50) Atkins, P.; Jones, L. Chemical Principles. 2nd ed.; Freeman \& Co: New York, 2002 .

(51) Do, K.; Muller, F. C.; Muller, G. A promising change in the selection of the circular polarization excitation used in the measurement of $\mathrm{Eu}(\mathrm{III})$ circularly polarized luminescence. J. Phys. Chem. A 2008, 112 (30), 6789-93 DOI: 10.1021/jp804463e.

(52) Vogel, A. I. In Vogel's Textbook of Quantitative Chemical Analysis; 5th ed.; John Wiley \& Sons, Inc.: New York, 1989; pp 309-323.

(53) Averill, D. J.; Allen, M. J. Synthesis, spectroscopic characterization, and reactivity of water-tolerant Eu3+-based precatalysts. Inorg. Chem. 2014, 53 (12), 6257-63 DOI: 10.1021/ic500790q.

(54) Russo, N.; Abashkin, Y.; Calaminici, P.; Mineva, T.; Sicilia, E.; Toscano, M. In Recent Advances in Density Functional Methods; Chong, D. P., Ed.; World Scientific Publishing Co.: Singapore, 1995; Vol. 1. 


\section{APPENDIX}

\section{Appendix A: ${ }^{1} \mathrm{H}$ NMR and ${ }^{13} \mathrm{C}$ NMR of $\mathrm{L}(\mathrm{Et})$}

\section{${ }^{1} \mathrm{H}$ NMR and ${ }^{13} \mathrm{C}$ NMR of $R, R$ enantiomer of $L(E t)$}

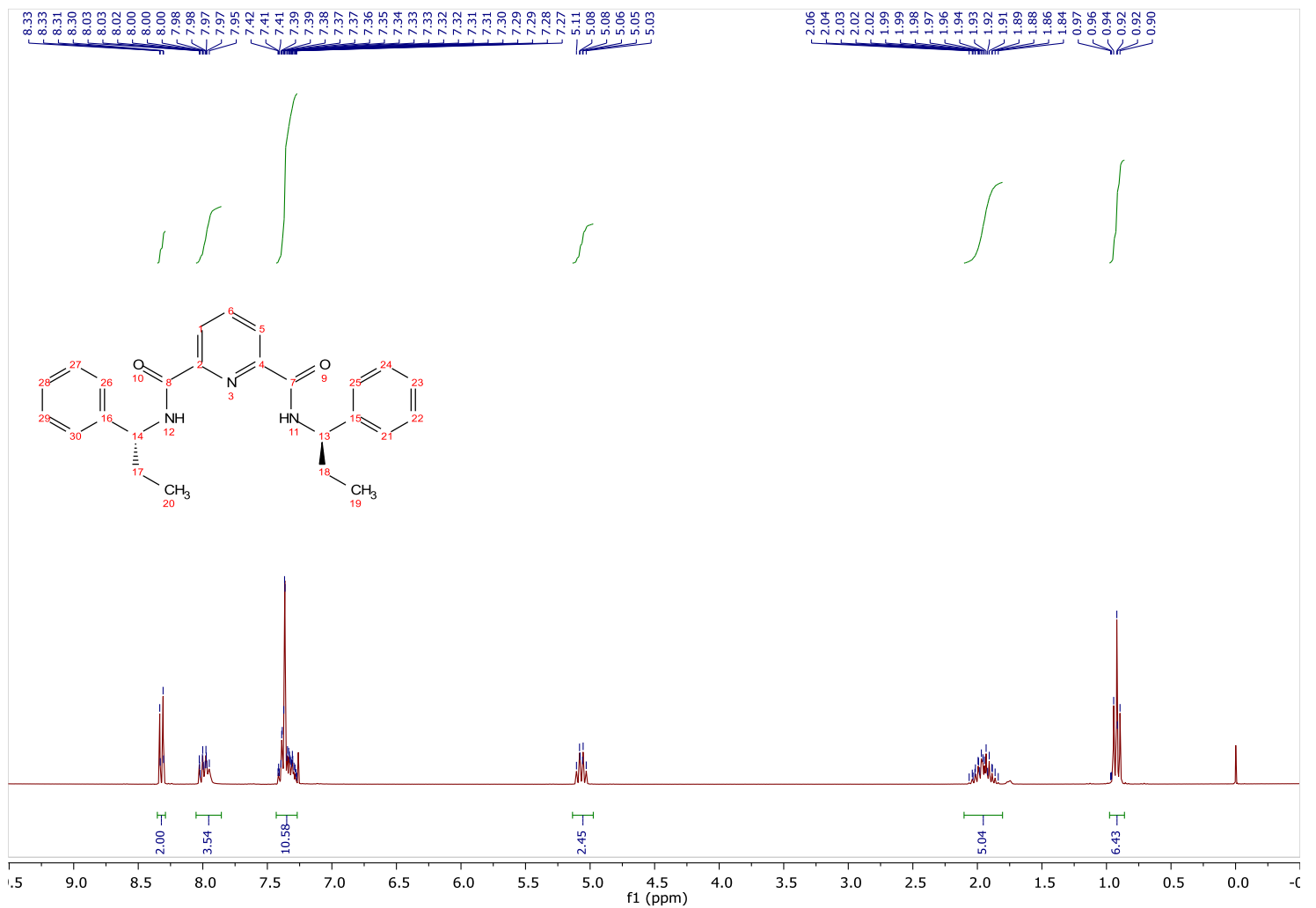

Figure 42. ${ }^{1} \mathrm{H}$ NMR of $R, R$ enantiomer of $\mathrm{L}(\mathrm{Et})(300 \mathrm{MHz}$, Chloroform- $d$ ) $\delta 8.32(\mathrm{~d}, J=7.7 \mathrm{~Hz}, 2 \mathrm{H}), 8.05-7.86(\mathrm{~m}, 4 \mathrm{H}), 7.43-7.27(\mathrm{~m}, 11 \mathrm{H}), 5.07(\mathrm{dt}, J=8.6$, $7.1 \mathrm{~Hz}, 2 \mathrm{H}), 2.10-1.81(\mathrm{~m}, 5 \mathrm{H}), 0.92(\mathrm{t}, J=7.4 \mathrm{~Hz}, 6 \mathrm{H})$. 


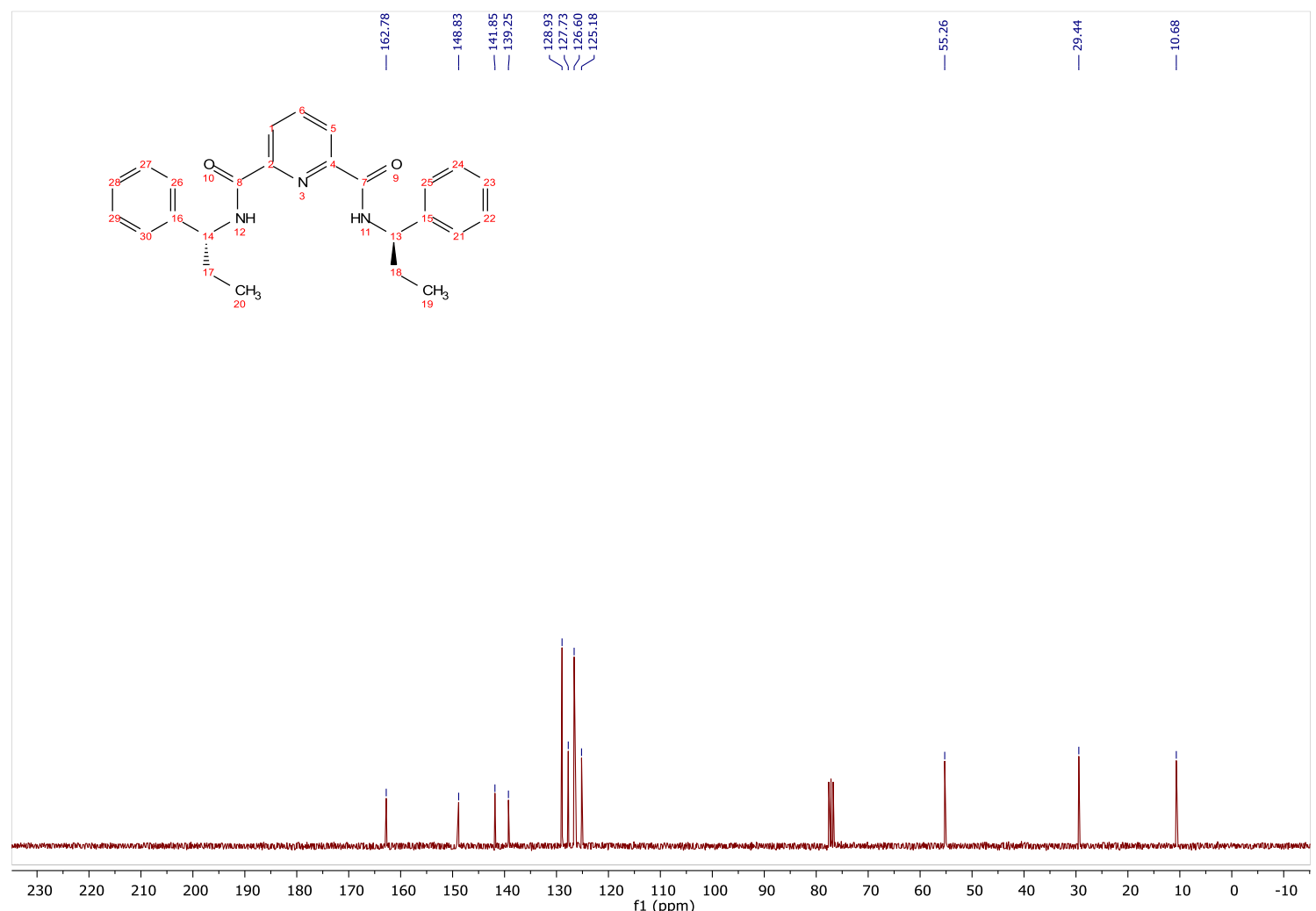

Figure 43. ${ }^{13} \mathrm{C}$ NMR of $R, R$ enantiomer of $\mathrm{L}(\mathrm{Et})(75 \mathrm{MHz}$, Chloroform d) $\delta 162.78,148.83,141.85,139.25,128.93,127.73,126.60,125.18,55.26,29.44,10.68$. 


\section{${ }^{1} \mathrm{H}$ NMR and ${ }^{13} \mathrm{C}$ NMR of $S, S$ enantiomer of L(Et)}

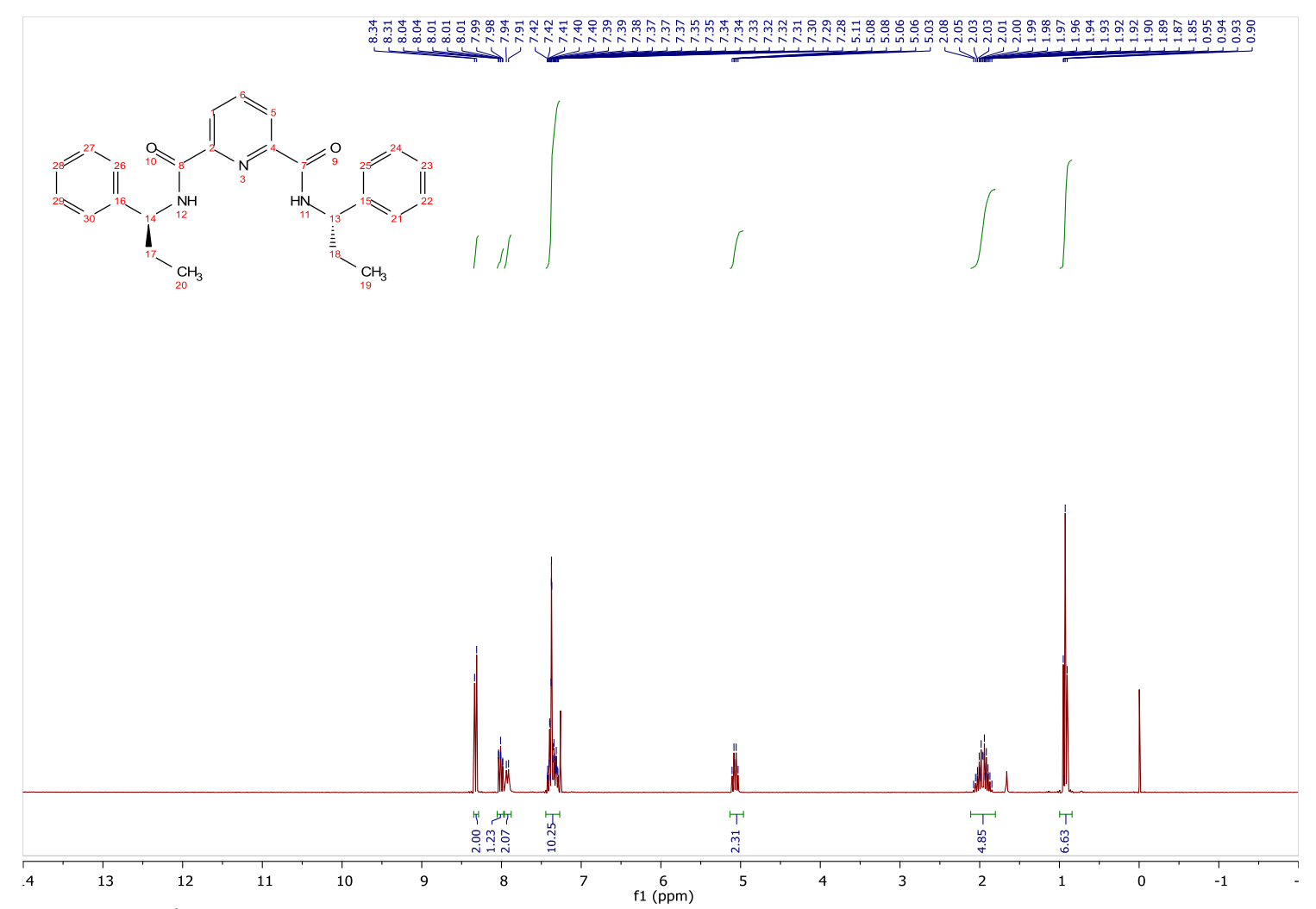

Figure 44. ${ }^{1} \mathrm{H}$ NMR of $S, S$ enantiomer of L(Et) (300 MHz, Chloroform- $d$ )

$\delta 8.32(\mathrm{~d}, J=7.8 \mathrm{~Hz}, 2 \mathrm{H}), 8.01(\mathrm{ddd}, J=8.0,7.4,0.4 \mathrm{~Hz}, 1 \mathrm{H}), 7.92(\mathrm{~d}, J=8.4 \mathrm{~Hz}, 2 \mathrm{H})$, $7.46-7.27(\mathrm{~m}, 11 \mathrm{H}), 5.07(\mathrm{dt}, J=8.4,7.2 \mathrm{~Hz}, 2 \mathrm{H}), 2.10-1.83(\mathrm{~m}, 4 \mathrm{H}), 0.93(\mathrm{t}, J=7.4$ $\mathrm{Hz}, 6 \mathrm{H})$ 


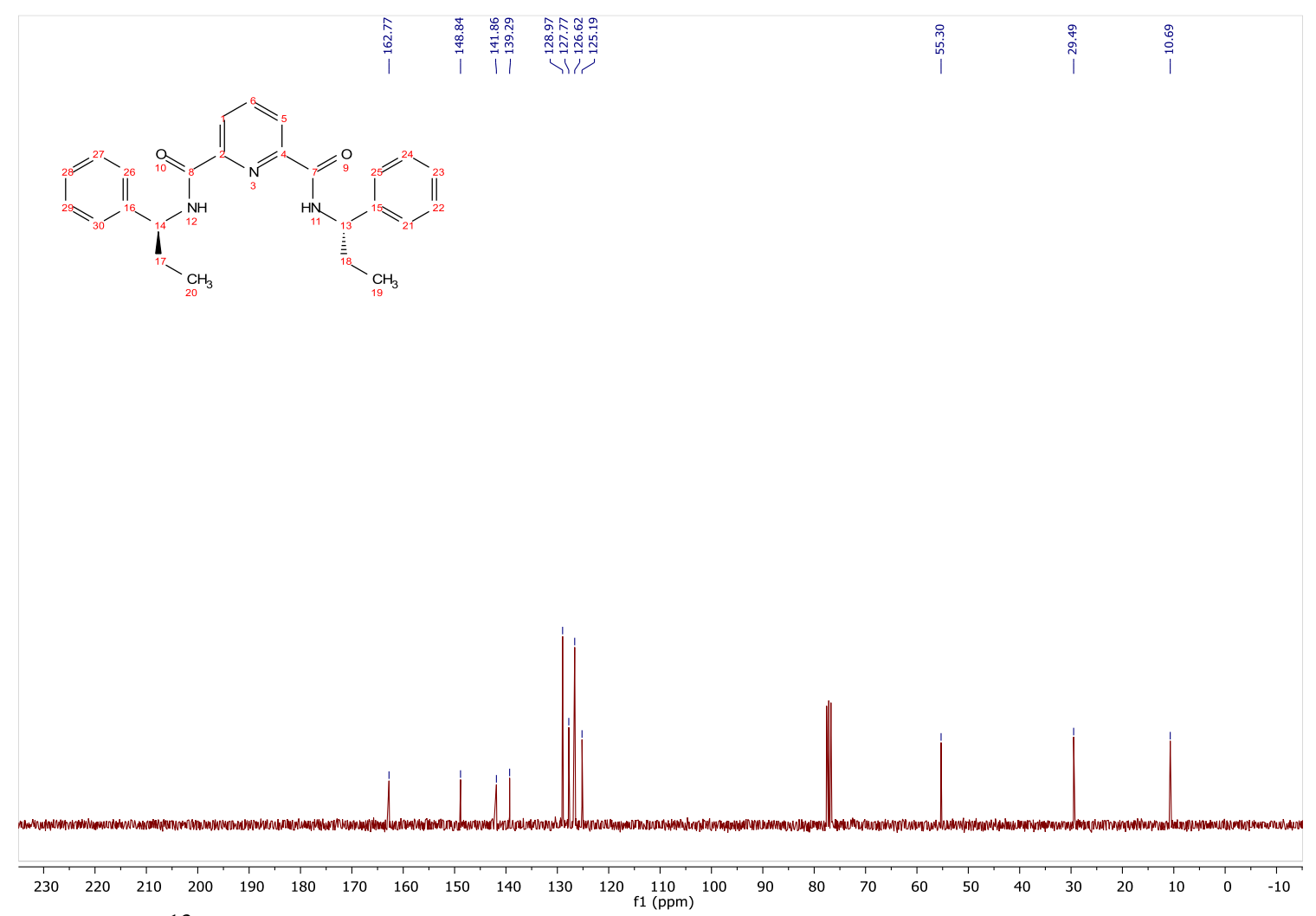

Figure $45 .{ }^{13} \mathrm{C}$ NMR $R, R$ enantiomer of $\mathrm{L}(\mathrm{Et})(75 \mathrm{MHz}$, Chloroform- $d$ )

${ }^{13} \mathrm{C}$ NMR (75 MHz, Chloroform- $d$ ) $\delta 162.87,148.94,141.96,139.38,129.07,127.87$, $126.72,125.29,55.40,29.59,10.78$. 


\section{Appendix B: Calculated Bond Lengths and Bond Angles}

\section{Bond Lengths and Bond Angles, S,S enantiomer of $\mathrm{L}(\mathrm{Et})$}

\begin{tabular}{|c|c|c|c|c|c|c|c|}
\hline Atom \# & Element & & $\begin{array}{l}\text { Distance } \\
\text { ngstroms) }\end{array}$ & & $\begin{array}{c}\text { Angle } \\
\text { (Degrees) }\end{array}$ & & $\begin{array}{l}\text { edral (torsion) } \\
\text { angle }\end{array}$ \\
\hline 1 & $\bar{C}$ & & & & & & \\
\hline 2 & $\mathrm{C}$ & 1 & 1.5192253 & & & & \\
\hline 3 & $\mathrm{C}$ & 2 & 1.4005609 & 1 & 122.7153153 & & \\
\hline 4 & $\mathrm{C}$ & 3 & 1.3944339 & 2 & 120.8854495 & 1 & -178.2848429 \\
\hline 5 & $\mathrm{C}$ & 4 & 1.3929248 & 3 & 120.2357769 & 2 & 0.5039865 \\
\hline 6 & $\mathrm{C}$ & 5 & 1.3935991 & 4 & 119.450353 & 3 & -0.3422841 \\
\hline 7 & $\mathrm{C}$ & 2 & 1.3991377 & 1 & 119.0479336 & 3 & -178.0704027 \\
\hline 8 & $\mathrm{H}$ & 7 & 1.0851564 & 2 & 119.3693916 & 1 & -2.437 \\
\hline 9 & $\mathrm{H}$ & 6 & 1.0841898 & 5 & 120.1200288 & 4 & -179.5641253 \\
\hline 10 & $\mathrm{H}$ & 5 & 1.0838528 & 4 & 120.2564179 & 3 & 179.8527897 \\
\hline 11 & $\mathrm{H}$ & 4 & 1.0842912 & 3 & 119.6849628 & 2 & -179.8695889 \\
\hline 12 & $\mathrm{H}$ & 3 & 1.0847335 & 2 & 120.2940737 & 1 & 0.9585392 \\
\hline 13 & $\mathrm{~N}$ & 1 & 1.4726176 & 2 & 110.6279715 & 3 & -43.1241589 \\
\hline 14 & $\mathrm{C}$ & 13 & 1.3667047 & 1 & 121.2999331 & 2 & -157.3673722 \\
\hline 15 & $\mathrm{C}$ & 14 & 1.5174518 & 13 & 115.1622169 & 1 & 175.9238704 \\
\hline 16 & $\mathrm{C}$ & 15 & 1.3964457 & 14 & 122.2975782 & 13 & 36.7642899 \\
\hline 17 & $\mathrm{C}$ & 16 & 1.3940762 & 15 & 118.5311494 & 14 & 177.3433497 \\
\hline 18 & $\mathrm{C}$ & 17 & 1.3865865 & 16 & 119.0422866 & 15 & 0.3210206 \\
\hline 19 & $\mathrm{C}$ & 18 & 1.4012345 & 17 & 118.4159139 & 16 & -0.9048891 \\
\hline 20 & $\mathrm{~N}$ & 15 & 1.3369259 & 14 & 115.1616578 & 13 & -146.2227475 \\
\hline 21 & $\mathrm{C}$ & 19 & 1.5175043 & 18 & 117.0228812 & 17 & 178.9482127 \\
\hline 22 & $\mathrm{~N}$ & 21 & 1.3591624 & 19 & 120.7999563 & 18 & 161.2903831 \\
\hline 23 & $\mathrm{C}$ & 22 & 1.4792638 & 21 & 133.1524244 & 19 & -4.3306791 \\
\hline 24 & $\mathrm{C}$ & 23 & 1.5241072 & 22 & 108.7545229 & 21 & -132.6438413 \\
\hline 25 & $\mathrm{C}$ & 24 & 1.4001044 & 23 & 121.6709176 & 22 & -69.3856251 \\
\hline 26 & $\mathrm{C}$ & 25 & 1.393301 & 24 & 120.8792307 & 23 & 178.853978 \\
\hline 27 & $\mathrm{C}$ & 26 & 1.3941679 & 25 & 120.1598803 & 24 & 0.3760225 \\
\hline 28 & $\mathrm{C}$ & 27 & 1.3930046 & 26 & 119.5103971 & 25 & -0.0656647 \\
\hline 29 & $\mathrm{C}$ & 24 & 1.3976255 & 23 & 119.9654578 & 22 & 109.8765169 \\
\hline 30 & $\mathrm{H}$ & 29 & 1.0848849 & 24 & 119.3188355 & 23 & 1.1262832 \\
\hline 31 & $\mathrm{H}$ & 28 & 1.0842605 & 27 & 120.1010546 & 26 & 179.7952582 \\
\hline 32 & $\mathrm{H}$ & 27 & 1.0841133 & 26 & 120.2155492 & 25 & 179.7554932 \\
\hline 33 & $\mathrm{H}$ & 26 & 1.0843028 & 25 & 119.7817718 & 24 & -179.950844 \\
\hline 34 & $\mathrm{H}$ & 25 & 1.0853455 & 24 & 120.1202099 & 23 & -1.6509986 \\
\hline
\end{tabular}




\begin{tabular}{lllllclc}
35 & $\mathrm{H}$ & 23 & 1.0861543 & 22 & 107.4650813 & 21 & -15.455917 \\
36 & $\mathrm{C}$ & 23 & 1.5409954 & 22 & 110.5780163 & 21 & 101.4475224 \\
37 & $\mathrm{C}$ & 36 & 1.5306633 & 23 & 113.1242937 & 22 & -173.9641831 \\
38 & $\mathrm{H}$ & 37 & 1.0933939 & 36 & 110.5507504 & 23 & 178.6879037 \\
39 & $\mathrm{H}$ & 37 & 1.0932019 & 36 & 111.7298378 & 23 & -61.3577849 \\
40 & $\mathrm{H}$ & 37 & 1.0931799 & 36 & 110.5457766 & 23 & 59.3361645 \\
41 & $\mathrm{H}$ & 36 & 1.0930594 & 23 & 106.9078583 & 22 & -53.1615421 \\
42 & $\mathrm{H}$ & 36 & 1.0961881 & 23 & 109.6005758 & 22 & 62.2147352 \\
43 & $\mathrm{H}$ & 22 & 1.0128527 & 21 & 110.9058981 & 19 & -179.5676384 \\
44 & $\mathrm{O}$ & 21 & 1.2288797 & 19 & 118.2423432 & 18 & -18.3548293 \\
45 & $\mathrm{H}$ & 18 & 1.0813109 & 17 & 122.5580535 & 16 & 178.9705621 \\
46 & $\mathrm{H}$ & 17 & 1.0839831 & 16 & 120.4412645 & 15 & -179.3730009 \\
47 & $\mathrm{H}$ & 16 & 1.0832094 & 15 & 120.7223852 & 14 & -0.7936159 \\
48 & $\mathrm{O}$ & 14 & 1.2198107 & 13 & 123.270156 & 1 & -5.5746328 \\
49 & $\mathrm{H}$ & 13 & 1.0084937 & 1 & 117.545761 & 2 & 0.7024346 \\
50 & $\mathrm{H}$ & 1 & 1.0941772 & 2 & 108.0038272 & 3 & -159.598791 \\
51 & $\mathrm{C}$ & 1 & 1.5508061 & 2 & 113.226455 & 3 & 83.2624971 \\
52 & $\mathrm{C}$ & 51 & 1.5293789 & 1 & 116.199283 & 2 & -63.859333 \\
53 & $\mathrm{H}$ & 52 & 1.0926832 & 51 & 112.1447245 & 1 & 63.955662 \\
54 & $\mathrm{H}$ & 52 & 1.0929692 & 51 & 110.000914 & 1 & -176.4053263 \\
55 & $\mathrm{H}$ & 52 & 1.0937424 & 51 & 111.4772852 & 1 & -57.5174902 \\
56 & $\mathrm{H}$ & 51 & 1.0952759 & 1 & 106.9399708 & 2 & 59.1112714 \\
57 & $\mathrm{H}$ & 51 & 1.0924101 & 1 & 106.8290292 & 2 & 172.9977835 \\
\hline
\end{tabular}

Bond Lengths and Bond Angles, $R, R$ enantiomer of L(Et)

\begin{tabular}{|c|c|c|c|c|c|c|c|}
\hline $\begin{array}{c}\text { Atom \# } \\
1\end{array}$ & $\frac{\text { Element }}{\mathrm{C}}$ & \multicolumn{2}{|c|}{$\begin{array}{c}\text { Distance } \\
\text { (Angstroms) }\end{array}$} & \multicolumn{2}{|r|}{$\begin{array}{c}\text { Angle } \\
\text { (Degrees) }\end{array}$} & \multicolumn{2}{|c|}{$\begin{array}{c}\text { Dihedral } \\
\text { (torsion) angle }\end{array}$} \\
\hline & & & & & & & \\
\hline 2 & $\mathrm{C}$ & 1 & 1.541824 & & & & \\
\hline 3 & $\mathrm{C}$ & 1 & 1.52179 & 2 & 114.542 & & \\
\hline 4 & $\mathrm{~N}$ & 1 & 1.471035 & 3 & 109.1205 & 2 & 125.3076 \\
\hline 5 & $\mathrm{H}$ & 1 & 1.092008 & 4 & 105.2339 & 2 & 116.3323 \\
\hline 6 & $\mathrm{C}$ & 2 & 1.530557 & 1 & 113.3121 & 3 & -62.9482 \\
\hline 7 & $\mathrm{H}$ & 2 & 1.095627 & 1 & 109.5461 & 3 & 60.52119 \\
\hline 8 & $\mathrm{H}$ & 2 & 1.093413 & 1 & 107.1443 & 3 & 175.7855 \\
\hline 9 & $\mathrm{H}$ & 6 & 1.092913 & 2 & 111.7685 & 1 & 61.32923 \\
\hline 10 & $\mathrm{H}$ & 6 & 1.09273 & 2 & 110.6424 & 1 & -178.491 \\
\hline
\end{tabular}




\begin{tabular}{|c|c|c|c|c|c|c|c|}
\hline 11 & $\mathrm{H}$ & 6 & 1.094178 & 2 & 110.9847 & 1 & -59.1315 \\
\hline 12 & $\mathrm{C}$ & 3 & 1.400173 & 1 & 121.4092 & 2 & -52.7632 \\
\hline 13 & $\mathrm{C}$ & 3 & 1.397861 & 1 & 120.1319 & 2 & 128.812 \\
\hline 14 & $\mathrm{C}$ & 12 & 1.393572 & 3 & 120.8247 & 1 & -177.954 \\
\hline 15 & $\mathrm{H}$ & 12 & 1.085284 & 3 & 120.1082 & 1 & 2.58933 \\
\hline 16 & $\mathrm{C}$ & 14 & 1.394084 & 12 & 120.1468 & 3 & -0.48603 \\
\hline 17 & $\mathrm{H}$ & 14 & 1.084244 & 12 & 119.79 & 3 & 179.8423 \\
\hline 18 & $\mathrm{C}$ & 16 & 1.393209 & 14 & 119.5519 & 12 & 0.061325 \\
\hline 19 & $\mathrm{H}$ & 16 & 1.083993 & 14 & 120.2097 & 12 & -179.775 \\
\hline 20 & $\mathrm{H}$ & 18 & 1.084142 & 13 & 119.7782 & 3 & 179.7599 \\
\hline 21 & $\mathrm{H}$ & 13 & 1.084928 & 3 & 119.3725 & 1 & -1.5201 \\
\hline 22 & $\mathrm{C}$ & 4 & 1.363353 & 1 & 122.6156 & 2 & -89.0687 \\
\hline 23 & $\mathrm{H}$ & 4 & 1.008307 & 1 & 118.0597 & 2 & 86.15491 \\
\hline 24 & $\mathrm{C}$ & 22 & 1.518139 & 4 & 115.0081 & 1 & -177.43 \\
\hline 25 & $\mathrm{O}$ & 22 & 1.220649 & 4 & 123.3324 & 1 & 1.471291 \\
\hline 26 & $\mathrm{C}$ & 24 & 1.397017 & 22 & 122.3966 & 4 & 36.26545 \\
\hline 27 & $\mathrm{~N}$ & 24 & 1.335986 & 22 & 115.1637 & 4 & -146.414 \\
\hline 28 & $\mathrm{C}$ & 26 & 1.393753 & 24 & 118.557 & 22 & 178.2222 \\
\hline 29 & $\mathrm{H}$ & 26 & 1.083303 & 24 & 120.8411 & 22 & 0.175151 \\
\hline 30 & $\mathrm{C}$ & 28 & 1.386984 & 26 & 119.0534 & 24 & 0.31671 \\
\hline 31 & $\mathrm{H}$ & 28 & 1.084066 & 26 & 120.3813 & 24 & -179.417 \\
\hline 32 & $\mathrm{C}$ & 30 & 1.400775 & 28 & 118.3495 & 26 & -1.33926 \\
\hline 33 & $\mathrm{H}$ & 30 & 1.081321 & 32 & 119.0752 & 27 & -178.914 \\
\hline 34 & $\mathrm{C}$ & 32 & 1.51759 & 30 & 117.194 & 28 & 179.3603 \\
\hline 35 & $\mathrm{~N}$ & 34 & 1.359859 & 32 & 120.7187 & 30 & 161.6003 \\
\hline 36 & $\mathrm{O}$ & 34 & 1.228851 & 32 & 118.2598 & 30 & -18.9854 \\
\hline 37 & $\mathrm{C}$ & 35 & 1.48212 & 34 & 132.4739 & 32 & -9.56514 \\
\hline 38 & $\mathrm{H}$ & 35 & 1.012145 & 34 & 111.0914 & 32 & 179.0191 \\
\hline 39 & $\mathrm{C}$ & 37 & 1.543652 & 35 & 111.6113 & 34 & -71.5427 \\
\hline 40 & $\mathrm{C}$ & 37 & 1.521753 & 35 & 107.9969 & 34 & 163.7472 \\
\hline 41 & $\mathrm{H}$ & 37 & 1.086941 & 35 & 107.6845 & 34 & 46.63071 \\
\hline 42 & $\mathrm{C}$ & 39 & 1.530859 & 37 & 112.7695 & 35 & 173.0293 \\
\hline 43 & $\mathrm{H}$ & 39 & 1.09565 & 37 & 109.4502 & 35 & -63.3253 \\
\hline 44 & $\mathrm{H}$ & 39 & 1.093892 & 37 & 107.8203 & 35 & 52.20496 \\
\hline 45 & $\mathrm{H}$ & 42 & 1.093439 & 39 & 110.6341 & 37 & -59.6294 \\
\hline 46 & $\mathrm{H}$ & 42 & 1.093242 & 39 & 111.541 & 37 & 60.86389 \\
\hline 47 & $\mathrm{H}$ & 42 & 1.093181 & 39 & 110.6559 & 37 & -179.244 \\
\hline 48 & $\mathrm{C}$ & 40 & 1.397303 & 37 & 120.1684 & 35 & -115.297 \\
\hline 49 & $\mathrm{C}$ & 40 & 1.400439 & 37 & 121.376 & 35 & 64.75424 \\
\hline 50 & $\mathrm{C}$ & 48 & 1.394382 & 40 & 120.8748 & 37 & -179.988 \\
\hline
\end{tabular}




$\begin{array}{llllllll}51 & \mathrm{H} & 48 & 1.084639 & 40 & 119.2554 & 37 & -0.22508 \\ 52 & \mathrm{C} & 50 & 1.393053 & 48 & 120.1428 & 40 & -0.36424 \\ 53 & \mathrm{H} & 50 & 1.084357 & 48 & 119.7759 & 40 & 179.7721 \\ 54 & \mathrm{C} & 52 & 1.394297 & 50 & 119.5504 & 48 & 0.320418 \\ 55 & \mathrm{H} & 52 & 1.084088 & 54 & 120.1902 & 49 & -179.753 \\ 56 & \mathrm{H} & 54 & 1.084357 & 49 & 119.7724 & 40 & 179.7863 \\ 57 & \mathrm{H} & 49 & 1.085498 & 54 & 119.0821 & 52 & 179.0115\end{array}$




\section{Appendix C: Supporting Information and Calculations}

General methods. Luminescence spectra taken on the Varian Cary Eclipse fluorometer were optimized by adjusting the excitation wavelength, delay time, scan rate, averaging times and slit widths. When scans were saturated, slits were reduced or a $1 \%$ or $2 \%$ attenuator was used to reduce the intensity.

$\mathrm{L}(\mathrm{Et})$ and $\left[\mathrm{Ln}(\mathrm{L}(\mathrm{Et}))_{3}\right]^{3+}$ complex quantum yields were measured with $\mathrm{L}(\mathrm{Me})$ and the respective $\left[\mathrm{Ln}(\mathrm{L}(\mathrm{Me}))_{3}\right]^{3+}$ complexes as a reference, and luminescence sensitization was measured using the $\left[\mathrm{Eu}(\mathrm{L}(\mathrm{Et}))_{3}\right]^{3+}$ complex. The quantum yield of $\mathrm{L}(\mathrm{Me})$ and its $\mathrm{Ln}^{3+}$ metal complexes have been previously determined, with an estimated error of $10 \%{ }^{23}$

Solutions used in these measurements were prepared at concentrations where the optical density of the sample was below the desired threshold and the Beer-Lambert law is obeyed, where $\mathrm{A}$ is absorbance, $\varepsilon$ is the molar absorptivity $\left(\frac{L}{m o l * c m}\right), \mathrm{c}$ is concentration $(\mathrm{M})$ and 1 is the cuvette path length $(\mathrm{cm}):^{21}$

$$
A=\varepsilon \times c \times l
$$

For the organic ligand, the concentration of the solution was chosen such that the absorbance as measured at the chosen wavelength on the Varian Cary $50 \mathrm{UV} /$ visible spectrophotometer with a cuvette path length of $1 \mathrm{~mm}$ is below 0.05 , and for the metal-ligand complex solutions, the chosen concentration was such that the absorbance is below 0.5 - this higher concentration is required because the complex starts to dissociate at lower concentrations. 
Circularly polarized luminescence. $g_{\text {lum }}$ values were taken every $0.2 \mathrm{~nm}$, and the collection time varies - for the same percent error, transitions where the $g_{\text {lum }}$ value is large and the species exhibits strong luminescence require fewer readings than transitions where the $g_{\text {lum }}$ value is small and the species exhibits weak luminescence. ${ }^{12}$ The standard deviation, $\sigma_{d}$, is 0.01 and is inversely related to the square root of the count of the total number of photon-pulses $(N)$, in the equation $\sigma_{d}=\sqrt{\frac{2}{N}}$. For the measurements where the direction of circular polarization of the excitation beam is changed, the excitation beam is passed through a linear polarizer and then a circular polarizer set to either $40^{\circ}$ or $130^{\circ}$. The $g_{\text {lum }}$ values reported are the average of the six sets of $g_{\text {lum }} \mathrm{s}$, where each set is the average of 100 readings. The reported error is the standard error of the mean, that is, for the $g_{\text {lum }}$ sets it is the standard deviation divided by the square root of the number of sets.

After any adjustment, the system is calibrated with a standard sample to confirm that the measurements are accurate. ${ }^{12}$ If necessary, a temperature control system may be used to adjust the temperature of the sample, heating via a cycling water bath or cooling via a diluted propylene glycol system under constant dry nitrogen gas flow.

NMR. ${ }^{1} \mathrm{H}$ NMR spectra, ${ }^{13} \mathrm{C}$ NMR spectra, and ${ }^{1} \mathrm{H}$ NMR titration experiments were performed on a $300 \mathrm{MHz}$ Mercury NMR spectrometer. NMR titrations of $\mathrm{La}^{3+}$ with $\mathrm{L}(\mathrm{Et})$ were performed by preparing a solution of $\left[\mathrm{La}\left(\mathrm{CF}_{3} \mathrm{SO}_{3}\right)_{3}\right]^{3+}$ in $\mathrm{CD}_{3} \mathrm{CN}$ and adding one equivalent of the $S, S$ enantiomer of $\mathrm{L}(\mathrm{Et})$ at a time, to prepare solutions with $\mathrm{R}$ $\left[\mathrm{La}^{3+}\right] /[\mathrm{L}(\mathrm{Et})]$ of $1,0.5,0.33$, and $0.2 .{ }^{1} \mathrm{H}$ NMR spectra of the solutions were taken at each iteration. NMR data was analyzed using MestReNova. 
Lifetime calculations. To calculate lifetime values, SigmaPlot was used to perform a nonlinear regression fit of the data obtained from the aforementioned lifetimes measurements to an exponential decay curve, where the exponent ( $b$ and $d$ ) is used to determine the lifetime $(1 / b$ and $1 / d)$. Figure 46 is an example of the fit.

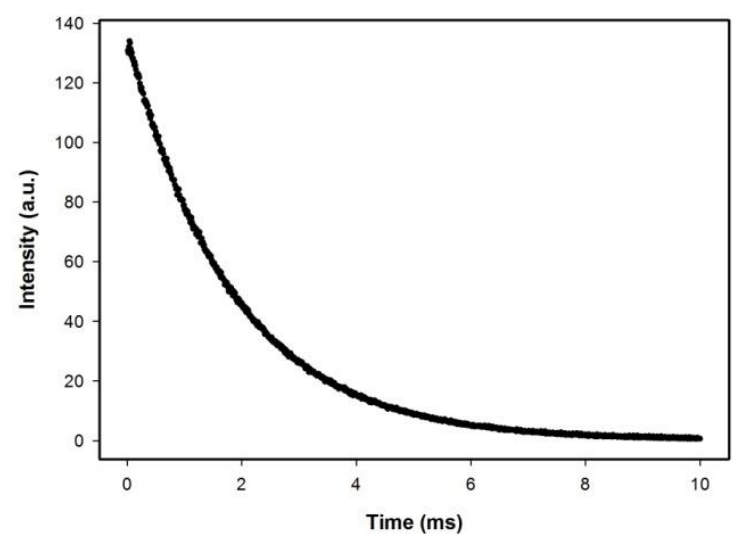

Figure 46. Lifetime Fit - scatter plot $=$ lifetimes data, solid line $=$ monoexponential and biexponential fit

Deconvolution of direct excitation xpectra. Direct excitation spectra of $\left[\mathrm{Eu}(\mathrm{L}(\mathrm{Et}))_{n}\right]^{3+}$ complexes with varying ratios of $\mathrm{Eu}$ and $\mathrm{L}(\mathrm{Et})$ were taken. These spectra were deconvoluted using PeakFit software, with Lorentzian line shapes.

An example of the deconvolution of the 1:10 ratio can be seen in Figure 47, where the upper curve is the original spectrum for the $1: 10$ ratio of $6.67 \mathrm{mM} \mathrm{Eu}^{3+}: \mathrm{L}(\mathrm{Et})$ in anhydrous acetonitrile at room temperature. 


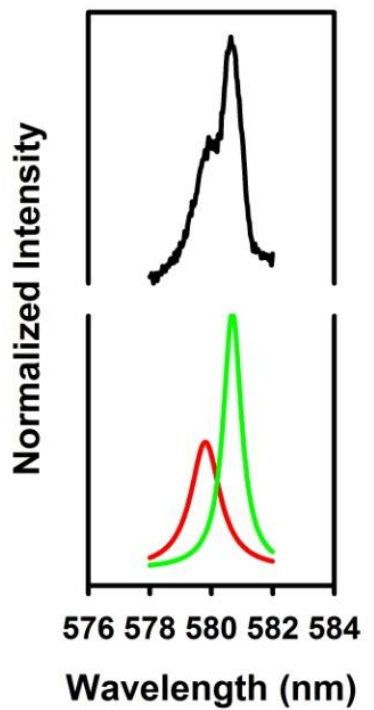

Figure 47. Deconvoluted peaks, laser excitation spectrum of $6.67 \mathrm{mM} \mathrm{1:10} \mathrm{Eu:L(Et)} \mathrm{in}$ anhydrous acetonitrile, upper line $=$ original spectrum, lower lines $=$ deconvoluted peaks

The lower curves are the deconvoluted peaks, the minor peak on the left (red) with a maximum at $580.0 \mathrm{~nm}$ and the major peak on the right (green) with a maximum at 580.64 $\mathrm{nm}$. Comparison of the deconvoluted peaks across samples on of these spectra allowed for the determination of the position of the peaks for the 1:1,1:2 and 1:3 species, as seen in Figure 48.

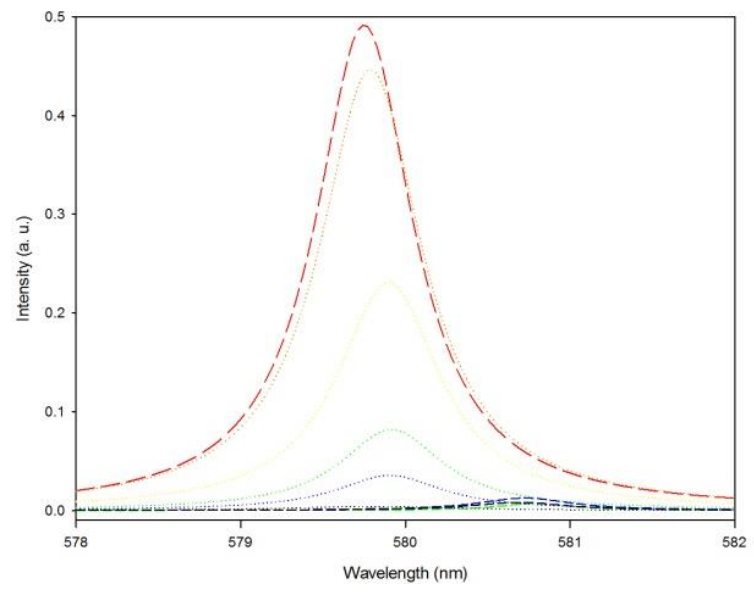

Figure 48. Laser excitation spectra of various ratios of Eu:L(Et) in anhydrous acetonitrile, peaks were deconvoluted using PeakFit software. Deconvoluted peaks of 1:0.5, 1:1, 1:2, 
1:3, 1:5, 1:10 ratios of $6.67 \mathrm{mM} \mathrm{Eu}: \mathrm{L}(\mathrm{Et})$, red, orange, yellow, green, blue, black lines, respectively.

$\Delta \mathbf{E}\left({ }^{3} \pi \pi^{*}-1 \pi \pi^{*}\right)$ and efficiency of ISC. In order to compare the change in $\Delta \mathrm{E}\left({ }^{3} \pi \pi^{*-1} \pi \pi^{*}\right)$ and efficiency of ISC upon complexation, luminescence measurements of $\mathrm{L}(\mathrm{Et})$ and $\left[\mathrm{Gd}(\mathrm{L}(\mathrm{Et}))_{3}\right]^{3+}$ were conducted at $77 \mathrm{~K}$, with all settings identical except $0.0 \mathrm{~ms}$ delay time for steady-state to observe emission from the singlet state, and $0.5 \mathrm{~ms}$ delay time for time-resolved to observe emission from the triplet state.

As there was overlap of singlet and triplet emission in the $0.0 \mathrm{~ms}$ delay time spectra, deconvolution was required for more accurate calculation of area. The deconvolution of overlapped peaks was performed through PeakFit software, using Lorentzian line shapes, as previously described in the discussion of deconvolution of direct excitation spectra. 